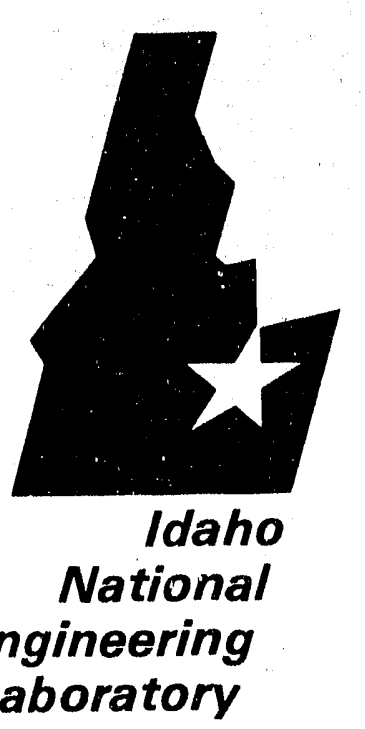

INFORMAL REPORT

EGG-WTD-9868

September 1991

Product Evaluation of In Situ Vitrification Engineering Test 4

\author{
C. A. Loehr \\ J. R. Weidner \\ S. O. Bates
}

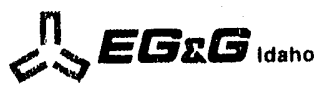

Work performed under DOE Contract No. DE-ACO7-761D01570 
This document contains new concepts or the author(s) interpretation of new calculations and/or measurements; accordingly, EG\&G Idaho, Inc. is required by the United States Government to include the following disclaimer:

\section{DISCLAIMER}

This report was prepared as an account of work sponsored by an agency of the United States Government. Neither the United States Government nor any agency thereof, nor any of their employees, makes any warranty, express or implied, or assumes any legal liability or responsibility for the accuracy, completeness, or usefuiness of any information, apparatus, product or process disclosed, or represents that its use would not infringe privately owned rights. Reterences herein to any specific commercial product, process, or senvice by trade name, trademark, manufacturer, or otherwise, does not necessarily constitute or imply its endorsement, recommendation, or favoring by the United States Government or any agency thereof. The views and opinions of authors expressed herein do not necessarily state or reflect those of the United States Government or any agency thereot. 
EGG-WID- -9868

DE92 012310

\title{
PRODUCT EVALUATION OF \\ IN SITU VITRIFICATION ENGINEERING \\ TEST 4
}

\author{
C. A. Loehr \\ J. R. Weidner \\ S. 0. Bates
}

Published September 1991

Idaho National Engineering Laboratory EG\&G Idaho, Inc.

Idaho Falls, Idaho 83415

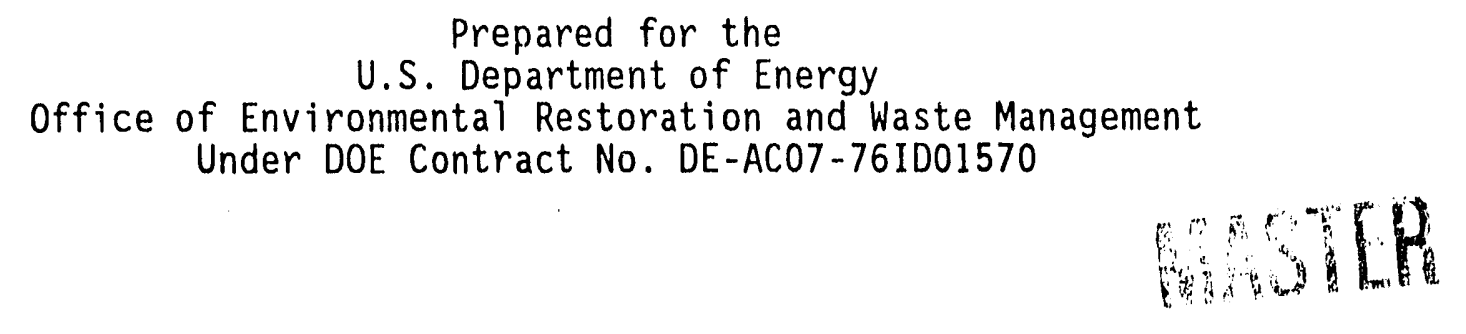


PRODUCT EVALUATION OF

IN SITU VITRIFICATION ENGINEERING

TEST 4

September 1991

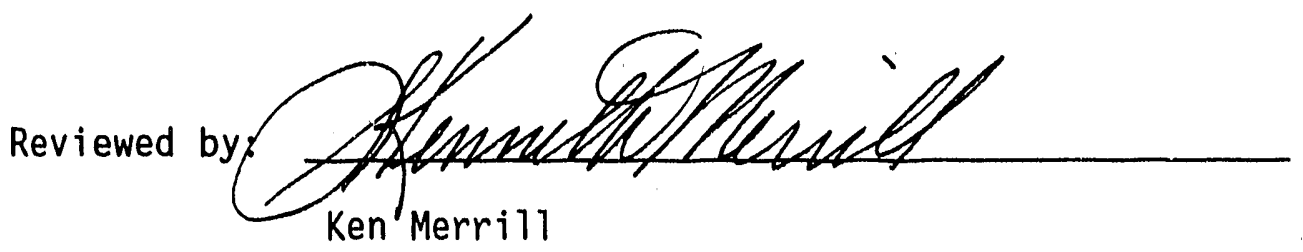

19 sept 91

Date

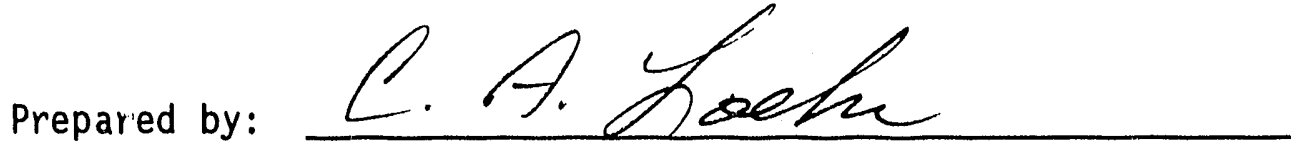

C. A. Lehr
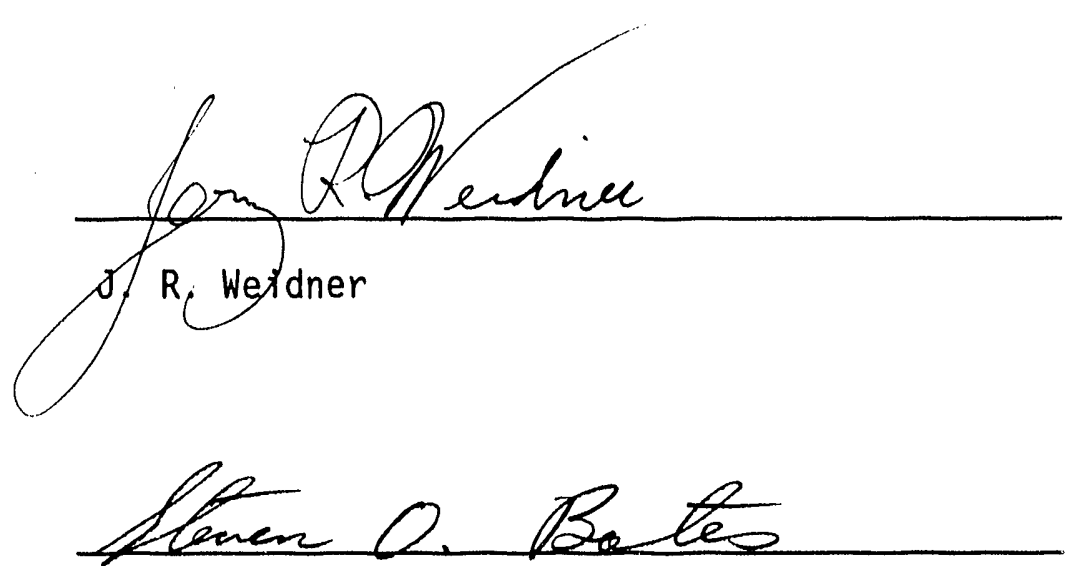

S. 0. Bates
Sept 19,191

Date

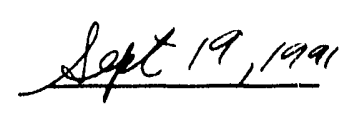

Date

$19 \operatorname{sent} 91$

Date 


\section{ABSTRACT}

The product of an in situ vitrification (ISV) test performed at engineering scale was examined in order to characterize the physical and chemical properties of the material, including chemical durability. Engineering-Scale Test 4 (ES-4) was conducted on soil with added hazardous and nonhazardous constituents to simulate buried waste at the Idaho National Engineering Laboratory (INEL). Specifically, Toxicity Characteristics Leach Procedure (TCLP) toxic metals, an organic sludge mixture, combustibles, and steels were added to INEL soil and placed above a block of basalt to simulate the INEL geologic setting. The chemical and physical properties were examined using $x$-ray diffraction (XRD), scanning electron microscopy (SEM) and other optical techniques, and by bulk chemical analysis. Chemical durability testing involved four types of leach testing: (a) TCL.P, (b) MCC-1, (c) Product Consistency Test (PCT), and (d) testing to determine the intrinsic (fastest) rate of waste form dissolution. These characteristics, in addition to megascopic observations, were examined in order to gain insight into the expected performance of a vitrified product in an ISV buried waste application similar to that studied.

The product was found to be heterogeneous in composition, containing coexisting vitreous, crystalline, and metallic phases. The major element composition of the glass was relatively homogenous. The evidence indicated that two silicate liquids were generated in the test, one from the basalt and another from the soil, and the liquids did not mix appreciably. Metallic phases were round to occur in glass at the center of the melt and at the bottom, where metal scrap articles accumulated with melted metal. The metal articles exhibited microstructural and chemical features that indicate they underwent partial melting. Metallic phase in the glass occurred principally as round inclusions several micrometers in size that apparently formed from melted metal. The identified crystalline phases include clinopyroxene in glassy-appearing samples, plagioclase and quartz in samples from the melt edge, and plagioclase with probable spinel and ilmenite in crystalline material originating from basalt. TCLP toxic metals were retained in the ES-4 product both in the glass and associated with iron metallic phases and were observed in both bottom and center samples. 
ES-4 glass samples did not exceed TCLP thresholds, but TCLP results for the product as a whole were inconclusive. Based on limited MCC-1 leach testing, the chemical durability of the glass phase of the ES-4 product appeared to be comparable to obsidian and granite, and 10 times that of typical high-level nuclear waste glasses. The measured intrinsic dissolution rates of the ES-4 sample tested were 5 to 7 times smaller than rates measured for typical borosilicate nuclear waste glasses. Further work is needed to determine the overall durability that would be expected for ISV products in buried waste applications because nonglassy phases have not been tested, product mechanical durability has not been addressed, and TCLP results from different tests are confilcting. 


\section{FOREWORD}

This report is one of several that evaluates the In Situ Vitrification (ISV) Engineering-Scale Test 4 (ES-4). The description of test operations and process results, along with Extraction Procedure Toxicity (EP Tox) and Toxicity Characteristics Leach Procedure (TCLP) measurements of the product and adjacent soil are given in Reference 1. Reference 2 summarizes some in-depth durability or leach testing, and modeling of an ES-4 product sample. This document describes the chemical and physical composition, microstructure, and leaching characteristics of ES-4 product samples; these data provide insight into the expected performance of a vitrified product in an ISV buried waste application similar to that studied in ES-4. 


\section{CONTENTS}

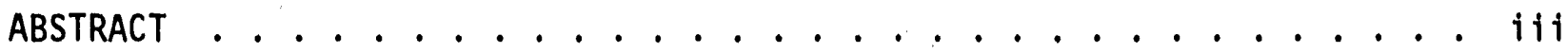

FOREWORD . . . . . . . . . . . . . . . . . . . . . v

ACRONYMS ............................. . $x i$

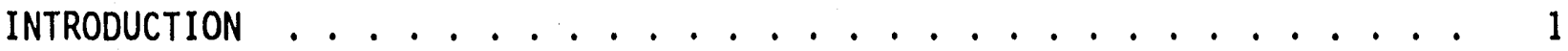

Test Description ...................... 1

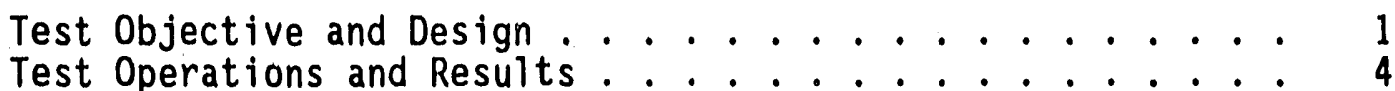

Product Evaluation Objectives ................ . 4

PRODUCT EVALUATION . . . . . . . . . . . . . . . . . . . . 5

Sampling and Analysis Strategy .. . . . . . . . . . . . 5

Chemical and Physical Property Characterization . . . . . 6

Chemical Durability................. 12

Analysis Techniques.................... 12

Chemical and Physical Property Characterization . . . . . 12

Chemical Durability .................. 17

Static Testing Procedures............... . 21

Intrinsic Rate Tests . . . . . . . . . . . . 22

Analysis Results and Discussion... . . . . . . . . . . . 23

Chemical and Physical Property Characterization . . . . . 23

Chemical Durability. . . . . . . . . . . . . . 55

MCC-1, PCT, and Determination of Intrinsic Rate of Dissolution . . 60

Static Tests .................. 60

Intrinsic Rate Testing . . . . . . . . . . . . . 62

CONCLUSIONS . . . . . . . . . . . . . . . . . . . . . 71

Chemical and Physical Property Characterization . . . . . . . . 71

Chemical Durability . . . . . . . . . . . . . . . 72

REFERENCES . . . . . . . . . . . . . . . . . . . . . . 74

APPENDIX A--MCC-1 AND PCT CONCENTRATION RELEASE DATA . . . . . . . . . . A-1 


\section{FIGURES}

1. Photograph of sample IC307A90E4 (photograph by R. E. McAtee) . . . . 7

2. Photograph of sample IC303A90E4 (photograph by R. E. McAtee) . . . 8

3. Photograph of sample IC306A90E4 (photograph by R. E. McAtee) . . . . 9

4. Range of $(S / V) \times$ time values used to investigate the static dissolution behavior of INEL ISV glasses ............ 21

5. SEM photomicrograph of subsample IC300D90E4 showing glass with bright round metallic inclusions (photomicrograph by D. V. Miley) .

6. SEM element map of subsample ICO5D90F4 showing round inclusions in glass and distribution of (a) FE and (b) P. Lighter areas indicate greater concentration ................

7. SEM element map of subsample IC306B90E4 showing round inclusions in glass and distribution of (a) $\mathrm{Fe}$ and (b) P. Lighter areas indicate greater concentration . . . . . . . . . . . . . . .

8. SEM photomicrograph of subsample IC300B90E4 showing crysta1line (labeled black) and glassy (labeled gray) areas (photomicrograph by D. V. Miley) . . . . . . . . . . . . . . .

9. SEM photomicrograph of subsample IC300E90E4 showing dendritic cystalline phase (photomicrograph by D. V. Miley) . . . . . . .

10. SEM photomicrograph of subsample IC300B90E4 showing two crystalline phases. One inase is identified with numbers 1 and 3 , and another is identified with numbers 2 and 4 (photomicrograph by D. V. Miley)

11. SEM photomicrograph of different crystalline phases (identified with numbers) in the nut, glass area of subsample IC303D90E4

(photomicrograph by D. V. Miley) ............

12. SEM photomicrograph of washer in subsample IC303D90E4

(photomicrograph by D. V. Miley) ..............

13. SEM photomicrograph of subsample IC303D90E4 showing metal zones of differing composition in the nut, thread area (photomicrograph by D. V. Miley) ..................

14. SEM photomicrographs of metal reaction zone in a nut, metal/glass interface area of subsample IC303D90E4; (a) is taken at 100X magnification and (b) is taken at 500X magnification of an area near the edge of the metal (photomicrograph by D. V. Miley) . . . . .

15. SEM photomicrograph of metal phases in subsample IC305B90E4 (photomicrograph by D. V. Miley) ............. 
16. SEM photomicrograph of subsample IC303C90E4 showing a glass (1abeled 13) - metal (labeled 12) interface with two phases present. The phase labeled 14 has 96.94 wt\% Ag and 3.06 wt\% Pb, and the phase labeled 15 has $4.39 \mathrm{wt} \% \mathrm{Ag}$ and $95.61 \mathrm{wt} \% \mathrm{~Pb}$ (photomicrograph by D. V. Miley)

17. SEM element map of metal reaction zone in subsample IC305B90E4 showing (a) SEM image, (b) Ag distribution, and (c) Se distribution. Darker areas indicate greater concentrations . . . . . . . . . .

18. SEM element map of metal reaction zone in subsample IC303D90E4 showing distribution of (a) $\mathrm{Fe}$ and (b) $\mathrm{Cr}$. Darker areas indicate greater concentrations ... . . . . . . . . . . . .

19. SEM element map of subsample IC300D90E4 showing distribution of (a) $\mathrm{Fe}$ and (b) $\mathrm{Ti}$ in metallic inclusions in glass. Darker areas indicate greater concentrations

20. MCC -1 and PCT release versus reaction progress (surface area. time/volume) of selected elements from ES-4 sample ES4-1.......63

21. Comparison based on MCC-1 (28-day, $\left.90^{\circ} \mathrm{C}\right)$ of ES-4 glass with other waste forms and natural analogs. Error bars indicate \pm 2 standard deviations

22. Time-dependent concentrations for selected elements during soxhlet extraction of sample ES4-1 at $100^{\circ} \mathrm{C}$

23. Dissolution behavior of P0798 glass with variation of in situ solution $\mathrm{pH}$ at $80^{\circ} \mathrm{C}$

24. Dissolution behavior of IFT sample IC007C901E at in situ solution $\mathrm{pH} 7$ and $80^{\circ} \mathrm{C}$

25. Dissolution behavior of sample ES4-1 at in situ solution pH 7 and $80^{\circ} \mathrm{C}$

\section{TABLES}

1. Material chemical additions to the ES-4 test soil . . . . . . . 2

2. Simulated organic sludge composition for ES-4 . . . . . . . . . 3

3. Analyses performed on samples . . . . . . . . . . . . . . . 11

4. SEM and ICP analyses for subsamples of sample IC007A90IE . . . . . 15

5. Quantitative and standardless SEM analyses for subsample ES4-M1-1 performed by INEL ..................... . . 18

6. Static testing for ISV product evaluation . . . . . . . . . . 20 
7. Index of refraction measurements . . . . . . . . . . . 27

8. Density measurements . . . . . . . . . . . . . . 28

9. Density measurement means and $90 \%$ confidence interval limits .... 29

10. Major element oxide concentrations of product subsamples in wt\%. Data of questionable quality are indicated with a Q. Elemental concentrations are indicated with asterisks ..........

11. Selected TCLP toxic and other metal concentrations of product subsamples in $\mu \mathrm{g} / \mathrm{g}$. Data of questionable quality are indicated with a Q. Data for which associated blanks were contaminated are rlagged

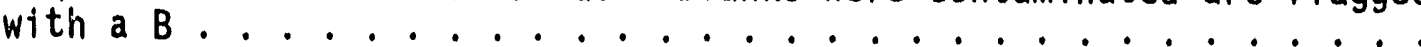

12. Phases identified by XRD ............... 36

13. SEM analysis of dendritic crystalline phase in

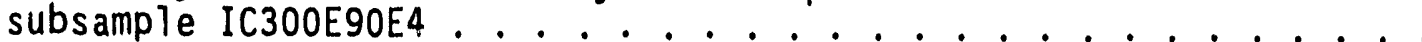

14. SEM analysis of two crystalline phases in subsample IC3OOB90E4. One phase is identified with numbers 1 and 3 , and another is identified with numbers 2 and $4 \ldots \ldots \ldots$

15. SEM analysis of crystalline phases found in the nut, glass area of

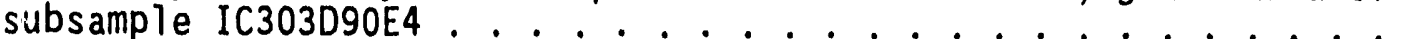

16. SEM analysis of subsample IC303B90E4 in and near metal phases ... 52

17. SEM analysis of the nut, thread area of subsample IC303D90E4 . . . 52

18. SEM analysis of a nut, metal/glass interface area of subsample IC303D90E4 in and near metal reaction zone .......... 53

19. SEM analysis of subsample IC305B90E4 in and near metal phases ... 54

20. Bulk chemical and $\mathrm{Fe}^{+2} / \Sigma \mathrm{Fe}$ analysis of sample ES4-1 . . . . . 661

21. Summary of average normalized release data for MCC-1 and PCT tests .................... 66

22. Dissolution rates measured for ES-4 glass samples by soxhlet

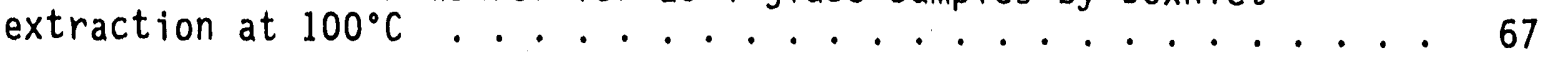

23. Comparison of intrinsic rates of dissolution $\left(80^{\circ} \mathrm{C}, \mathrm{pH} 8\right) \ldots 70$ 


\section{ACRONYMS}

BSE backscattered electron

CERCLA Comprehensive Environmental Response, Compenstaion, and Liability Act

CVAAS Cold Vapor Atomic Absorption

EP Tox Extraction Procedure Toxicity

ES-4 Engineering-Scale Test 4

GFAA graphite furnace atomic absorption

IC Ion Chromatography

ICP-AES inductively coupled plasma atomic emissions spectroscopy

IFT Intermediate Field Test

INEL Idaho National Engineering Laboratory

ISE ion specific electrode

ISV in situ vitrification

NIST National Institute of Standards and Technology

PCT Product Consistency Test

PFA perfluoroalkoxy polymer

PNL Pacific Northwest Laboratory

RPD relative percent difference

SDA Subsurface Disposal Area

SEM Scanning electron microscopy

TCLP Toxicity Characteristics Leach Procedure

XRD $\quad x$-ray diffraction 


\section{PRODUCT EVALUATION OF IN SITU VITRIFICATION ENGINEERING TEST 4}

\section{INTRODUCTION}

In situ vitrification (ISV) is an in situ thermal treatment process that is being investigated by the Idahe National Engineering Laboratory (INEL) for application to buried waste sites. ISV is a thermal treatment process that converts contaminated soil into a chemically inert and stable glass and crystalline product. The INEL is evaluating whether the treatment process is viable for remediating a buried mixed transuranic waste site at the INEL Subsurface Disposal Area (SDA). The SDA is a Comprehensive Environmental Response, Compensation, and Liability Act (CERCLA) site.

As part of the INEL investigation, a series of scaled tests have been performed that address issues associated with vitrification of buried waste. Several engineering-scale tests were performed in 1990 to support the INEL investigation; this report examines the properties of the product of one of these tests.

\section{TEST DESCRIPTION}

\section{Test Objective and Design}

The Engineering-Scale Test 4 (ES-4) test objective was to obtain information on the ISV processability of buried waste at the INEL Subsurface Disposal Area (SDA) and the associated product quality. The test focused on ISV of hazardous and nonhazardous components of the waste in the INEL geologic setting. Specifically, eight Toxicity Characteristics Leach Procedure (TCLP) toxic metals, an organic sludge mixture, combustibles, and steels were added to INEL SDA soil for the test. Table 1 gives the chemical form and amount of TCLP toxic metals used in the test and Table 2 gives the composition of the organic sludge used. Paper $(0.5 \mathrm{wt} \%)$ and wood $(0.5 \mathrm{wt} \%)$ comprised the combustibles added to the test and stainless steel (5.8 wt\%) and carbon steel 
Table 1. Material chemical additions to the ES-4 test soil (see Reference 1)

\begin{tabular}{|c|c|c|}
\hline Mixture & Compound & Amount \\
\hline Metal-Soil & $\begin{array}{l}\text { INEL Soil } \\
\text { Stainless Steel } \\
\text { Carbon Steel } \\
\text { Paper } \\
\text { Wood }\end{array}$ & $\begin{array}{l}286.4 \mathrm{~kg} \\
19.51 \mathrm{~kg} \\
19.51 \mathrm{~kg} \\
1682 \mathrm{~g} \\
1682 \mathrm{~g}\end{array}$ \\
\hline EP Tox Metals & $\begin{array}{l}\mathrm{Pb} \text { (Metal) } \\
\mathrm{Cr}_{2} \mathrm{O}_{3} \\
\mathrm{BaCO}_{3} \\
\mathrm{SeO}_{2} \\
\mathrm{As}_{2} \mathrm{O}_{3} \\
\mathrm{CdO} \mathrm{Ag} \\
\mathrm{Ag}_{2} \mathrm{O} \\
\mathrm{Hg} \text { (Metal) }\end{array}$ & $\begin{array}{r}700.0 \mathrm{~g} \\
102.3 \mathrm{~g} \\
100.6 \mathrm{~g} \\
98.4 \mathrm{~g} \\
92.4 \mathrm{~g} \\
80.0 \mathrm{~g} \\
75.2 \mathrm{~g} \\
70.0 \mathrm{~g}\end{array}$ \\
\hline Organic Sludge/Grease & & $\begin{array}{l}(0.4 \mathrm{gal}) \\
1514 \mathrm{~mL}\end{array}$ \\
\hline
\end{tabular}


Table 2. Simulated organic sludge composition for ES-4 (see Reference 1)

\begin{tabular}{|c|c|c|c|}
\hline Component & $\begin{array}{l}\text { Volume } \\
(\%)\end{array}$ & $\begin{array}{l}\text { Volume } \\
(\mathrm{mL})\end{array}$ & $\begin{array}{l}\text { Weight } \\
\text { (g) }\end{array}$ \\
\hline $\begin{array}{l}\text { Texaco Regal 0il } \\
\text { (R\&0 68, Segal 10193) }\end{array}$ & 31.7 & 279 & 254.7 \\
\hline $\mathrm{CCl}_{4}$ & 19.9 & 174 & 278.1 \\
\hline $\begin{array}{l}\text { Unocal Soluble } 0 i 1 \\
10 \text { (cutting fluid) }\end{array}$ & 12.8 & 113 & 103.2 \\
\hline Ethyl Ether & 4.53 & 40 & 28.5 \\
\hline $1,1,1$-trichloroethane & 4.07 & 35 & 48.3 \\
\hline PCE & 3.05 & 27 & 39.3 \\
\hline TCE & 3.05 & 27 & 43.8 \\
\hline Total & 79.1 & 695 & 795.9 \\
\hline
\end{tabular}

a. $\mathrm{V} / \mathrm{V}=81.5 \mathrm{CaO} \cdot \mathrm{SiO}_{2} / 18.5$ organics. Amount of $\mathrm{CaO} \cdot \mathrm{SiO}_{2}: 3071 \mathrm{~mL}$. 
(5.8 wt\%) comprised the stee 1 added. The test configuration included a basalt block at the base of the volume to be vitrified. Details of the test are described in Reference 1.

\section{Test Operations and Results}

The test was performed at Pacific Northwest Laboratory (PNL), Richland, $W A$, using engineering-scale equipment with an electrode separation of $30 \mathrm{~cm}$ (12 in.). A temperature of $1601^{\circ} \mathrm{C}$ was the highest recorded in the melt. After the test, the vitrified glass product was fused to the basalt block. Also, four metal pools were observed between the glass and basalt at locations that corresponded to electrode locations.

\section{Product Evaluation Objectives}

The general strategy for the evaluation of waste forms produced during the ISV process is described in Reference 3. Three general tasks were involved in the evaluation of the ISV waste form (a) bulk descriplition of the product, (b) chemical and physical property characterization, and (c) chemical durability testing. The first task generates a megascopic description of the product and associated phases present. The second generates an understanding of the elemental composition, structure, and distribution of the phases in the product. Chemical durability testing involves four types of leach testing for three purposes: (a) TCLP to meet regulatory requirements for landfill disposal, (b) MCC-1 and Product Consistency Test (PCT) to allow comparison to similar waste forms and natural analogues, and (c) testing to determine the intrinsic (fastest) rate of waste form dissolution for risk assessment source term use. Detailed strategies for accomplishing the product evaluation tasks are given in Reference 4. Because of the test design, ES-4 product evaluation has been tailored to address the distribution of the TCLP toxic metals in the product and in the phases observed in the product. 


\section{PRODUCT EVALUATION}

\section{Sampling and Analysis Strategy}

The sampling of the ES-4 product occurred in two episodes. First, PNL conducted core sampling of the product to support general test evaluation. The PNL samples were the only samples with known sample locations because the block was broken open. During the second sampling episode, after the block was broken, INEL and PNL personnel collected samples for product characterization and chemical durability studies. This report primarily discusses results of analysis of the samples collected during the second episode. The sampling and analysis guidelines used for the product evaluation are provided in Reference 4. Sampling strategies for chemical and physical property characterization and for chemical durability studies are given in the following paragraphs.

Seventeen grab samples from the ES-4 product were collected for study and analysis. The samples were chosen so that one or more examples of each megascopically distinguishable morphology was represented in the sample collection. Where possible, samples were selected that contained two or more features so that the relationships among them could be established. At the time of sampling, the product had been broken up and stored in covered, but not sealed, five-gallon and fifty-five gallon steel drums. The samples were damp to the touch; some iron samples were oxidized and hydrated, i.e., rusted, on the specimen surface, and water was visibly present within the drums. Presumably, changing temperature, atmospheric pressure, and humidity in the storage area had caused water to condense within the drums. The broken and random nature of the product components prevented systematic sampling and knowledge of the precise location of the individual samples within the undisturbed product. Nevertheless, a reasonable interpretation of the general location of several samples was possible.

Several kinds of material were distinguishable in hand specimens. Most of the product was a dark-green glass with less than 1 percent by volume (vol\%) vesicles (i.e., bubbles) that were less than $2 \mathrm{~mm}$ in diameter and less than 1 vol\% anhedral white spots, presumed to be crystals, that were less than 
$2 \mathrm{~mm}$ in diameter. Dark-brown streaks and round to nodular magnetic inclusions less than $2 \mathrm{~mm}$ in diameter, probably metallic iron, were common. This material was interpreted to be from the center of the melt. a The "rind" was the friable material at the interface between glass and soil. It was the original soil which had been dehydrated and sintered. The rind was brick red in some areas and gray-white in others. The red areas were probably from the top of the melt in contact with air because the red color indicated strongly oxidizing conditions. The gray-white areas suggested more reducing conditions, probably the sides of the melt where it was not exposed to air. Metal occurred as round to nodular masses up to approximately $3 \mathrm{~cm}$ in diameter and also as unmelted articles from the original scrap such as bolts, nuts, rods, and plates (see Figure 1). A few metal articles were partially melted. Most of the metal was adjacent to the basalt which suggests that the metal settled to the bottom of the melt. Figure 2 shows a picture of a sample believed to come from the bottom of the melt. The basalt slab originally placed at the bottom of the test container was reiognized as the gray to black, microcrystalline material. In some areas, it wrapped around unmelted steel articles indicating that the basalt in these locations was liquid when the metal came in contact with it. This feature is shown in Figure 3 . Such basalt was also in sharp contact with dark-green glass indicating that the two silicate liquids did not mix appreciably. Gas bubbles (i.e., vesicles) were prominent in the upper $30 \mathrm{~cm}$ of the product. Bubble size ranged from about $10 \mathrm{~cm}$ to microscopic. Some kubbles contained magnetic metallic spheroids.

\section{Chemical and Physical Property Characterization}

Chemical and physical properties were measured or observed using megascopic hand-specimen examination, polarizing light microscopy (specifically, index of refraction), density measurements, bulk chemical analysis, $x$-ray powder diffraction (XRD), and scanning electron microscopy (SEM). Index of refraction and XRD analyses provided information about the mineralogy, and thus composition of the product. Product composition was also

a. Private communication with Richard K. Farnsworth, EG\&G Idaho, Inc., Idaho Falls, Idaho, August 9, 1990. 


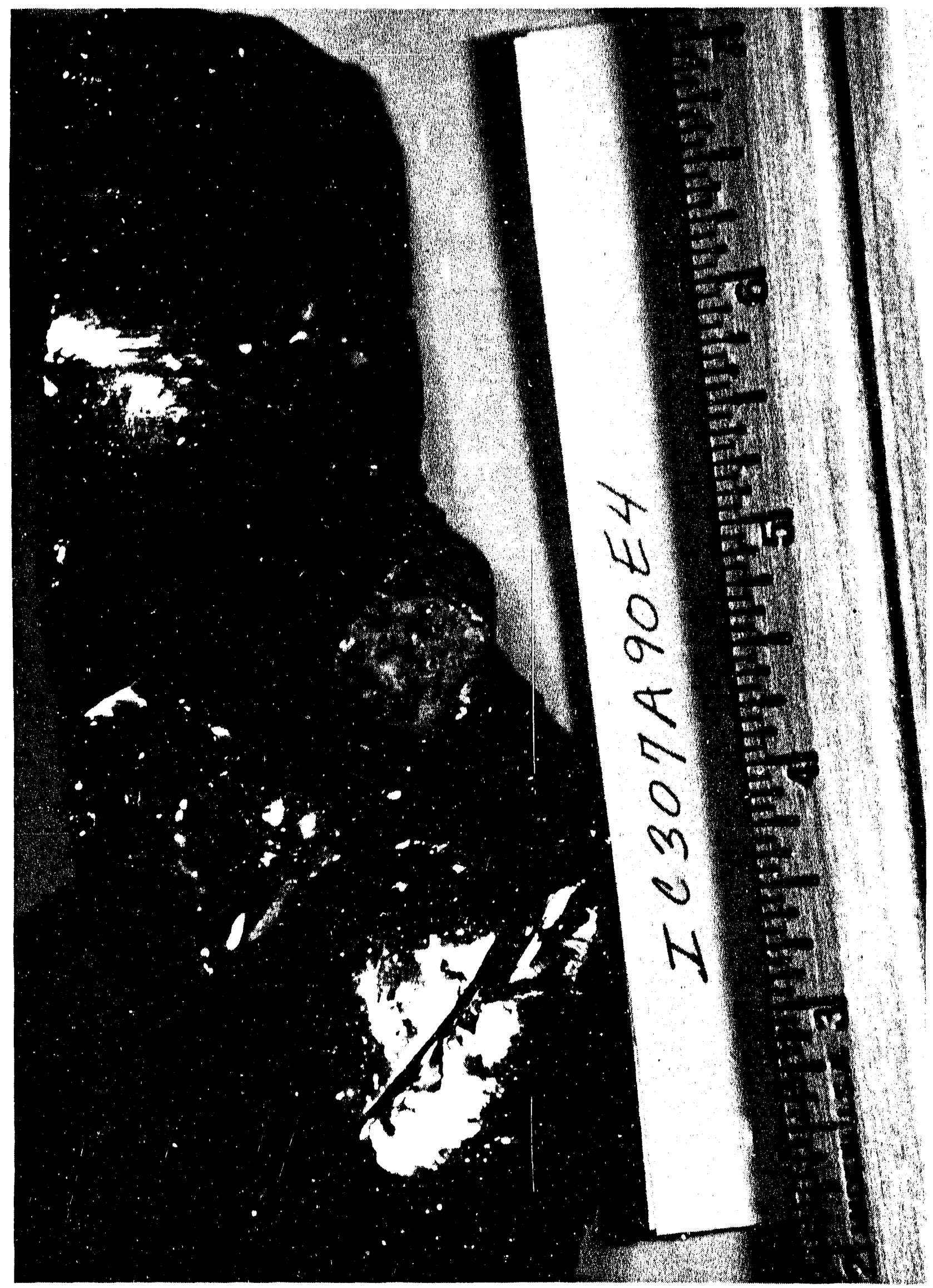

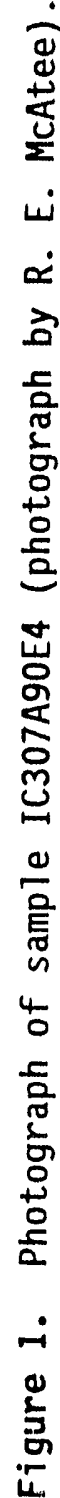




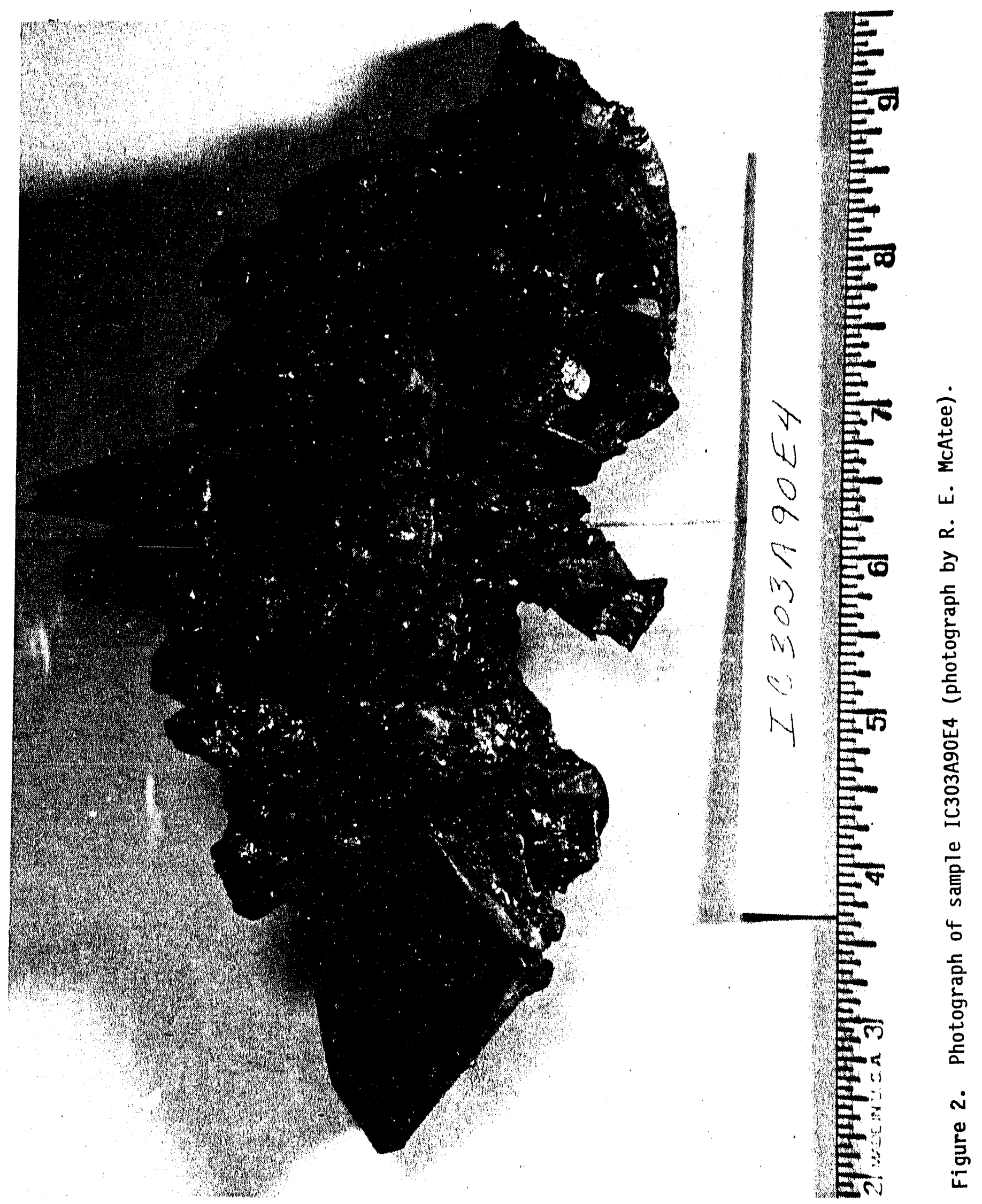




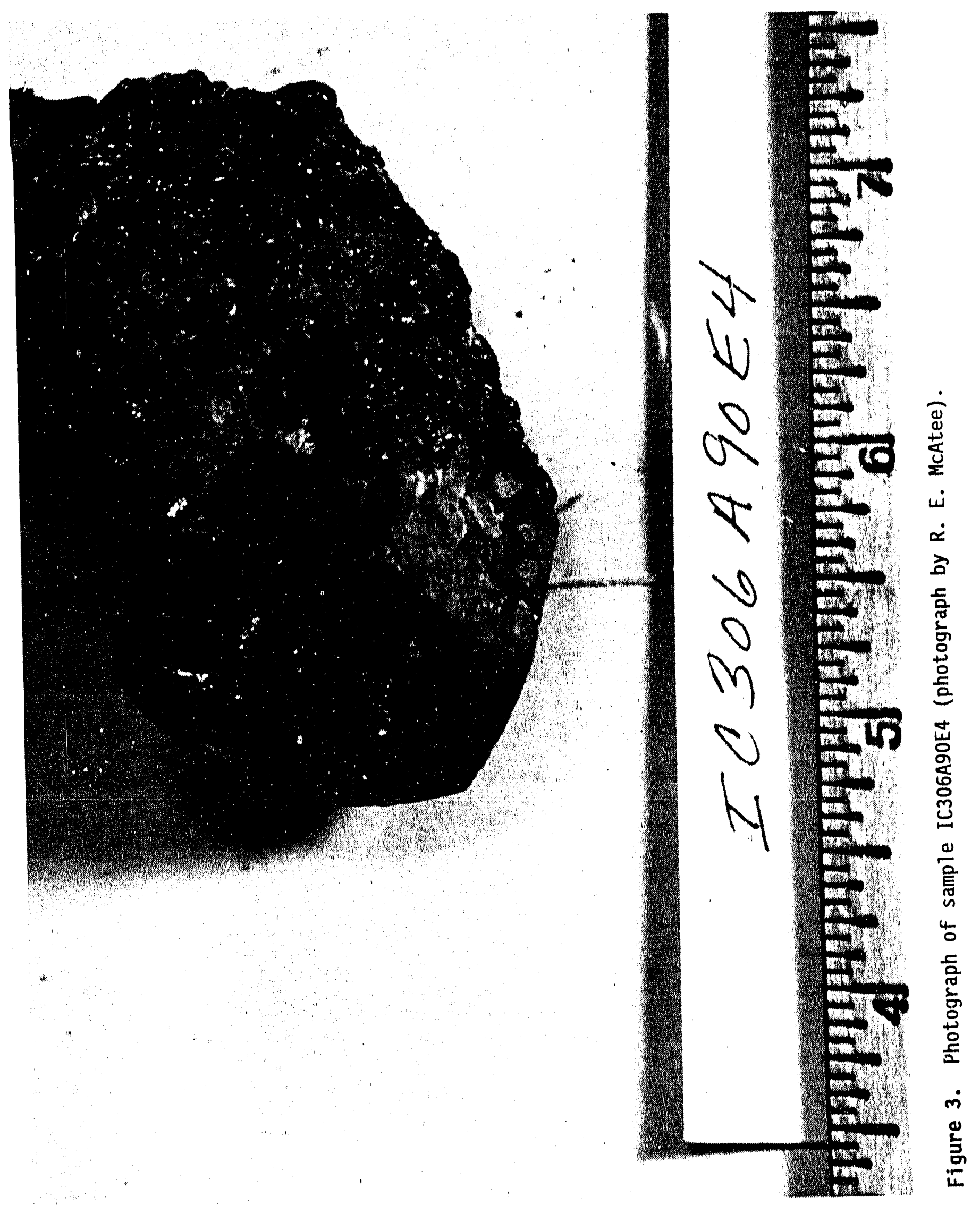


derived from bulk chemical analysis and density measurements. SEM analysis provided insight into the composition and interrelationships of specific phases present.

Analyses were performed on three top samples, two samples from glass near metal, three center samples, one edge sample, and one sample from the bottom at the basalt contact. Also studied were two glass samples and a sample with a crystalline phase from unknown locations. The identification and general location of the samples are given in the hand specimen description section below. Generally, tw' or more phases coexisted in each sample; thus, subsamples were prejared based on the features observed and submitted for analysis as indicated in Table 3. Subsamples are identified with letters B, $c$, etc. in the sixth position of the sample number.

Index of refraction was measured or 12 subsamples, bulk chemical analyses was performed on 10 subsamples, 11 subsamples were analyzed by XRD, bulk density was measured on 7 subsamples, and 17 subsamples were examined using SEM. Up to 23 phases and/or microstructures were analyzed in each subsample using SEM. The top, center, and edges of the block were examined with all techniques except density; density was measured on center and edge samples. SEM and bulk chemistry were also performed on the bottom sample with metal phases. A blind quality control sample was submitted for SEM analysis.

Generally, index of refraction and density were performed on glassy material and SEM analyses focused on features of samples that appeared to be heterogeneous (multi-phase). Bulk chemical analysis for major elements, selected minor elements, and TCLP toxic metals was performed on phases that were megascopicly homogenous in order to support estimation of phase compositions.

Additional samples were collected by PNL to support general test evaluation. Four samples were taken along a vertical profile in the approximate center of the vitrified product, one metal "pool" sample was collected from beneath each electrode, and five pretest and posttest basalt samples were taken. Pretest basalt sample locations were at the edge of the 
Table 3. Analyses performed on samples

\begin{tabular}{|c|c|c|c|c|c|c|c|}
\hline Sample & Subsample & $\begin{array}{c}\text { Bulk } \\
\text { Chemistry }\end{array}$ & Density & $\begin{array}{c}\text { Index of } \\
\text { Refraction }\end{array}$ & SEM & $\underline{X R D}$ & TCLP \\
\hline ES4-1 & ES4 - 1 & & Y & & $Y$ & & \\
\hline$E S 4-1 P$ & ES4-1P & & & Y & & Y & \\
\hline ES4-MI & ES4-M1 & & & Y & $Y$ & Y & \\
\hline ES4 -M2 & ES4-M2 & & & $Y$ & & $Y$ & \\
\hline ES4-T1 & ES4-T1 & & & Y & Y & $Y$ & \\
\hline ES4 - T2 & ES4-T2 & & & Y & & $Y$ & \\
\hline ICO07A9OIE & IC007B9OIE & & & & Y & & \\
\hline IC300A . 54 & IC300B9OE 4 & & & & Y & & \\
\hline IC3OUÁYUE4 & IC300C90E4 & Y & Y & $Y$ & & Y & Y \\
\hline IC300A90E4 & IC300D90E4 & & & & Y & & \\
\hline IC300A90E4 & IC300E90E 4 & & & & $y$ & & \\
\hline IC301A90E4 & IC301B90E4 & $Y$ & & & & & \\
\hline IC301A90E4 & IC301C9OE4 & Y & & & & & \\
\hline IC301A90E4 & IC301D90E4 & & & & $Y$ & & \\
\hline IC302A90E4 & IC302B90E 4 & & & & Y & & \\
\hline IC302A90E4 & IC302C9OE 4 & Y & Y & Y & & $Y$ & \\
\hline IC302A90E4 & IC302D90E4 & & & & Y & & \\
\hline IC302A90E4 & IC302E90E4 & & & & & & Y \\
\hline IC303A90E4 & IC303B90E 4 & Y & & & $Y$ & & \\
\hline IC303A90E 4 & IC303C9OE 4 & & & & Y & & \\
\hline IC303A90E4 & IC303D90E4 & & & & $Y$ & & \\
\hline IC303A90E 4 & IC303E90E4 & & & & & & Y \\
\hline IC305A90E 4 & IC305B90E 4 & & & & $Y$ & & \\
\hline IC305A90EA & IC305C90E 4 & & & & Y & & \\
\hline IC305A90E4 & IC305D90E4 & Y & Y & $Y$ & $Y$ & Y & \\
\hline IC306A90E4 & IC306B90E4 & Y & Y & Y & Y & Y & \\
\hline IC307A90E4 & IC307B90E4 & & Y & Y & & & \\
\hline IC308A90E4 & IC308B90E4 & & & & $Y$ & & \\
\hline IC308A90E4 & IC308C90E 4 & Y & $Y$ & Y & & Y & \\
\hline IC308A90E4 & IC308D90E4 & $Y$ & Y & Y & & Y & \\
\hline
\end{tabular}


basalt block while posttest basalt sample locations were through the center of the block. All samples were analyzed for TCLP toxic metals.

\section{Chemical Durability}

Chemical durability testing involves four types of leach testing: (a) TCLP, (b) MCC-1, (c) PCT, and (d) testing to determine the intrinsic (fastest) rate of waste form dissolution. TCLP meets minimum regulatory testing requirements established for landfill disposal. MCC-1 and PCT are used to compare ISV waste forms to similar waste forms and natural analogs. The intrinsic rate of dissolution $\left(k_{+}\right)$is the most technically relevant glass parameter when evaluating and predicting the dissolution behavior (durability) of the glass (see Reference 3 ).

Three samples were submitted for TCLP testing. One sample from the base of the melt contained metal and basaltic phases and the other two samples were heterogeneous glasses from the approximate center of the melt. In addition, PNL collected four product samples from a vertical profile in the approximate center of the block and four metal samples from the "pools" between the glass and basalt block under each electrode for TCLP testing. One pretest (no specific location) and 3 posttest (from the middle of basalt block) basalt samples were collected for TCLP testing. One sample, ES4-1, also examined in the chemical and physical property characterization, was subjected to MCC-1, PCT, and intrinsic rate of dissolution testing.

\section{Analysis Techniques}

Samples were submitted for analysis under chain of custody. Analysis methods for chemical and physical property characterization and for chemical durability testing are given in Reference 4 . The methods, analysts, and data validation results are given in the following paragraphs.

\section{Chemiral and Physical Property Characterization}

Polarizing Light Microscopy. Index of refraction was measured on 12 powdered subsamples using the Becke line method for determining index of 
refraction. An $01 y m p u s$ BH polarized light microscope and refraction 0 ils from Cargill Laboratories were used for the analysis. The Metals and Ceramics Unit, EG\&G Idaho, Inc., performed the analysis at INEL.

Density Measurements. Apparent bulk density measurements were performed on seven subsamples by the Metal and Ceramics Unit, EG\&G Idaho, Inc., using a standard procedure slightly modified from ASTM C-93-84 (the archimedean method). The procedure was tested using NBS 710 standard glass and achieved excellent agreement with the published values for this standard. A standard deviation of $0.0035 \mathrm{~g} / \mathrm{cm}^{3}$ resulted from laboratory duplicate analysis.

Bulk Chemical Analysis. Bulk chemical analysis for major elements, selected minor elements, and TCLP toxic metals were performed on 10 subsamples. Nine of the subsamples were analyzed at INEL and one vas analyzed at PNL in conjunction with durability testing. The subsamples were analyzed for $\mathrm{Si}, \mathrm{Mn}, \mathrm{Fe}, \mathrm{Mg}, \mathrm{Ca}, \mathrm{AT}, \mathrm{Na}, \mathrm{K}, \mathrm{P}, \mathrm{Ti}$, and TCLP toxic metals As, $\mathrm{Hg}$, Se, $\mathrm{Cr}, \mathrm{Cd}, \mathrm{Pb}, \mathrm{Ag}$, and $\mathrm{Ba}$.

The INEL analyses were performed by the Separations and Chemical Analysis Unit of EG\&G Idaho, Inc., at INEL using inductively coupled plasma atomic emissions spectroscopy (ICP-AES) on an ARL 3410 instrument. The preparation of glass samples involved first crushing, then dissolution using HF and nanopure water, followed by two additions of $\mathrm{HNO}_{3}$ and nanopure water. The metal samples were prepared using the described HF dissolution on metal shavings. For $\mathrm{Si}$ analysis, a sodium tetraborate (flux) fusion was performed on the glass and metal samples, followed by dissolution using concentrated $\mathrm{HNO}_{3}$ and NP $\mathrm{H}_{2} \mathrm{O}$. The ICP analyses were performed using standard techniques. A multipoint calibration with replicate standard determinations was performed over a suitable concentration range.

The samples were submitted for analysis under chain of custody. ${ }^{\text {a }}$ No special preservation or storage of the samples was required. The quality control associated with the analyses included one matrix blank, one duplicate sample (glass only), one biank spike, and one sample spike. The quality

a. Chain of custody was adequate, with the exception that one sample label was misprinted. 
control procedures and data $^{a}$ were reviewed for compliance with acceptable limits and practice. No sample spikes for $\mathrm{Ca}, \mathrm{Na}, \mathrm{As}, \mathrm{Hg}$, Se, or $\mathrm{Cd}$ were prepared and no check standards were run for $\mathrm{P}, \mathrm{Ag}, \mathrm{Ba}$, and $\mathrm{Hg}$; analyses with no check standard are omitted from the data set. Check standards were off as much as $14 \%$ for As, $12.4 \%$ for Se, $20 \%$ for $\mathrm{Cd}$, and $13 \%$ for $\mathrm{Si}$ without reanalysis, which resulted in some data being flagged as questionable. The relative percent difference (RPD) between duplicate samples was high for Se $(26 \%)$ and $\mathrm{Na}(44 \%)$. High concentrations in blanks were noted for Se analyses; the affected samples are flagged with a $B$. The recovery for Fe in the spiked metal sample was 103 or $106 \%$, depending on the $\mathrm{Fe}$ wavelength used for analysis. The spike recovery for $S i$ in the blank sample was $65.5 \%$.

Besides quality control data, a reasonable test of the reliability of the data is that the sum of the major elements' oxides of an acceptable analysis will be $100 \pm 5$ weight percent (wt\%). Many of these analyses do not meet this requirement; in fact, the sums range as low as 54.8 to $111.7 \%$. If samples with questionable values are omitted, the sums range from 68.3 to $111.7 \%$.

For the PNL major element analysis, ${ }^{b}$ sample preparation was performed by $\mathrm{NaOH} / \mathrm{Na}_{2} \mathrm{O}_{2}$ and $\mathrm{KOH} / \mathrm{KNO}_{3}$ fusions of samples ground to -200 mesh. The fusions were dissolved in deionized water and analyzed by ICP-AES using standard procedures. The reported sum of the major element oxide data varied was 98 and $91 \mathrm{wt} \%$ for the two samples discussed in this report. Graphite furnace atomic absorption (GFAA) was used to measure $\mathrm{Ag}, \mathrm{As}$, and Se. The $\mathrm{Fe}^{2+} / \mathrm{Fe}$ ratio was determined by standard colorimetric techniques.

Interlaboratory variability is apparent in Table 4, which gives, for a single sample, bulk chemical nalysis results from PNL and INEL and SEM results from INEL and the Idaho Geologic Survey/Comer Laboratories. The bulk chemical analyses differ substantially for $\mathrm{SiO}_{2}, \mathrm{TiO}_{2}$, and possibly $\mathrm{Fe} 0, \mathrm{CaO}$, and $\mathrm{BaO}$. The quantitative SEM, the methods for which were tested by blind analysis of three National Bureau of Standards glass standards, and the

a. Only summarized, not raw, data was available for review; therefore, initial and continuing calibration of the instrument was not verified.

b. Analysis was of samples that were subjected to durability tests MCC-1, $P C T$, and intrinsic rate of dissolution. 
Table 4. SEM and ICP analyses for subsamples of sample ICO07A90IE

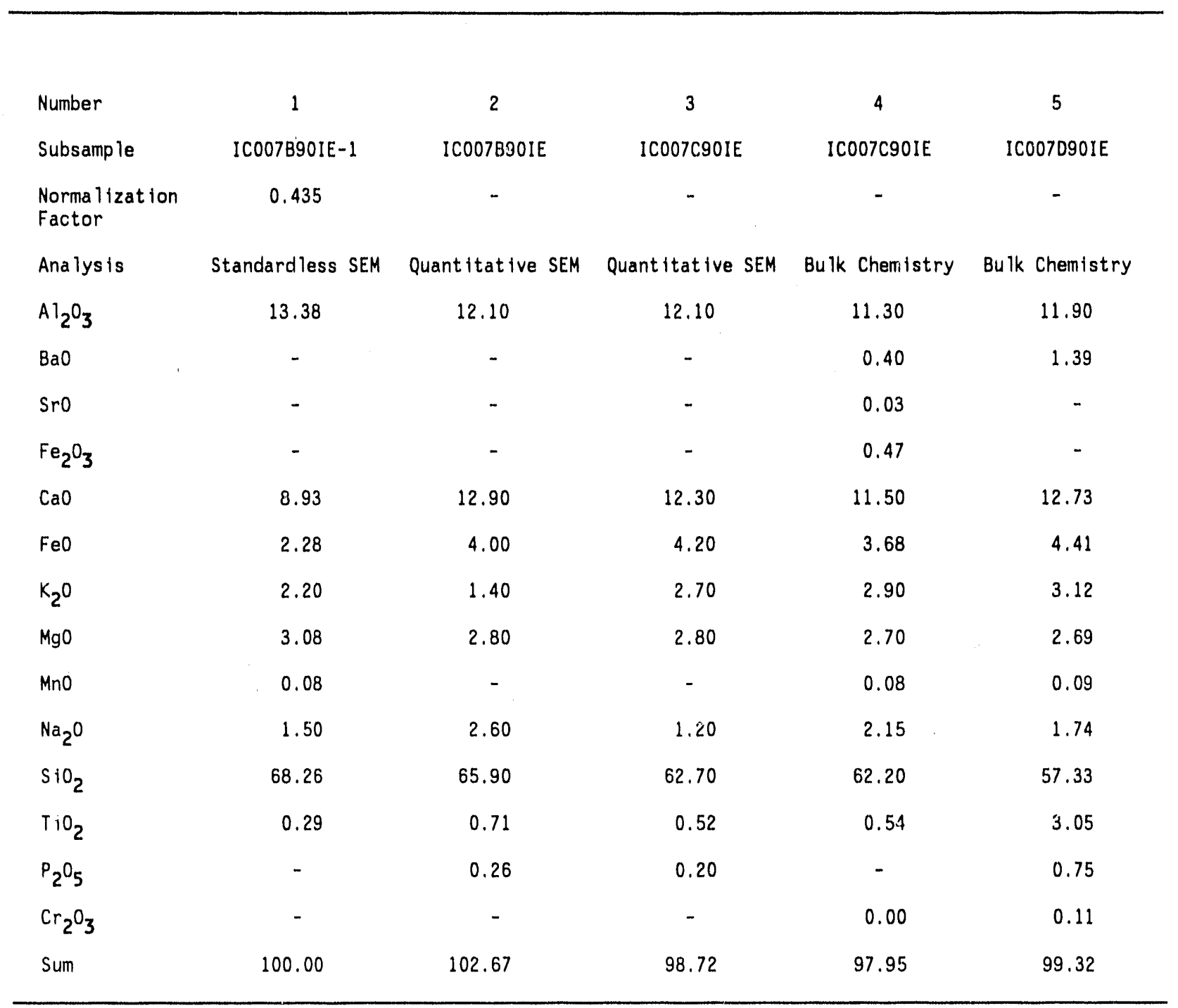


PNL analysis (No. 4) are in approximate agreement. Although for the comparison sample, the oxide sum for the analysis performed by INEL is $99.3 \mathrm{wt} \%$, the sums for other samples are much lower. Because of the low sums, analytical quality control problems, and the differences observed (especially in $\mathrm{SiO}_{2}$ ) compared to quantitative SEM analyses and the PNL analysis, the data are believed to be accurate to only one significant digit.

XRD. X-ray powder diffraction was performed on 11 subsamples using an automated diffractometer equipped with a monochrometer and using $\mathrm{Cu} \mathrm{K} \alpha$ radiation. The goniometer was used in step scan mode with 0.015 degree two theta per step and held one second per step. The goniometer scanned from 15 to $70^{\circ} 2 \theta$. The sample preparation involved grinding to pass a -200 mesh screen using either an agate or W-WC container. For an internal standard, either 15 or $10 \mathrm{wt} \% \mathrm{CaF}_{2}$ was added to the sample. The internal standard was not used to correct bias in D-spacings, rather it was used in order to track possible error in D-spacings for interpretation purposes. The data were automatically compared to the Powder Diffraction Files by computer match to obtain the identification of the crystalline compounds present in the sample. The compound identity selected by computer must be used with caution because compounds found in the ISV product were not necessarily those found in the computer file. The $x$-ray diffraction measurements were made by personnel in the Metals and Ceramics Unit, EG\&G Idaho, Inc. Final interpretation of the data and compound identification was done by the authors using both the $x$-ray diffraction data and the microchemical data.

SEM. Microchemical analyses were performed on 17 subsamples using SEM by the Metais and Ceramics Unit, EG\&G Idaho, Inc. Samples were either mounted as standard metallographic mount specimens or thin sections mounted on glass slides. All samples were polished through $3 \mu \mathrm{m}$ diamond abrasive. A thin coating of thermally evaporated carbon was applied to the sample surfaces to render them electrically conductive for examination in the SEM.

Data derived from the SEM examinations were of three types: (a) photomicrographs of microstructural features, (b) energy dispersive $x$-ray spectrometry (EDS) determinations of elemental compositions of phases, and (c) $x$-ray maps showing elemental distribution within microstructural features. The magnifications shown on the photomicrographs are accurate within about $5 \%$, 
based on measurements performed on an National institute of Standards and Technology (NIST) calibration standard. Photomicrographs were made of representative areas of each sample using both secondary and backscattered electron (BSE) imaging. The analyses reported were performed by a "standardless" calculation, which uses internally generated peak locations and shapes for comparison with the unknowns, rather than referring to previously acquired spectra from standard samples. Factory representatives for the SEM quote an accuracy of $4-8 \%$ for standardless analyses. One sample was run both using standards and by the standardless method; Table 5 gives the results. The analysis using standards is identified as a quantitative SEM analysis in the table. The standardless method normalizes the results by the normalization factor given so that the sum is close to $100 \%$. It is apparent from the table that the standardless analyses can be off by as much as $25 \%$ of the quantitative analyses and in the case of $\mathrm{Na}$ and $\mathrm{Mg}, 100-200 \%{ }^{\text {a }}$ Table 4 also gives standardless and quantitative SEM analyses, each performed at different laboratories, for a single sample. The quantitative SEM work shown in Table 4 was carried out at the Idaho Geologic Survey/Comer Laboratories electron microprobe laboratory at the University of Idaho using an ARL-EMX electron microprobe. ${ }^{b}$ The standardless analyses are off by as much as $60 \%$ for some of the oxides. Because of the demonstrated inaccuracy of standardless analyses, they are considered semi-quantitative in this study.

\section{Chemical Durability}

TCLP. INEL samples were analyzed for TCLP metals according to EPA SW 846 Method 1311. As, $\mathrm{Ba}, \mathrm{Cd}, \mathrm{Cr}, \mathrm{Pb}$, Se, and $\mathrm{Ag}$ in the leachate were analyzed by ICP-AES and $\mathrm{Hg}$ was analyzed by Cold Vapor Atomic Absorption (CVAAS). The analyses were performed by the Environmental Chemistry Unit of EG\&G Idaho, Inc., at INEL. Metal samples collected by PNL for TCLP analysis to support test evaluation did not follow the above referenced TCLP method; rather, an unapproved modified method that used unbroken sample was used.

a. Na is known to be depleted by interaction with the electron beam unless corrective action is taken, and this could cause some of the discrepancy observed.

b. The Idaho Geologic Survey/Comer Laboratories analyses are the mean of about twenty individual measurements, and the INEL analyses are single measurements. 
Table 5. Quantitative and standardless SEM analyses for subsample ES4-M1-1 performed by INEL

\begin{tabular}{|c|c|c|c|}
\hline Number & 1 & 2 & 3 \\
\hline Subsample & ES4-M1-1 & ES4-M1-1 & $E 24-M 1-1$ \\
\hline $\begin{array}{l}\text { Normalization } \\
\text { Factor }\end{array}$ & - & 0.450 & 1.154 \\
\hline Analysis & $\begin{array}{c}\text { Quantitative } \\
\text { SEM }\end{array}$ & $\begin{array}{c}\text { Standardless } \\
\text { SEM }\end{array}$ & $\begin{array}{c}\text { Standardless } \\
\text { SEM }\end{array}$ \\
\hline $\mathrm{Al}_{2} \mathrm{O}_{3}$ & 12.41 & 15.67 & 14.32 \\
\hline $\mathrm{CaO}$ & 3.44 & 2.92 & 3.97 \\
\hline $\mathrm{FeO}$ & 1.07 & 0.80 & 1.23 \\
\hline $\mathrm{K}_{2} \mathrm{O}$ & 2.59 & 2.46 & 3.00 \\
\hline MgO & 1.23 & 2.55 & 1.43 \\
\hline $\mathrm{Na}_{2} \mathrm{O}$ & 1.05 & 3.25 & 1.21 \\
\hline $\mathrm{SiO}_{2}$ & 66.10 & 71.43 & 76.30 \\
\hline $\mathrm{TiO}_{2}$ & 0.70 & 0.61 & 0.82 \\
\hline $\mathrm{Cr}_{2} \mathrm{O}_{3}$ & 0.16 & 0.15 & 0.18 \\
\hline Sum & 88.92 & 100.00 & 102.66 \\
\hline
\end{tabular}


The quality control associated with the INEL analysis was reviewed for compliance with acceptable limits. The majority of QC analyses were found to be within acceptable limits; however, the relative percent difference (RPD) for IC303E90E4 Ag duplicates was low, one continuing calibration blank for Ba was high, and no ICP interference check samples were analyzed for As or Se. Some of the data have been bias-corrected because of spike sample recovery problems, which is an acceptable practice. Standards were analyzed at concentration levels that make the data adequate for a pass/no pass determination, but not a quantitative leaching assessment.

MCC-1, PCT, and Determination of Intrinsic Rate of Dissolution. The product evaluation analysis of ES-4 waste form with respect to durability was conducted at PNL (see Reference 2). The sample analysis that was conducted on the ES-4 sample included elemental analys is (ICP-AA), $\mathrm{Fe}^{+2} / \Sigma \mathrm{Fe}$ determination, and static and intrinsic rate of dissolution durability tests.

Glass sample material to be used for MCC $-1^{5}$ type closed system leach tests was cut into coupons of approximately $4 \mathrm{~cm}^{2}$ surface area using a diamond impregnated saw. The coupons were ultrasonically cleaned in acetone, absolute ethanol, and deionized water, and dried at rooin temperature for two hours prior to being placed into a desiccator until needed. Sample material to be used for modified PCT and intrinsic rate tests [soxhlet and $\mathrm{pH}$ stat/ion specific electrode (ISE)] was prepared by breaking the glass into small pieces with a steel anvil and crushing the pieces with a mortar and pestle. The crushed material was sieved through a 100 mesh screen and collected on a 200 mesh screen. After sieving this material, the granules that did not pass through the 200 mesh screen were collected into $30 \mathrm{~g}$ batches. These batches were ultrasonically cleaned in deionized water by decanting stirred supernate three times and replacing with fresh water. The deionized water was decanted after the final rinse and replaced with $30 \mathrm{~mL}$ of absolute ethanol. After decanting the ethanol, the cleaned glass was dried for 15 min at $50^{\circ} \mathrm{C}$ in a vacuum oven. The separate batches of glass were then combined into a single jar and stored in a desiccator until needed. The specific surface area of the cleaned glass was calculated assuming an average spherical size particle of $0.112 \mathrm{~mm}$ diameter and the measured glass density. 
A series of closed-system, isothermal experiments was designed to elucidate the dissolution behavior, alteration phase formation, and elemental solubilities for the INEL ISV glasses. The test matrix is given in Table 6 . Three different surface area-to-volume $(S / V)$ ratios were investigated with

Table 6. Static testing for ISV product evaluation

\begin{tabular}{|c|c|c|c|c|c|c|c|c|}
\hline \multirow[b]{2}{*}{ MATERIAL } & \multirow[b]{2}{*}{ IEST } & \multirow[b]{2}{*}{$\mathrm{s} / \mathrm{V}, \mathrm{m}^{-1}$} & \multirow[b]{2}{*}{ Temperature } & \multicolumn{5}{|c|}{ NUMBER OF TESTS } \\
\hline & & & & 7 & 14 & $\underline{28}$ & $\underline{56}$ & 91 \\
\hline ES4-1 & $M C C-1$ & 10 & $90^{\circ} \mathrm{C}$ & 1 & 3 & 1 & 1 & 3 \\
\hline Blank & & & $90^{\circ} \mathrm{C}$ & 1 & 1 & 1 & 1 & 1 \\
\hline ES4-1 & PCT & 100 & $90^{\circ} \mathrm{C}$ & 3 & 1 & 3 & 1 & 3 \\
\hline ES4-1 & PCT & 1000 & $90^{\circ} \mathrm{C}$ & 3 & 1 & 3 & 1 & 3 \\
\hline Blank & & & $90^{\circ} \mathrm{C}$ & 1 & 1 & 1 & 1 & 1 \\
\hline
\end{tabular}

overlapping $(S / V) \times$ time as illustrated in Figure 4 . This range was selected so that sufficient glass reaction occurs to saturate the leachate with respect to the major elements of concern. The $10 \mathrm{~m}^{-1} \mathrm{~S} / \mathrm{V}$ experiments were performed with the MCC-1 method and the higher S/V tests used a modified MCC $-3^{6}$ test called the Product Consistency Test (PCT). ${ }^{7}$

Only experiments at $90^{\circ} \mathrm{C}$ in deionized water have been conducted. Although $90^{\circ} \mathrm{C}$ is far above the expected temperature range where the ISV waste form may be contacted by water, the elevated temperature permits the more rapid dissolution and can be view as an extrapolation of greater reaction progress or long times. It has also been recently demonstrated that the basic mechanism of the reaction of a complex waste glass with water does not change up to $200^{\circ} \mathrm{C} .^{8}$ Also, $90^{\circ} \mathrm{C}$ has been a de facto standard for the majority of dissolution experiments that have been conducted with nuclear waste glasses. Comparisons of the performance of INEL ISV glasses with this extensive database are facilitated by using the same conditions. 


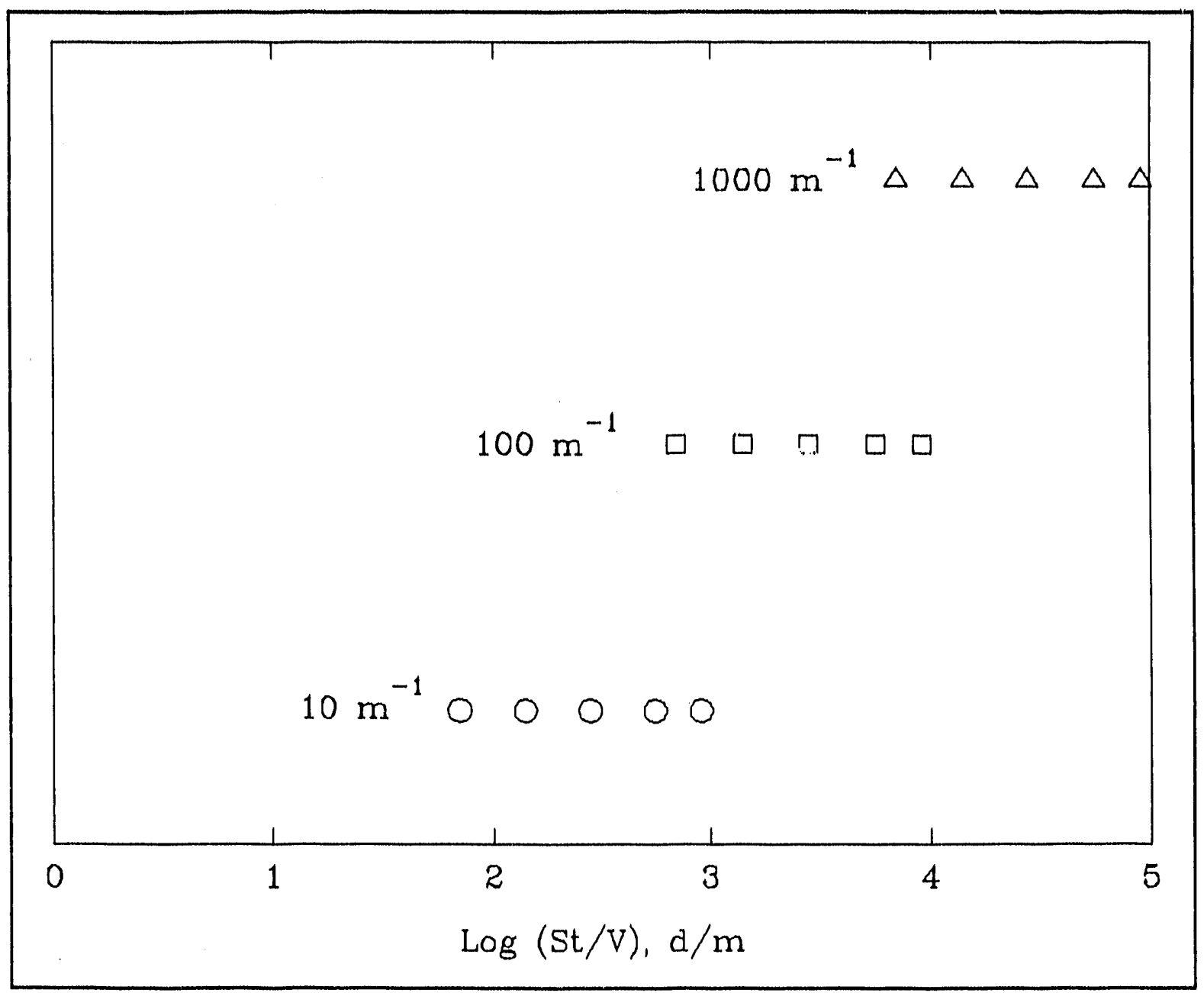

Figure 4. Range of $(S / V) \times$ time values used to investigate the static dissolution behavior of INEL ISV glasses.

\section{Static Testing Procedures}

MCC-1. A single coupon or appropriate mass of crushed glass was added to a Teflon ${ }^{\circledR}$ perfluoroalkoxy polymer (PFA) jar containing $\approx 40 \mathrm{ml}$ of deionized water to achieve the desired $S / V$ ratio. The jar was then sealed and placed in an oven that was kept at $90 \pm 2{ }^{\circ} \mathrm{C}$. Because Teflon PFA is a relatively porous polymer, atmospheric gases readily diffuse through the container wall keeping the leachate in contact with air during the test. ${ }^{9}$ At the end of the planned test duration for the ES4-1 samples, the containers were removed from the oven and allowed to cool. The containers were then weighed and an aliquot of unfiltered leachate was removed to determine $\mathrm{pH}$ and discarded. The remaining leachate was filtered, using a $0.45 \mu \mathrm{m}$ filter, into three polyethylene vials. Two of the leachates were acidified to $1 \mathrm{wt} \% \mathrm{HNO}_{3}$; one was analyzed by ICP-AES 
and the other placed in storage. The third leachate sample was analyzed by Ion Chromatography (IC).

PCT. The PCT is a modifted MCC-3 agitated powder leach test which is similar to the MCC-1 test procedure except that the glass is in a powdered form, and glass powder and leachant are agltated by rotating the Teflon container in which the sample is placed. The elemental leachate concentrations from PCT tests are estimated to be representative of longer-term (more saturated leachates) extrapolation of MCC-1 test results. This objective is achleved more rapidly in the PCT test because higher $S / V$ ratios are used than those used for the MCC-1 tests. Because of the higher S/V used in the PCT testing compared to that used for MCC-1 testing, the leachants in the PCT tests became saturated much sooner than the leachants in the MCC-1 tests. This saturation slows the dissolution process. Therefare, direct comparison of normalized release values from the MCC-1 and PCT tests is not approprtate except at the same $(S / V) \times$ time values.

\section{Intrinsic Rate Tests}

The two experimental methods used to measure the dissolution rate include Soxhlet extraction and $\mathrm{pH}$ stat. These methods are described below. Detailed descriptions of the methods are presented in Reference 10.

Soxhlet. Extensive Soxhlet extraction data have been obtained on nuclear waste glasses at temperatures ranging from 50 to $200^{\circ} \mathrm{C}$ (see References 8 and 11). Because the Soxhlet extractor provides a continuous flux of distilled water over the sample, dilute conditions are maintained throughout the duration of the test as required to accurately measure $k_{+}$. The primary disadvantage of the Soxhlet device is the difficulty in applying reduced pressures to run at temperatures lower than $100^{\circ} \mathrm{C}$ and the difficulty in measuring and controlling the $\mathrm{pH}$ of the distillate.

pH Stat/ISE. The pH stat method ${ }^{12}$ has significant advantages over other dissolution rate measurement methods because the solution $\mathrm{pH}$ is held constant over the course of the test automatically by adding small quantities of a strong acid or base to the solution. A high density of data is thereby generated in a short time. 
The time rate-of-change in the concentration of a soluble glass component, such as $\mathrm{Na}$, was monttored along with the $\mathrm{H}_{3} \mathrm{O}^{+}$consumption, and an fon-selective electrode was used to monitor the selected cation concentration. Ion specific electrodes were used that were capable of measuring concentrations of monovalent cations as $10 \mathrm{w}$ as $10^{-6} \mathrm{M}$ and will tolerate prolonged exposure to temperatures between 70 and $80^{\circ} \mathrm{C}$.

\section{ANALYSis RESULTS AND DISCUSSION}

\section{Chemical and Physical Property Characterization}

Hand Specimen Descriptions. This section presents a discussion of the megascopic properties of each of the samples together with an estimate of its position in the original waste form, if possib?e.

IC300A90E4. This sample was a dark-green glass containing less than 1 vol\% bubbles (diameter $<2 \mathrm{~mm}$ ) and less than 1 vol\% anhedral white crystals. Traces of magnetic material were in the vesicles and glass. Streaks of brown-glassy slightly magnetic material were also present. This sample was from the center, bottom half of the melt.

IC301A90E4. Vesicles, ranging in diameter up to $7 \mathrm{~cm}$, characterize this glass sample. An outer, finely vesiculated, red zone, about $8 \mathrm{~mm}$ thick, was present. The red color indicated strongly oxidizing conditions, probably from contact with air while hot. This sample probably formed at the top of the melt in contact with air.

IC302A90E4. This sample consisted primartly of dark-green glass containing mostly large bubbles up to $10 \mathrm{~cm}$ in diameiar. White anhedral crystals ( $<1 \mathrm{~mm}$ diameter) made up about 1 vol\%. Devitrified materlal (up to 30 vol\%) was present in a swirly pattern around the bubbles. Trace amounts of magnetic metals were also present. The glass content and vesiculated nature suggest that this sample was formed in the center, upper half of the melt.

IC303A90E4. Metal nodules and a metal plate in a basaltic matrix were the principle features of this sample. The basaltic matertal was the dark 
gray-black, fine grained microcrystalline matertal and made up about 30 vol\% of the sample. About 10 vol\% of the sample was green-gray glass containing brown swirls and about 1 v01\% was white anhedral crystals (<0.5 mm diameter). A steel washer was partially melted. The presence of basaltic material suggested that the sample was located at the bottom of the melt in contact with the basalt. The partially melted steel washer and the basaltic matrix structure suggest that the temperature in this region of the melt was above the melting point of basalt. Molten basalt normally does not form glass."

IC304A90E4. This sample showed the relation between rind (reddish in color and $\approx 2.7 \mathrm{~cm}$ thick) and glass. The glass was very finely vesiculated at the contact with the rind. The bubbles increased in size to several centimeters toward the probable center of the melt. The glass was gray near the large vesicles and appeared to be devitrified. It contained less than 1 vol\% of small (<1 mm diameter) anhedral white crystals. Yellow, presumably crystalline, material was present in 1 to $2 \mathrm{~mm}$ thick swirls approximately parallel to the contact with the rind. A steel bolt was also present and cut across the contact with the rind. This sample was probably from the top, center area of the melt. This interpretation is suggested by the reddish color, indicating melt contact with air, and the relation between the rind and the distribution of bubbles in the glass.

IC305A90E4. Dark green, slightly vesiculated (<2 vo1\%, 3-8 mm diameter) glass having $\approx 1$ vol\% anhedral white crystals, was in sharp contact with gray vesiculated material with bubbles up to $5 \mathrm{~mm}$ in diameter. The glass contained dark-brown parallel swirls about $1 \mathrm{~mm}$ thick and $5 \mathrm{~mm}$ in length. Glass also contained a stiel bolt located near the gray vesiculated zone and an irregularly shaped metallic inclusion measuring about $1 \times 4 \mathrm{~cm}$. This sample was probably located near the center of the melt.

IC306A90E4. This sample contained gray densely vesicular (microscopic to $5 \mathrm{~mm}$ in diameter), crystalline material in contact with and filling a large $3.5 \mathrm{~cm}$ diameter steel nut. A $4 \mathrm{~cm}$ long wedge of gray-green glass and a sma11 area of devitrified material were also present. The glass had less than 1 vol\% white anhedral crystals which were less than $1 \mathrm{~mm}$ in diameter.

a. Based on personal experience of J. R. Weidner. 
IC0307A90E4. This dark green-glass contained a few vesicles, approximately $3 \mathrm{~mm}$ in diameter, brown swirls, and white crystals as observed in other samples. The glass contained metallic, ilightly magnetic, inclusions of irregular shape up to $1 \mathrm{~cm}$ in diameter. A $3 \mathrm{~cm}$ diameter steel nut was included in the glass.

IC308A90E4. This sample was gray and densely vesiculated (microscopic to $5 \mathrm{~mm}$ in diameter). The vesicles decreased in size towards gray contact material. No magnetic properties were observed. This sample was probably from the outer surface of the melt, but on the side so that it would not be oxidized by contact with air.

IC309A90E4. This sample contained dark-green glass with less than 1 vol\% vesicles (1-3 mm diameter), brown slightly-magnetic swirls 1-2 cm long, but less than $1 \mathrm{~mm}$ wide, with metallic inclusions. Finely disseminated (<1 vol\%) white specks were also observed. This sample was probably from the center or bottom half of the melt.

IC310A90E4. This sample was very similar to IC308A90E4, with the addition of some dark-green glass in sharp contact with vesicular gray material. The glass was virtually identical to IC309A90E4.

IC0311A90E4. This sample was composed of gray, probably crystalline, material which had a mold of a bolt impressed into the surface. Several spherical, $3 \mathrm{~mm}$, strongly magnetic metal inclusions were also present in the crystalline material.

ES4-1. This sample was composed of 10 grams of dark green glass containing less than 1 vol\% anhedral white crystals having a diameter less than $2 \mathrm{~mm}$ and less than 1 vol\% of microscopic to $0.5 \mathrm{~mm}$ diameter vesicles. The sample was slightly magnetic. The sample was collected and provided by Dr. B. P. McGrail, PNL.

ES4-1P. This sample was provided by Dr. B. P. McGrail, PNL, and consisted of two grams of gray powder. It was included in the plastic bag labeled ES4-1 and was, therefore, presumed to be a powder of ES4-1. 
ES4-M1. This sample was two grams of gray powder provided by Dr. B. P. McGrail, PNL. The sample was removed from plece(s) of adhering metal.

ES4-M2. This sample was two grams of gray powder provided by Dr. B. P. McGrail, PNL. The sample was removed from piece(s) of adhering metal.

ES4-T1. This sample was provided by Dr. B. P. McGrail, PNL. It consisted of 11 grams of highly vesiculated (microscopic to $1.5 \mathrm{~cm}$ diameter) glassy and devitrified material. Slightly magnetic orange-red grains were present on the interior surfaces of the large vesicles. Some surfaces had a soft, platy, metallic-looking substance, probably graphite, with a rounded morphology. It was believed to be from the top of the melt.

ES4-T2. This sample consisted of approximately 12 grams of highly vesiculated (microscopic to $2 \mathrm{~cm}$ in diameter) devitrified and glassy material. It was provided by Dr. B. P. McGrail, PNL. It was belteved to be from the top of the melt.

Polarizing Light Microscopy. Index of refraction measurements are given in Table 7. Glass, with a index of refraction of approximately 1.51, was identified as a major phase in 7 of the 12 samples examined. A plagioclase feldspar, possibly albite, which had a refraction index of 1.53 , was apparently present in subsamples IC308C90E4 and IC308D90E4. Subsample IC308D90E4 al so had quartz. present, as did subsample IC306B90E4. The above interpretations are supported by $x$-ray diffraction data discussed below. One phase observed in subsample IC306B90E4 with an index of refraction of 1.49 may be cristobalite, but cristobalite was not identified with $x$-ray diffraction. Finally, two samples identified megascopically as glass had index of refractions of 1.524; the associated phase, if different from glass, has not been identified.

Density Measurements. The density measurements range from 2.327 to 2.981 $\mathrm{g} / \mathrm{cm}^{3}$ and are given in Table 8 . As expected, the vesicular material had lower density values. The highest density was determined from crystalline material and all glass sample densities were bracketed by the extremes. Table 9 gives 
Table 7. Index of refraction measurements

\begin{tabular}{|c|c|c|c|}
\hline Megascopic Description & Subsample & \multicolumn{2}{|c|}{$\begin{array}{l}\text { Index of } \\
\text { Refraction }\end{array}$} \\
\hline Glass & IC307B90E4 & 1.524 & - \\
\hline Glass & IC305D90E4 & 1.510 & - \\
\hline Glass & IC300C90E4 & 1.524 & - \\
\hline Glass & IC302C90E4 & 1.514 & - \\
\hline Grey Crystalline Material & IC306B90E4 & 1.490 & 1.544 \\
\hline Grey Vesicular Material & IC308C90E4 & 1.532 & - \\
\hline Grey Ves:cular Material With Soil Contact & IC308D90E4 & 1.532 & 1.554 \\
\hline Powdered Glass & ES4-1P & 1.512 & - \\
\hline Powdered Glass Near Metal & ES4-M1 & 1.508 & - \\
\hline Powdered G1ass Near Metal & ES4-M2 & 1.514 & - \\
\hline Vesiculated Material & ES4-T2 & 1.512 & - \\
\hline Vesiculated Material & ES4-T1 & 1.512 & - \\
\hline
\end{tabular}


Table 8. Density measurements

\begin{tabular}{lcc}
\hline \multicolumn{1}{c}{ Phase } & Subsample & Density \\
\cline { 2 - 3 } Glass & IC307B90E4 & 2.453 \\
Glass & ES4-1 & 2.442 \\
Glass & IC302C90E4 & 2.361 \\
Glass & IC300C90E4 & 2.452 \\
Glass & IC305D90E4 & 2.457 \\
Glass & ES4-1 & 2.437 \\
Grey Crystalline Material & IC306B90E4 & 2.981 \\
Grey Vesicular Material & IC308D90E4 & 2.327 \\
Grey Vesicular Material & IC308C90E4 & 2.327 \\
\hline
\end{tabular}


Table 9. Density measurement means and $90 \%$ confidence interval limits

\begin{tabular}{llccc}
\hline \multicolumn{1}{c}{ Phase } & & $\begin{array}{c}\text { Upper } 90 \% \\
\text { Confidence } \\
\text { Limit }\end{array}$ & $\begin{array}{c}\text { Mean } \\
\text { Gonfidence } \\
\text { Limit }\end{array}$ \\
\cline { 4 - 5 } Grey Vesicular Material & 2.3270 & & 2.371 & 2.394 \\
\hline
\end{tabular}


$90 \%$ confidence 1 imits for the mean densities for the glass and vesicular phases. Since the density measurements were identical for the two vesicular samples tested, the mean and confidence limits were all equal. Based on the glass sample results, one can be $90 \%$ confident that the true mean glass density was between 2.471 and $2.394 \mathrm{~g} / \mathrm{cm}^{3}$.

The crystalline material had a density that was higher than expected from nonmetallic minerals on average $\left(2.65-2.75 \mathrm{~g} / \mathrm{cm}^{3}\right)$, and the $\mathrm{glass}$ was slightly lower. However, $\mathrm{Mg}$ and $\mathrm{Fe}$ bearing silicates such as spinel and augite have densities that range from $3.6-4.0$ and $3.2-3.4 \mathrm{~g} / \mathrm{cm}^{3}$, respectively, while albite has a density of $2.62 \mathrm{~g} / \mathrm{cm}^{3} .{ }^{13}$ The sample density depends on the relative proportions of component minerals; minerals such as spinel and augite may be present in the gray crystalline material, resulting in a higher than average density. Metal content can also contribute to higher than average density. Likewise, a lack of crystalline phases, such as in glasses, in general will result in a lower than average density.

Bulk Chemical Analysis. The bulk chemical major element oxide concentration for subsamples analyzed by INEL are shown in Table 10. Data of questionable quality are indicated with a $Q$. With two exceptions, subsamples IC306B90E4 and IC303B90E4, the analyses appeared to be quite similar. The similar samples were glass or rind samples with approximately $13-14 \% \mathrm{Al}_{2} \mathrm{O}_{3}$, $4 \% \mathrm{CaO}, 4-6 \% \mathrm{FeO}, 2.5 \% \mathrm{~K}_{2} \mathrm{O}, 2 \% \mathrm{MgO}, 0.1-0.2 \% \mathrm{MnO}$, and $2 \% \mathrm{Na}_{2} \mathrm{O}$. $\mathrm{SiO}_{2}$ concentrations were erratic; of values of acceptable quality, some appeared low in conjunction with low sums, indicating analytical recovery problems. Subsample ES4-1, analyzed at PNL, was the highest oxide sum with $\mathrm{SiO}_{2}=59.4 \mathrm{wt} \%$, and may represent the most accurate analysis of the samples.

Subsample IC303B90E4 was a metal sample, and the analyses in Table 10 reflect this fact (analyses presented are elemental). Subsample IC306B90E4 is composed of gray crystalline material and had higher $\mathrm{MgO}, \mathrm{FeO}$, and $\mathrm{CaO}$ than glass, samples. 


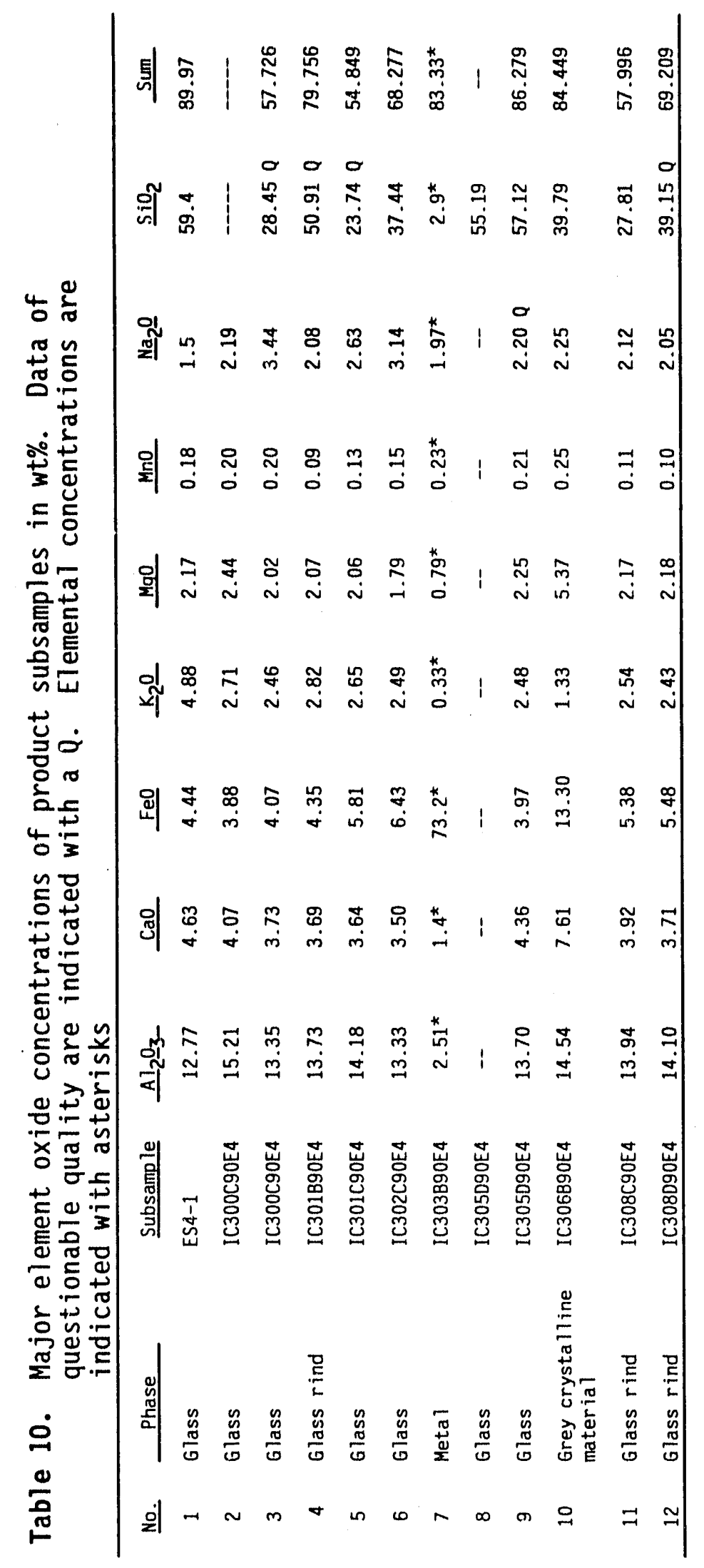


Table 11 gives selected TCLP toxic and other metal concentrations for bulk subsamples analyzed by INEL. Data of questionable quality are indicated with a $Q$ and data for which associated blanks were contaminated are flagged with a $B$. The analysis results appear to be somewhat dependent on subsample phase characteristics. For instance, the highest (by far) $\mathrm{Cr}$ measurement was made on the metal subsample; the remaining $\mathrm{Cr}$ measurements were variable. The $\mathrm{Pb}$ measurements were also quite variable, with no apparent pattern. Tf values were relatively constant in the subsamples with one exception, an anomalously high value in the gray crystalline material. The metal subsample exhibiting a concentration slightly higher than other subsamples was also relatively constant. Se appears to be bimodal in that it occurs at levels of approximately $70 \mu \mathrm{g} / \mathrm{g}$ or less and also at $285 \mu \mathrm{g} / \mathrm{g}$ in ES4-1; however, because ES4-1 was analyzed at PNL, the difference observed could be due to interlaboratory variability.

PNL had pretest basalt and posttest basalt, glass, and metal samples analyzed for TCLP toxic metal concentrations. The pretest and posttest basalt bcth had detectable $\mathrm{Ba}, \mathrm{Cd}, \mathrm{Cr}$, and $\mathrm{Pb}$; pretest concentrations did not appear to be different from posttest concentrations. The glass samples had detectable $\mathrm{Ag}, \mathrm{Ba}, \mathrm{Cr}, \mathrm{Hg}$, and $\mathrm{Pb}$. The $\mathrm{Ba}$ and $\mathrm{Cr}$ were detected in all glass samples; $\mathrm{Ag}$ and $\mathrm{Pb}$ were deteced and $\mathrm{Ba}$ was highest in glass samples collected in the bottom portion of the melt. The metals $\mathrm{Ag}, \mathrm{As}, \mathrm{Ba}, \mathrm{Cr}, \mathrm{Hg}, \mathrm{Pb}$, and $\mathrm{Se}$ were all detected in the metal samples, with few exceptions; Cd was detected in one sample at a concentration of $25.9 \mu \mathrm{g} / \mathrm{g}$.

PNL glass sample analysis results for $\mathrm{Cr}$ were approximately the same order of magnitude as INEL samples; however, less variability was observed in the PNL data. The highest Pb value in the PNL glass samples was $222 \mu \mathrm{g} / \mathrm{g}$; INEL analyses ranged higher. Except for Cd, the PNL metal samples contained concentrations of TCLP toxic metals as much as 10 times more than that observed in the single INEL metal sample. The Hg levels observed in PNL glass samples were $0.06,0.23$, and $<0.05 \mu \mathrm{g} / \mathrm{g}$ in two samples; comparable values were observed in the metal samples. Information on metal concentrations of 


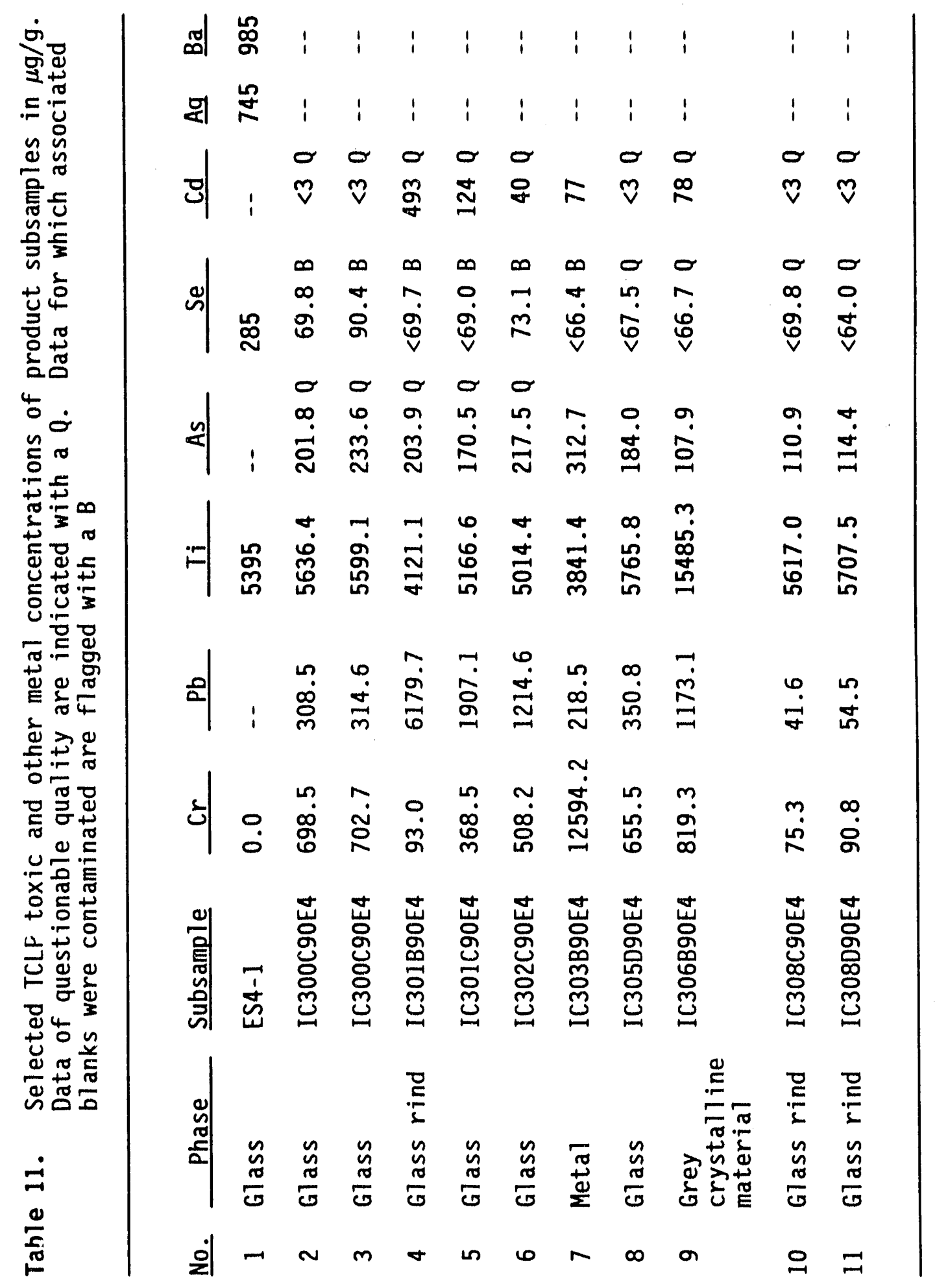


PNL samples was provided by private communication with Richard K. Farnsworth, EG\&G Idaho, Inc., Idaho Fal1, Idaho, August 27, 1991.

XRD. The $x$-ray powder diffraction data were obtained using an instrument which automatically chooses the most likely crystalline material present in an analyzed sample. This was done by computer match between the measured $x$-ray powder diffraction data and a computer library file of x-ray diffraction data. This system provided satisfactory identification of the crystalline phases present provided the system analyzed contained relatively few phases (four or less), the phases made up about 5 vol\% of the sample or more, and the data for the phases were present in the computer $x$-ray diffraction file.

The application of this $x$-ray diffraction identification method to the identification of the crystalline phases found in the ES-4 product was complicated by several factors. Clearly, an identification using this approach required that the appropriate data be in the library file if a match and identification of an unknown material was to be achieved. There was no prior way to determine if the appropriate data was in the file. Further, much of the ES-4 product could be described as a quenched glass which had partially devitrified. Consequentiy, many of the crystalline phases had variable composition, even within a single crystal, as observed in Reference 10, and did not yield a set of diffraction data that was unique to that material. Thus the computer match might indicate the mineral diopside, $\mathrm{CaMgSi}_{2} \mathrm{O}_{4}$, as being present. A second measurement on another sample, or even the same sample, might indicate the mineral hedenbergite, $\mathrm{CaFeSi}_{2} \mathrm{O}_{4}$. In fact, neither identification is likely to be correct, but rather the identification reflects the dominant component of the solid solution controlling the diffraction data. The procedure used was to identify the material by the crystallographic structural family name, which in this example was clinopyroxene. A last complication was the nature of the data in the computer library-file itself. Many of the data were measured on materials synthesized at conditions different from those of the ISV process and therefore had different $x$-ray diffraction properties. In view of the above factors, the $x$-ray powder diffraction data presented in this report is used primarily to identify the crystallographic structure type of the crystalline materials. 
With the above described caveats in mind, the following phase identifications have been made for the ES-4 product. The crystalline phases present are quartz, clinopyroxene, spine1, and plagloclase. In addition, glassy material was identified by XRD powder patterns. XRD powder patterns for $\mathrm{Fe}$, steel, and/or stainless steel were recognized. Also detected was $\mathrm{CaF}_{2}$, which was added to each sample as an internal standard. Finally, WC, which was the grinding medium for the samples, was detected in some samples. Table 12 gives the phases identified in each subsample analyzed.

SEM. Using the SEM, the ES-4 glass was found to typically contain numerous bright round metallic inclusions that were typically several micrometers in size. An example is shown in Figure 5. The inclusions were presumed to have been melted; they were composed primarily of Fe with some $P$. In some cases the $P$ occurs at the outer edges of the inclusion (see Figure 6 ) and in some cases throughout (see Figure 7). The latter phenomenon could occur if the SEM mount cut through only the outer ring of an inclusion. The P-ring phenomenon had been observed in other ISV melts (see Reference 10) and is believed to be of the composition $\mathrm{Fe}_{3} \mathrm{P}$ while the center is metallic $\mathrm{Fe}$.

In some areas of the glass, several crystalline phases were observed, one or two of which appeared to be dominant. The boundaries between glass and crystalline areas were often indistinct and irregular (see Figure 8 where the crystalline phase is labeled black and the glassy phase is labeled gray). Near soil contacts, islands of quartz, likely remnants of soll grains, were observed.

One common crystalline phase, a calcium iron magnesium aluminum silicate (clinopyroxene), was dendritic in structure, and varied in $\mathrm{Mg}, \mathrm{Fe}, \mathrm{Ca}$, and $\mathrm{Al}$ composition. The dendritic structure is shown in Figure 9. Table 13 gives the SEM analyses for the areas indicated by number in Figure 9. The XRD support for the identification of this phase as clinopyroxene is indirect.

Another crystalline phase is evident in areas of Figure 10 labeled 1 and 3. Based on indirect XRD results and microchemical data, the phase is belived to be a sodium and calcium aluminum silicated (plagioclase). Areas 
Table 12. Phases identffied by XRD

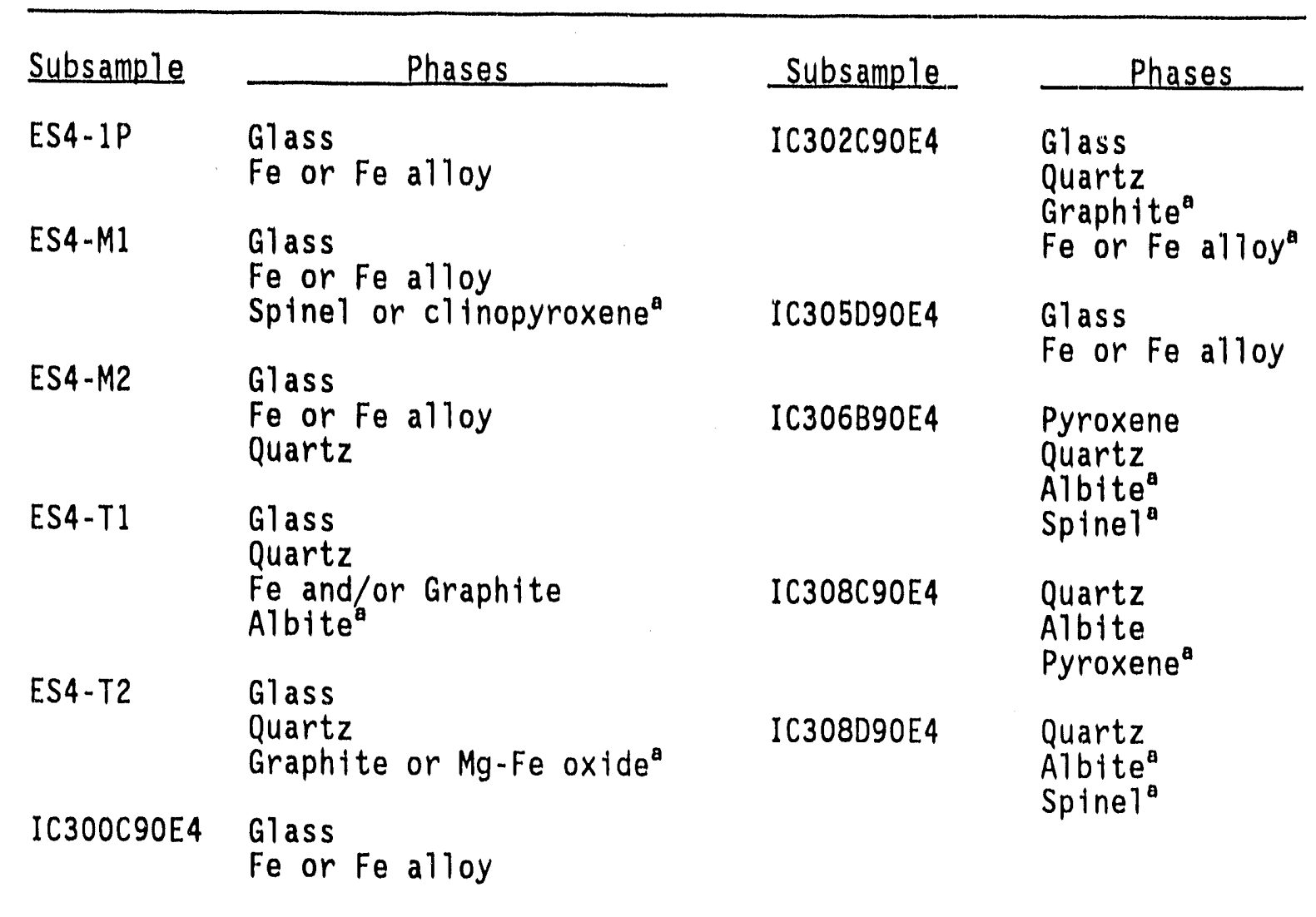

a. Uncertain identification. 


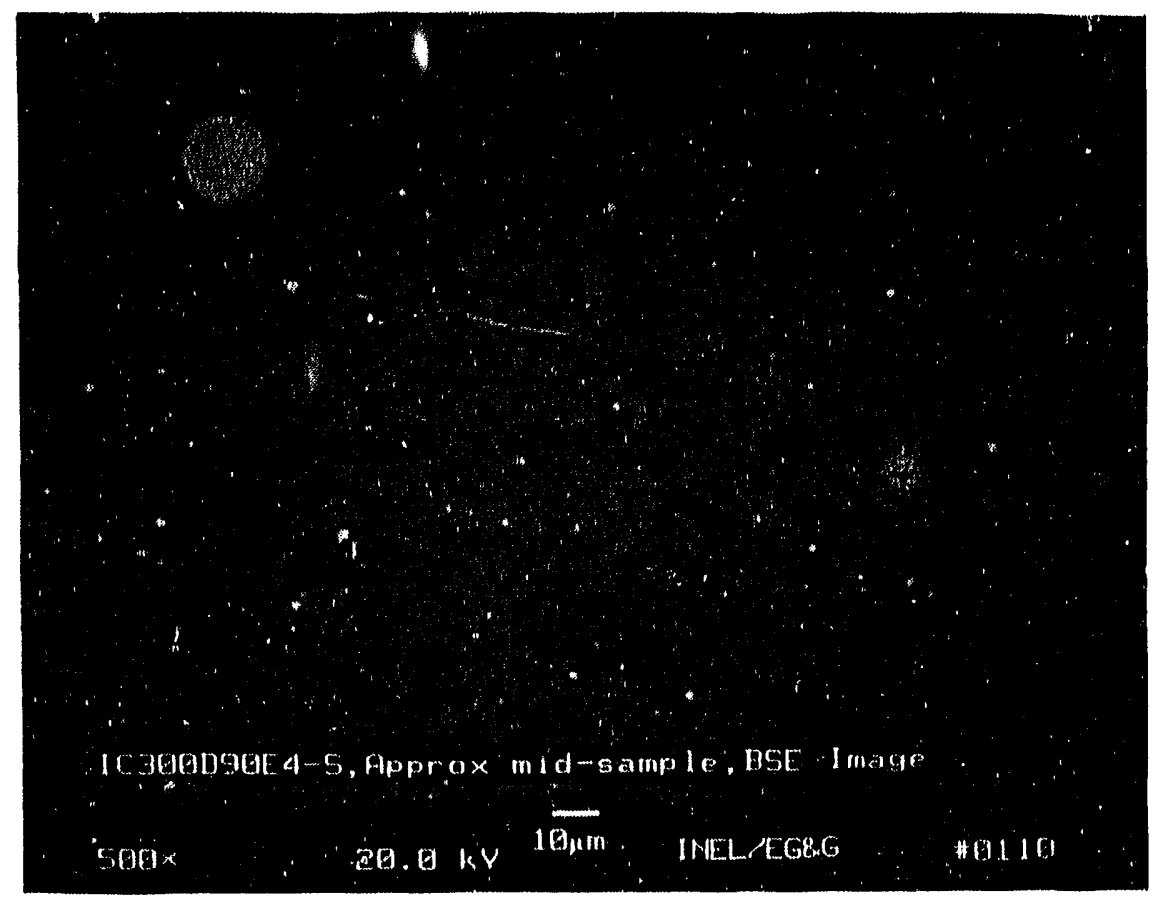

Figure 5. SEM photomicrograph of subsample IC300D90E4 showing glass with bright round metallic inclusions (photomicrograph by D. V. Miley). 


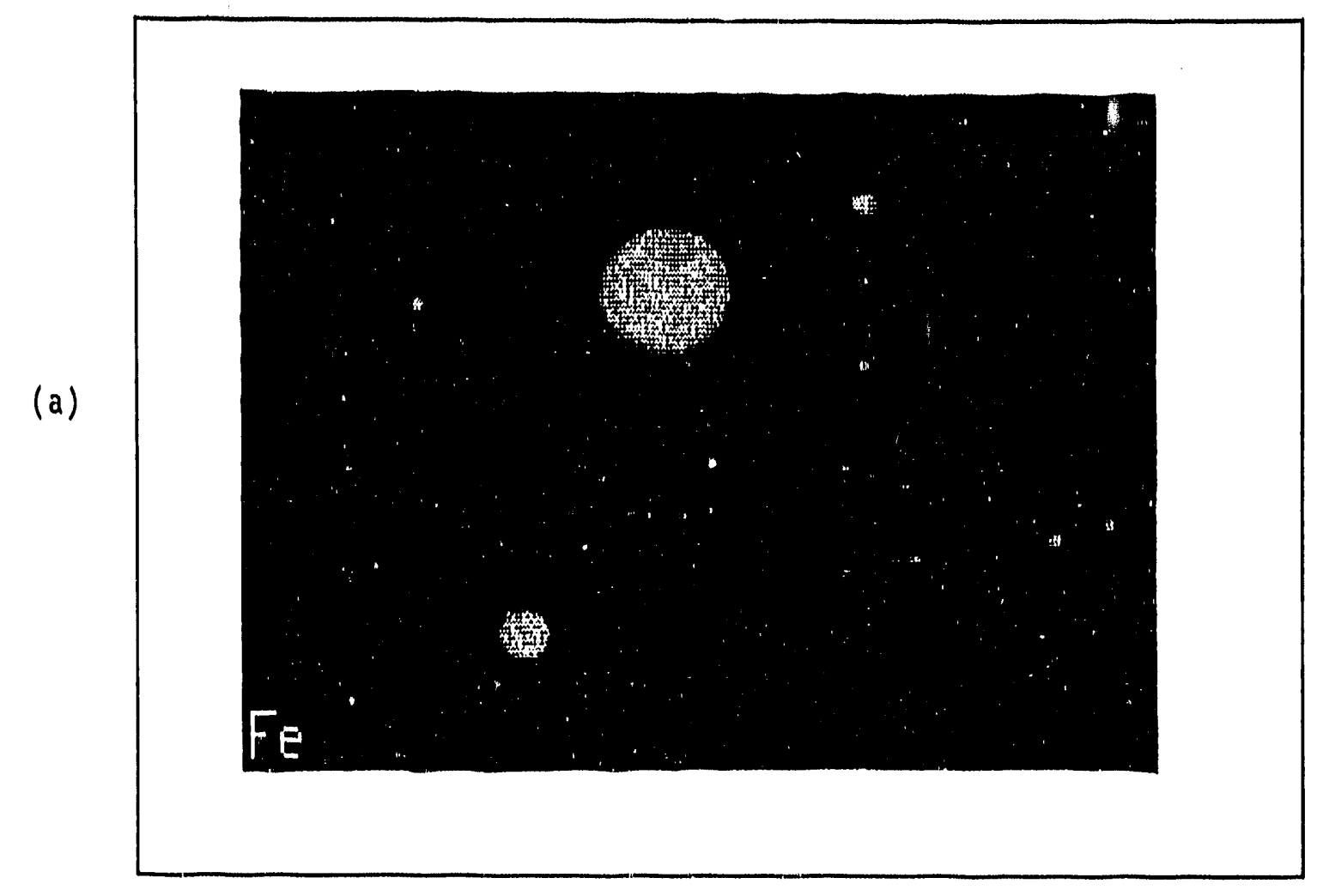

(b)

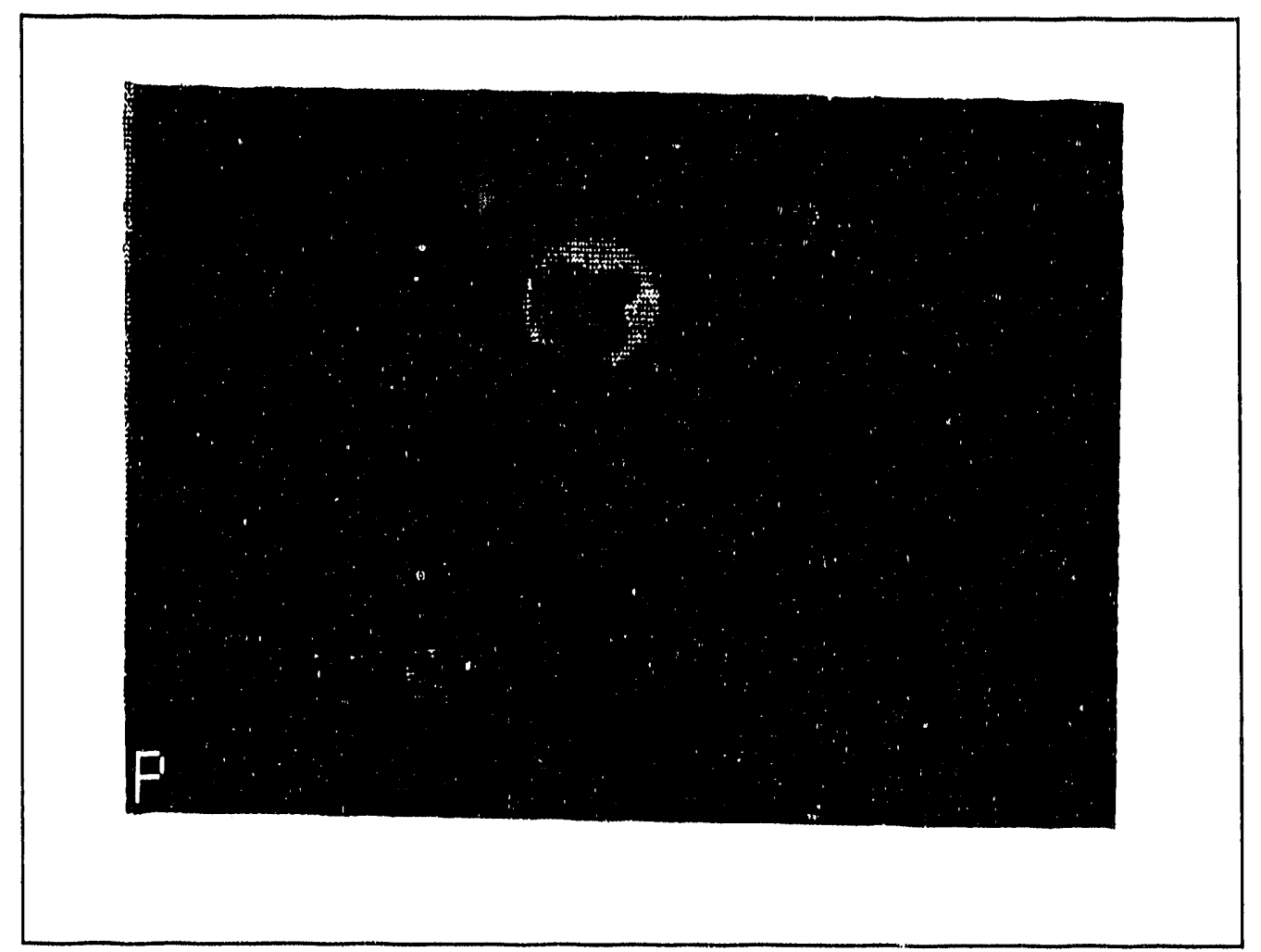

Figure 6. SEM element map of subsample ICO5D90E4 showing round inclusions in glass and distribution of (a) FE and (b) P. Lighter areas indicate greater concentrations. 


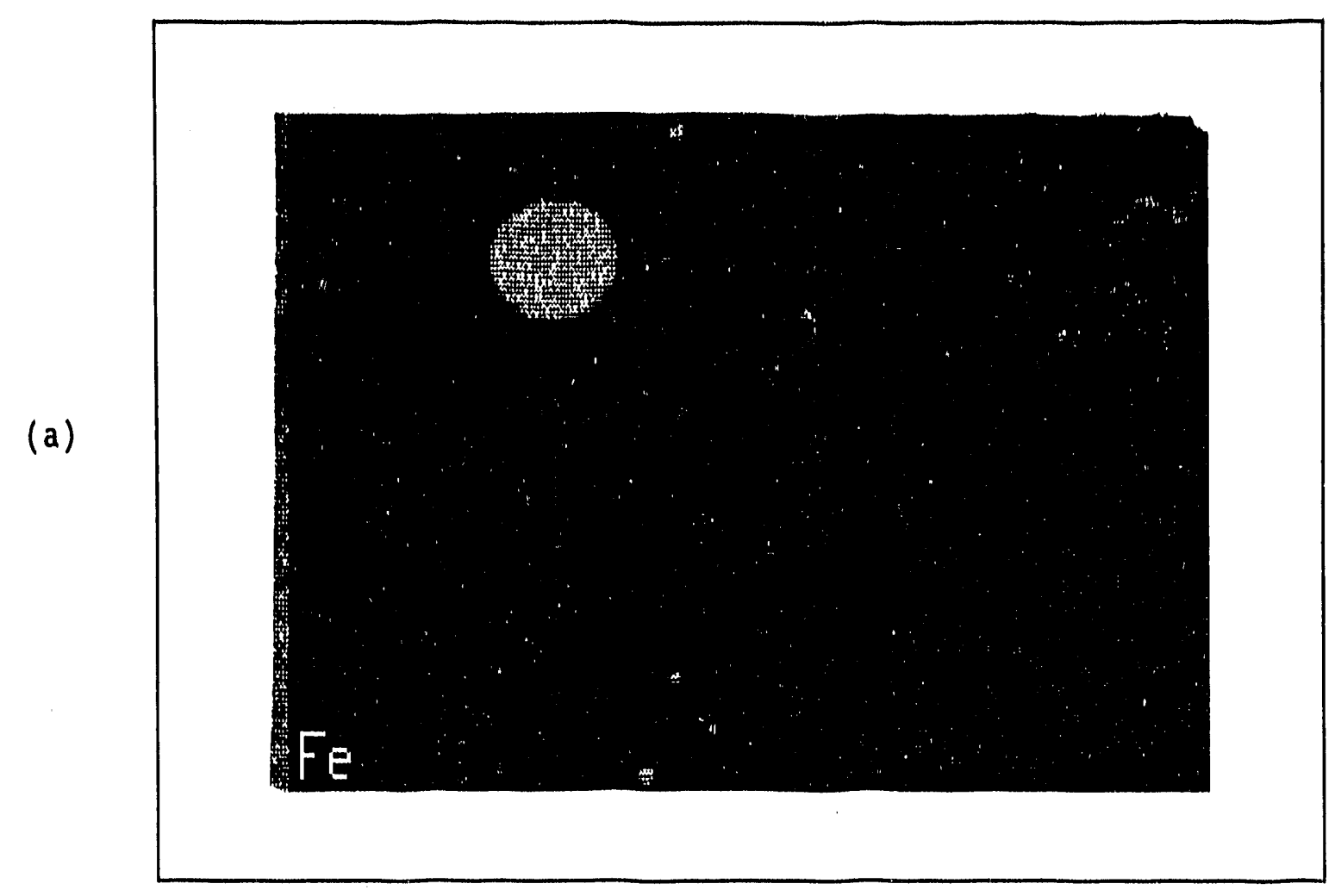

(b)

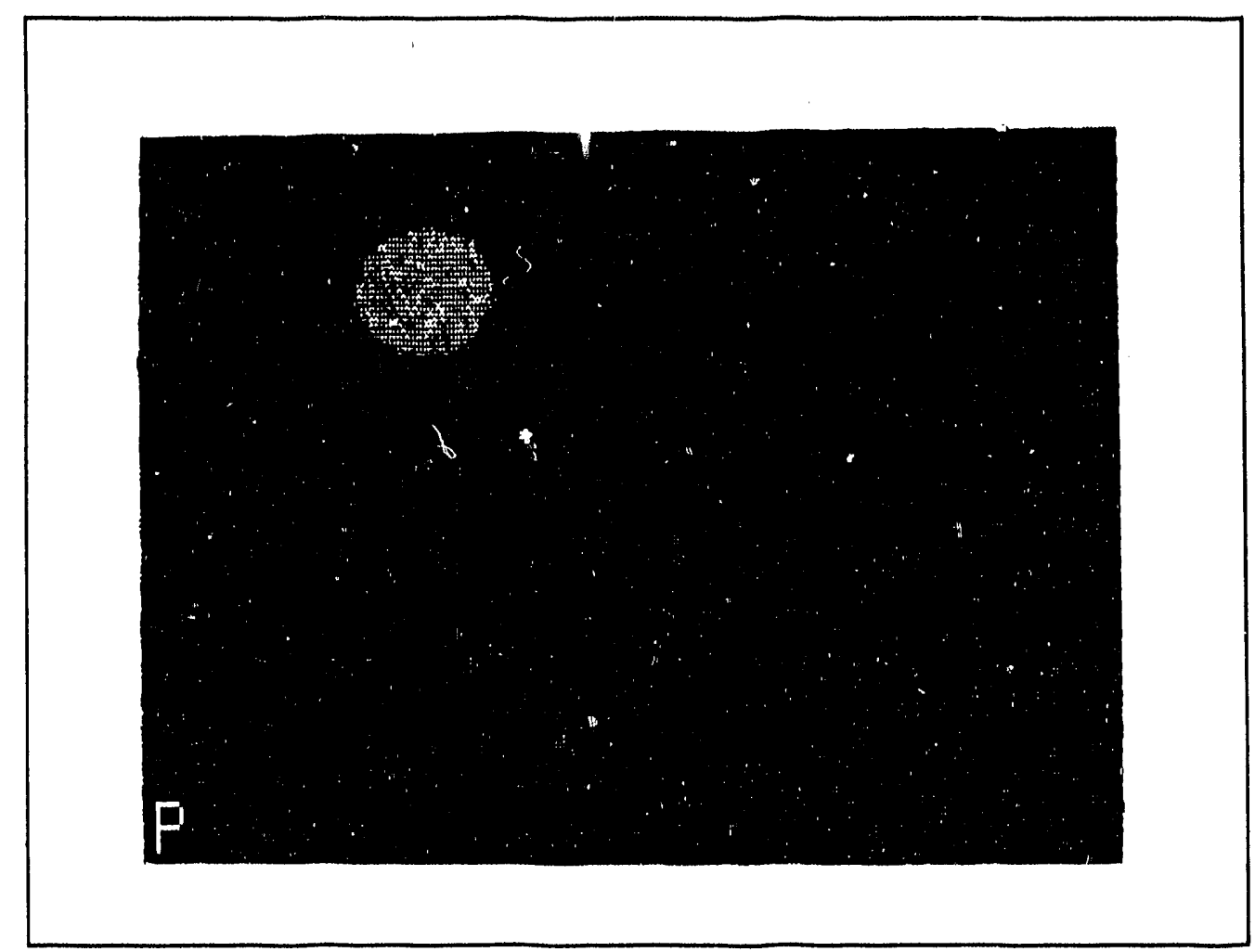

Figure 7. SEM element map of subsample IC306B90E4 showing round inclusions in glass and distribution of (a) Fe and (b) P. Lighter areas indicate greater concentrations 


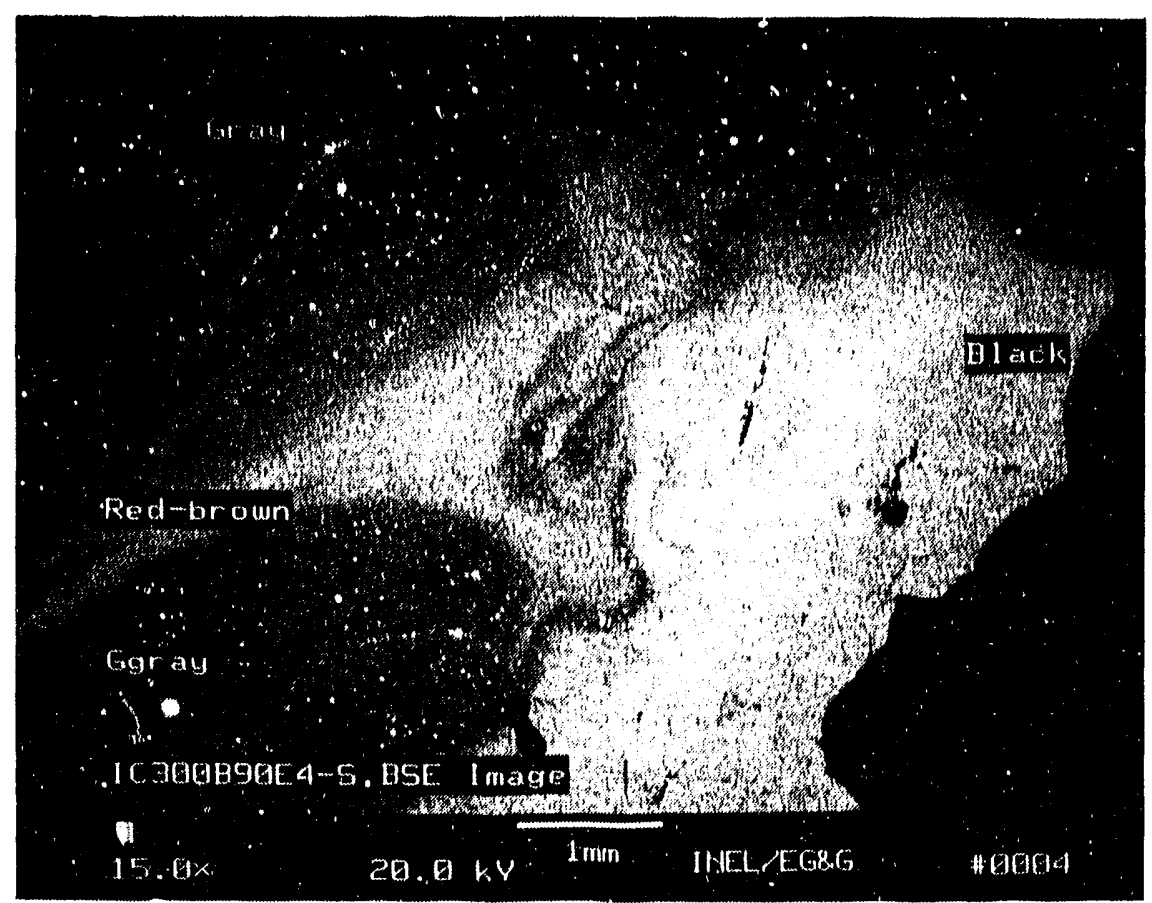

Figure 8. SEM photomicrograph of subsample IC300B90E4 showing crystalline (labeled black) and glassy (1abeled gray) areas (photomicrograph by $D . V$. Miley). 


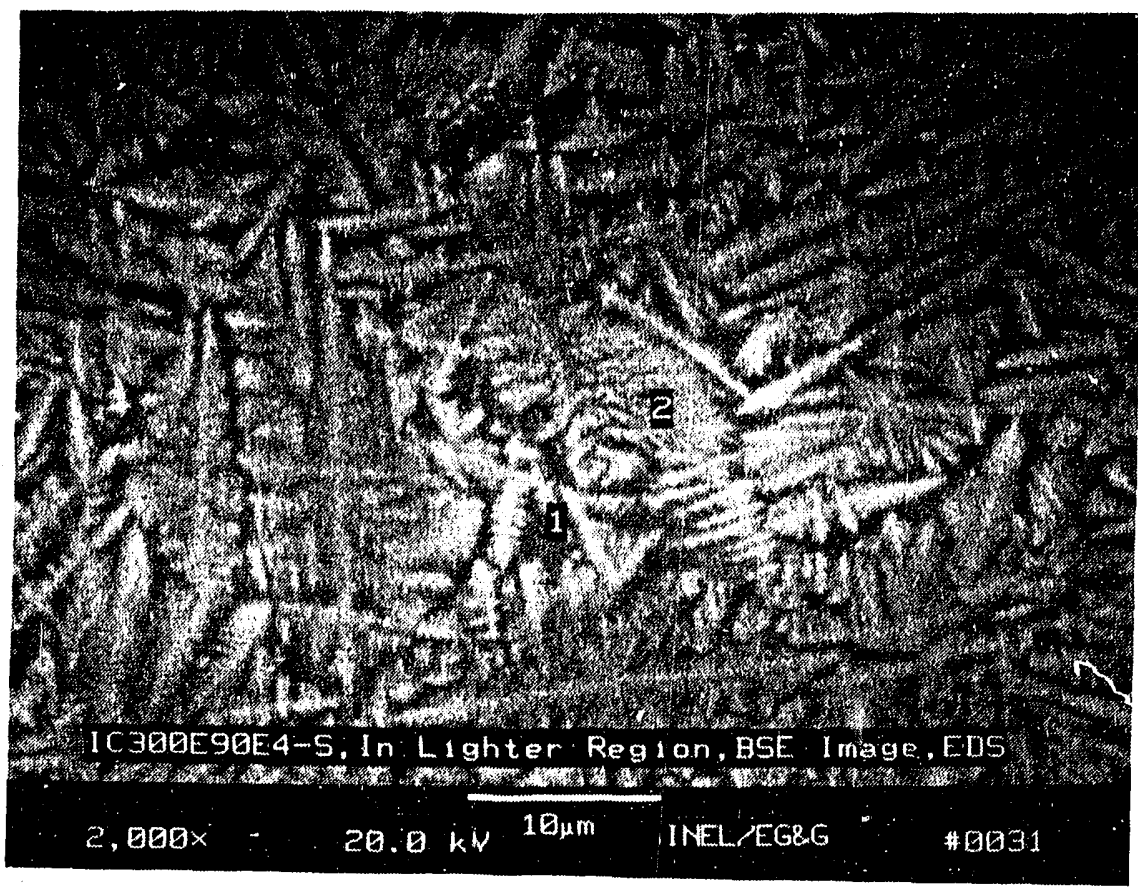

Figure 9. SEM photomicrograph of subsample IC300E90E4 showing dendritic crystalline phase (photomicrograph by D. V. Miley). 


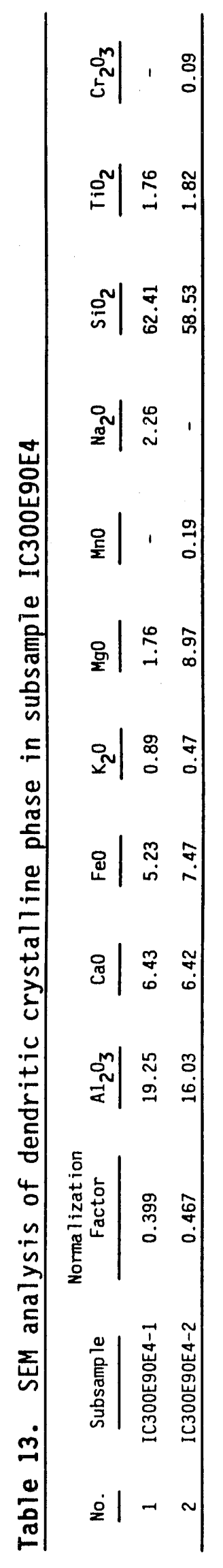




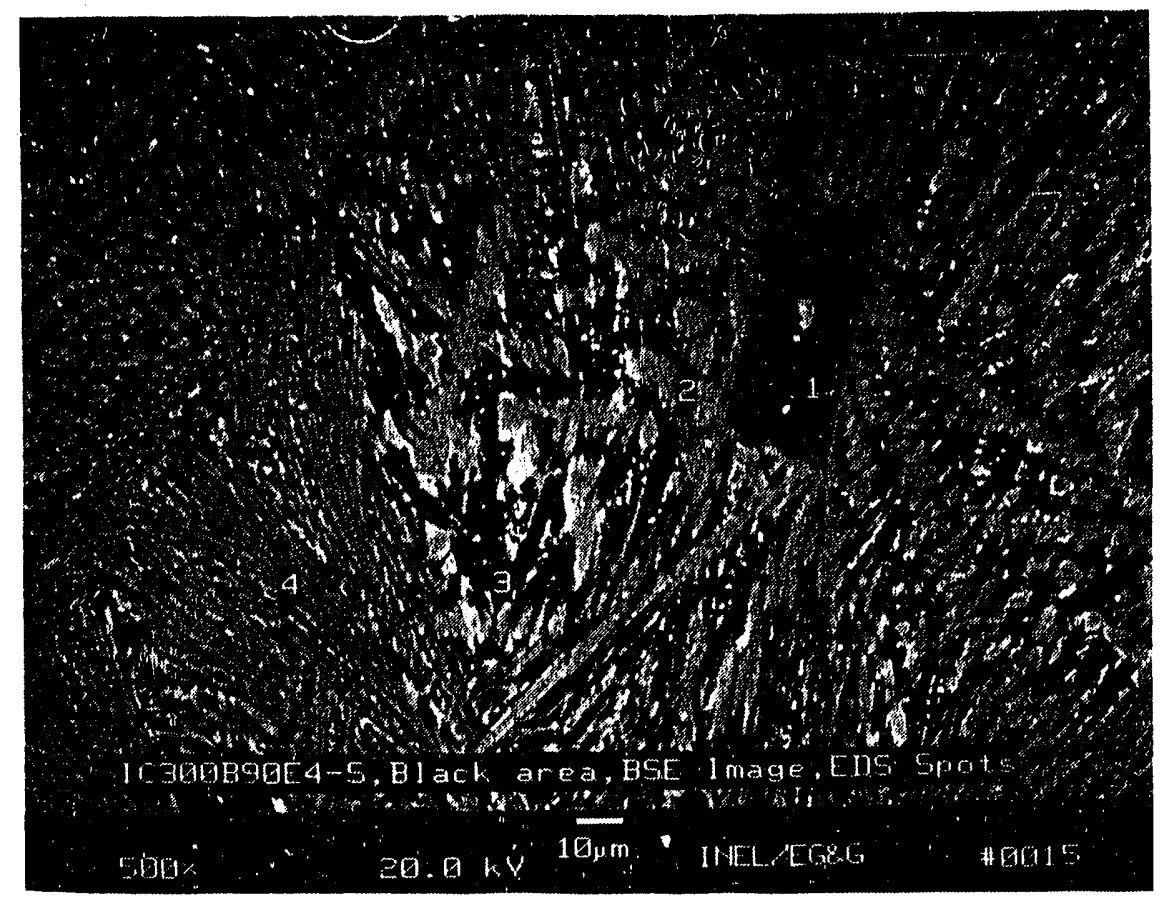

Figure 10. SEM photomicrograph of subsample IC300B90E4 showing two crystalline phases. One phase is identified with numbers 1 and 3 , and another is identified with numbers 2 and 4 (photomicrograph by D. V. Miley). 


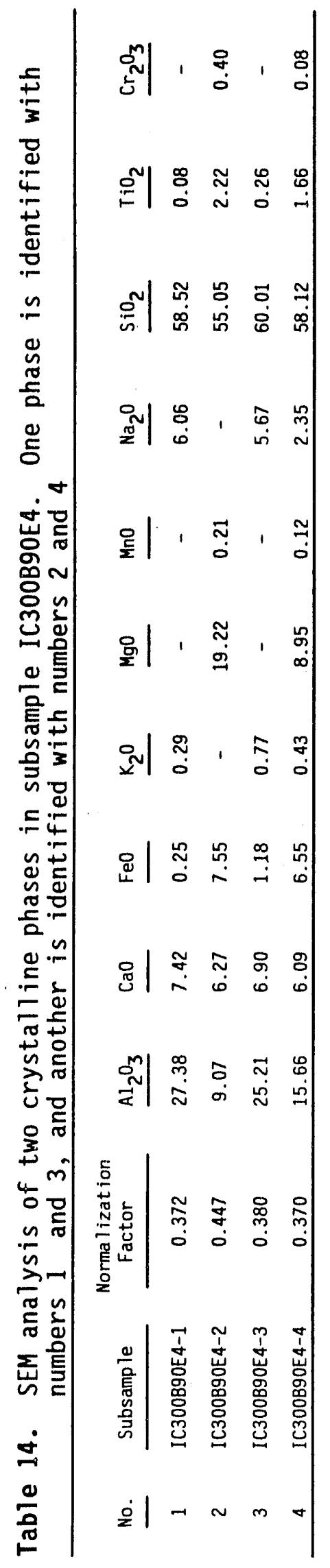


labeled 2 and 4 are interpreted to be clinopyroxene based on the chemical data and indirect XRD results. The microchemical data are given in Table 14, which gives the SEM analysis for the numbered areas of Figure 10.

Two other phases have also been identified as present (see areas 19 and 20 of Figure 11); these could be an iron and magnesium aluminum oxide (spine1) and iron and titanium oxide (ilmenite), but the Si content (see Table 15, which has the SEM analyses that correspond to areas numbered in Figure 11) was perplexing. Spinel and ilmenite do not contain Si, but the crystals examined may be heterogeneous, explaining the presence of $\mathrm{Si}$. In addition, $\mathrm{Al}$, which is one possible component of spinel, was lacking. However, the crystal morphology in area 19 corresponds to that of spinel, and spinel was identified by XRD in other subsamples. Other phases observed in Figure 11 are the plagioclase (number 21) and what are presumed to be clinopyroxenes (numbers 22 and 23), although the evidence for clinopyroxene identification is not conclusive. Samples with the plagioclase, spinel, and ilmenite phases appear gray and crystalline in hand specimen, and presumably were originally basalt.

Interfaces of glass with largely unmelted metal pieces exhibit what are apparently reaction zones in the metal edges. These zones are of several types, as shown in Figures 12, 13, 14, and 15. The zones contain secondary metallic phases or crystalline phases that are present in a variety of microstructures such as dendritic, rounded, and irregular shaped, or are simply compositionally zoned with no distinctive microstructure. Figure 12 has a zone of round inclusions along the edge of the metal washer (1ighter area). Figure 13 has compositional zoning indicated by numbers 7,8 , and 9 . Figure 14 provides two different magnifications of a metal reaction zone (1ighter area) which shows dendritic and rounded features that occur parallel to the edge of the metal. Figure 15 shows irregularly shaped metallic areas $(2,3$, and 4 ) in the metal (1). The SEM analyses that correspond to identified areas in Figures 12, 13, 14, and 15 are given in Tables 16, 17, 18, and 19.

The chemical characteristics of the metal associated with the features observed in Figures 12, 13, 14, and 15 varied; in Figure 12, the inclusions contianed $\mathrm{SiO}_{2}$ (analysis number 2) and small blebs of material at the 


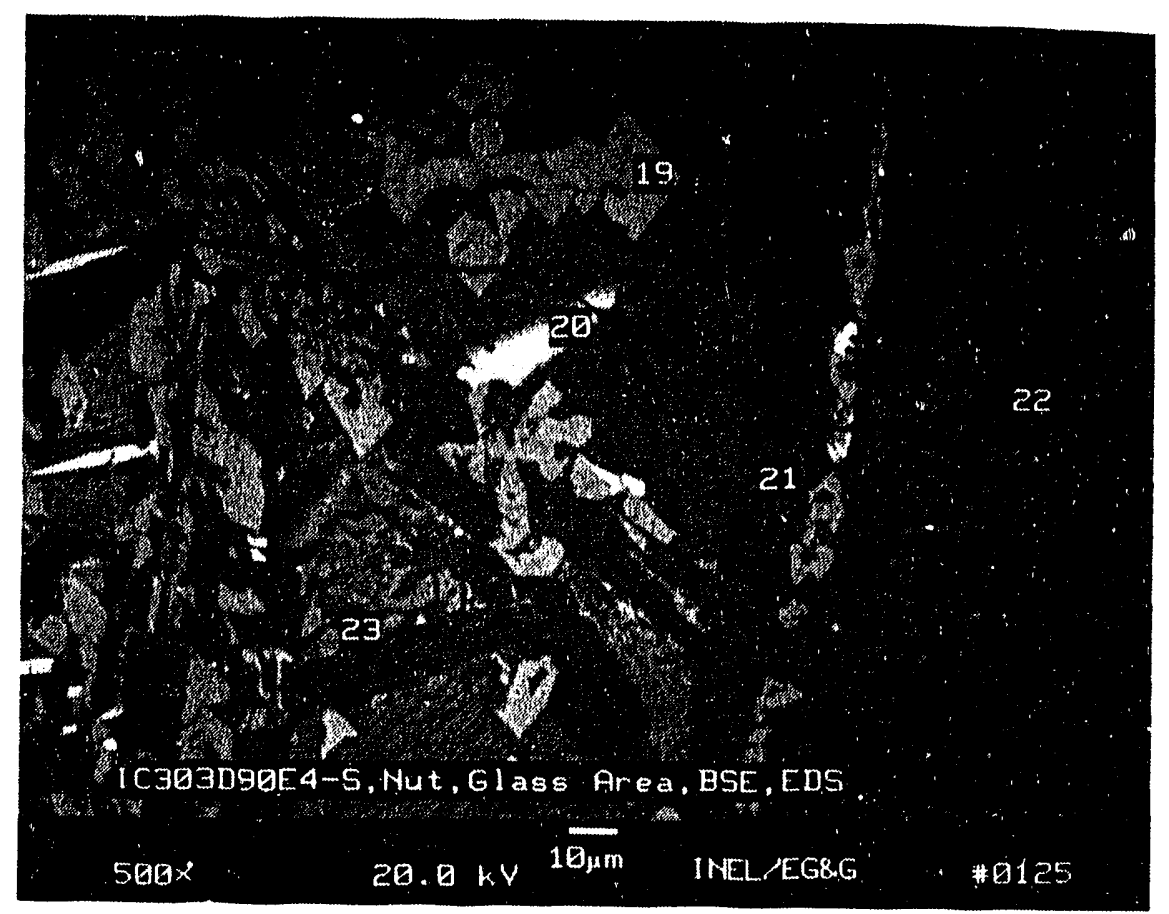

Figure 11. SEM photomicrograph of different crystalline phases (identified with numbers) in the nut, glass area of subsample IC303D90E4 (photomicrograph
by $D$. V. Miley). 


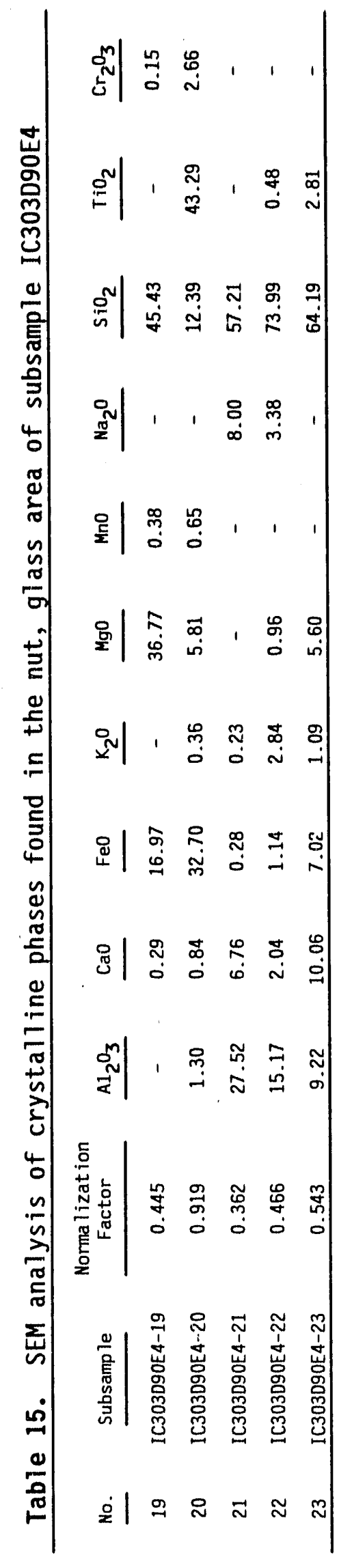




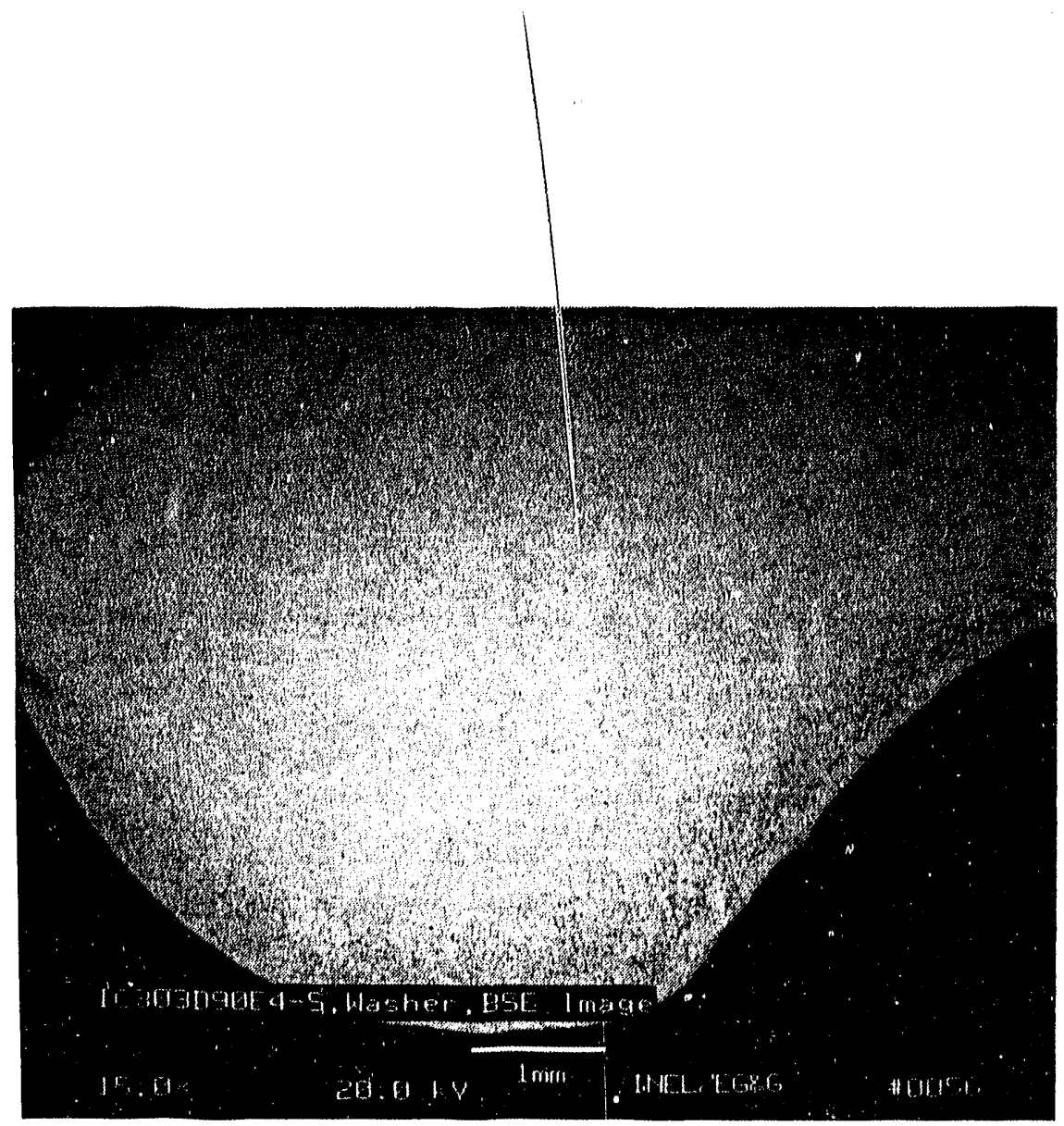

Figure 12. SEM photomicrograph of washer in subsample IC303D90E4 (photomicrograph by D. V. Miley). 


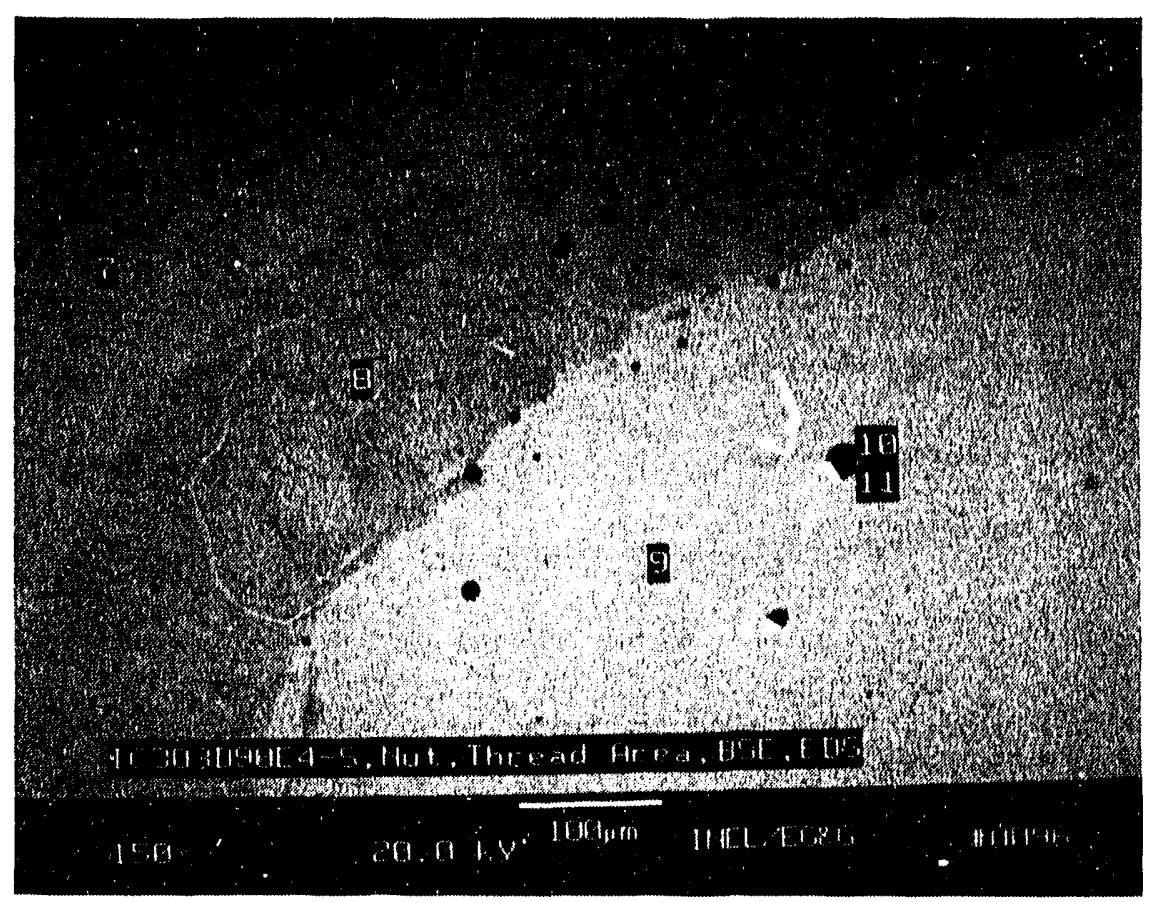

Figure 13. SEM photomicrograph of subsample IC303D90E4 showing metal zones of differing composition in the nut, thread area (photomicrograph by D. V. Miley). 
(a)

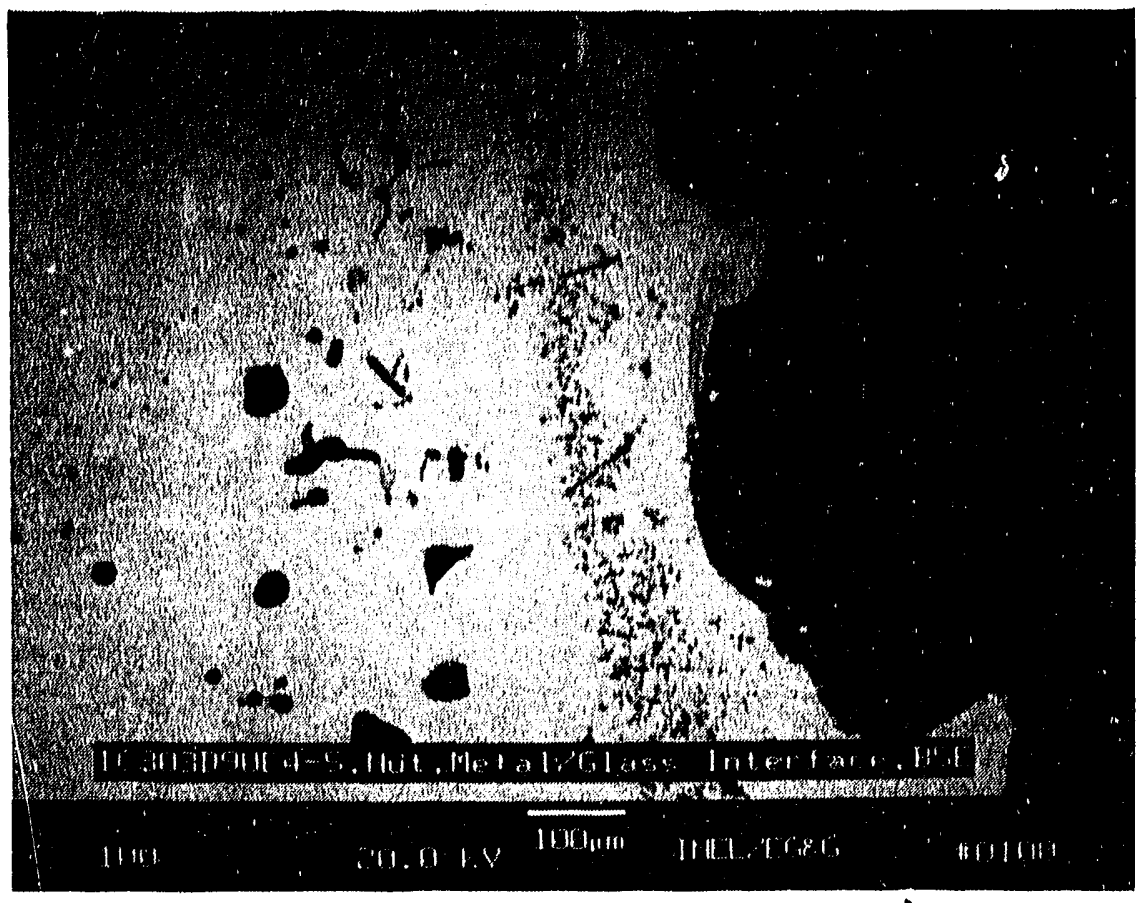

(b)

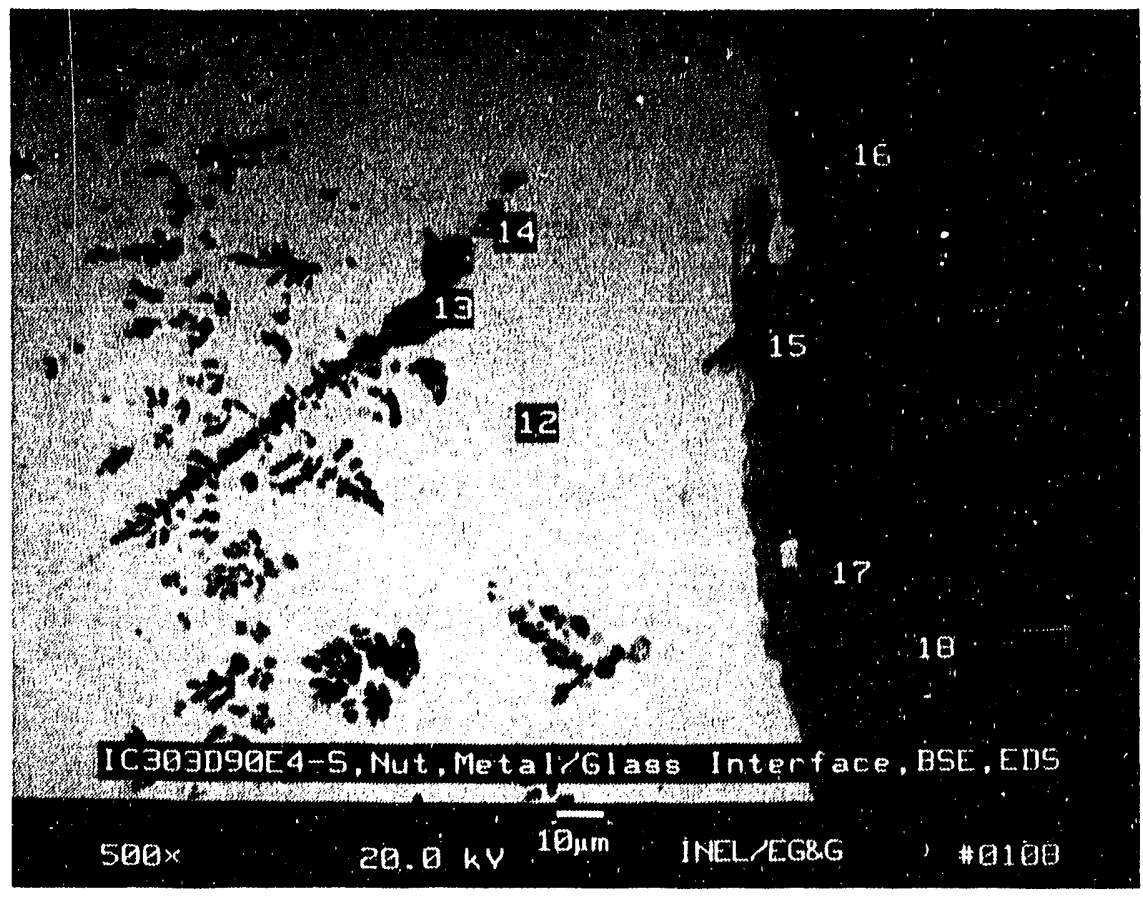

Figure 14. SEM photomicrographs of metal reaction zone in a nut, metal/glass interface area of subsample IC303D90E4; (a) is taken at 100X magnification and (b) is taken at 500x magnification of an area near the edge of the metal (photomicrograph by D. V. Miley). 


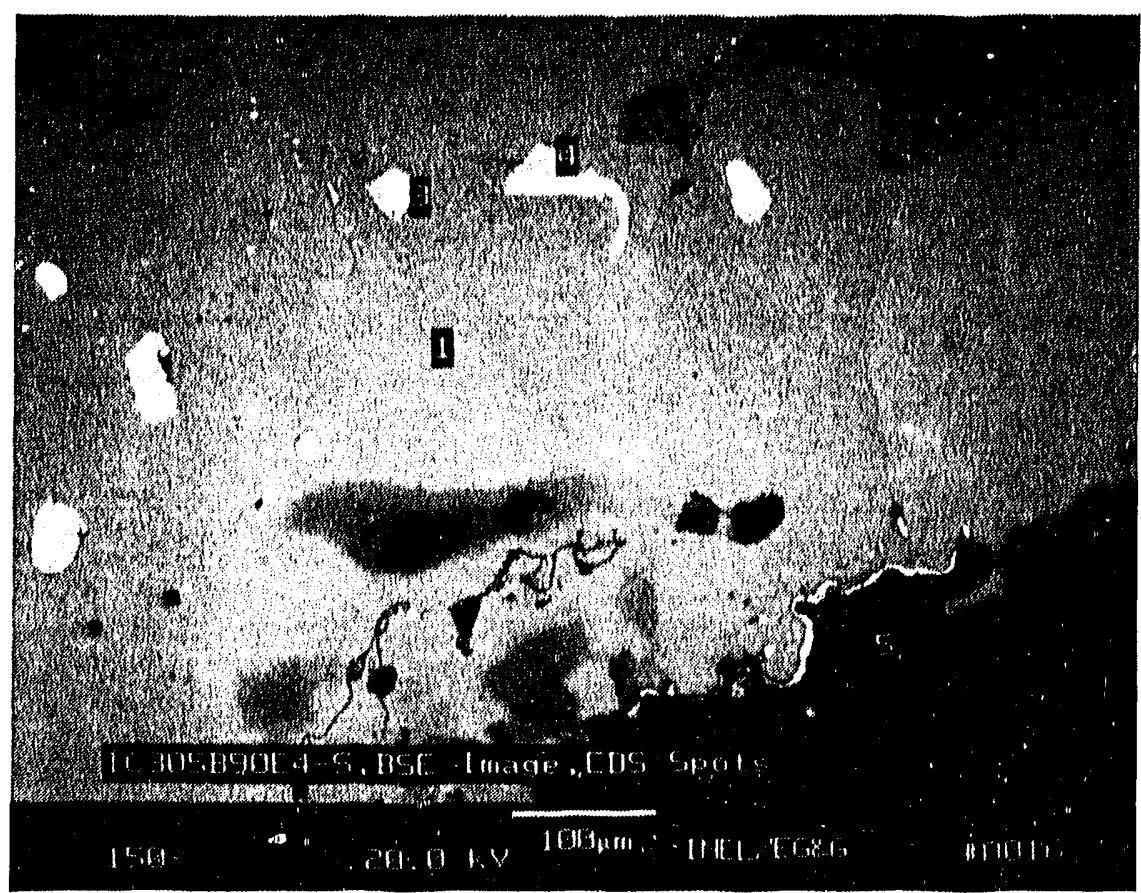

Figure 15. SEM photomicrograph of metal phases in subsample IC305B90E4 (photomicrograph by D. V. Miley). 

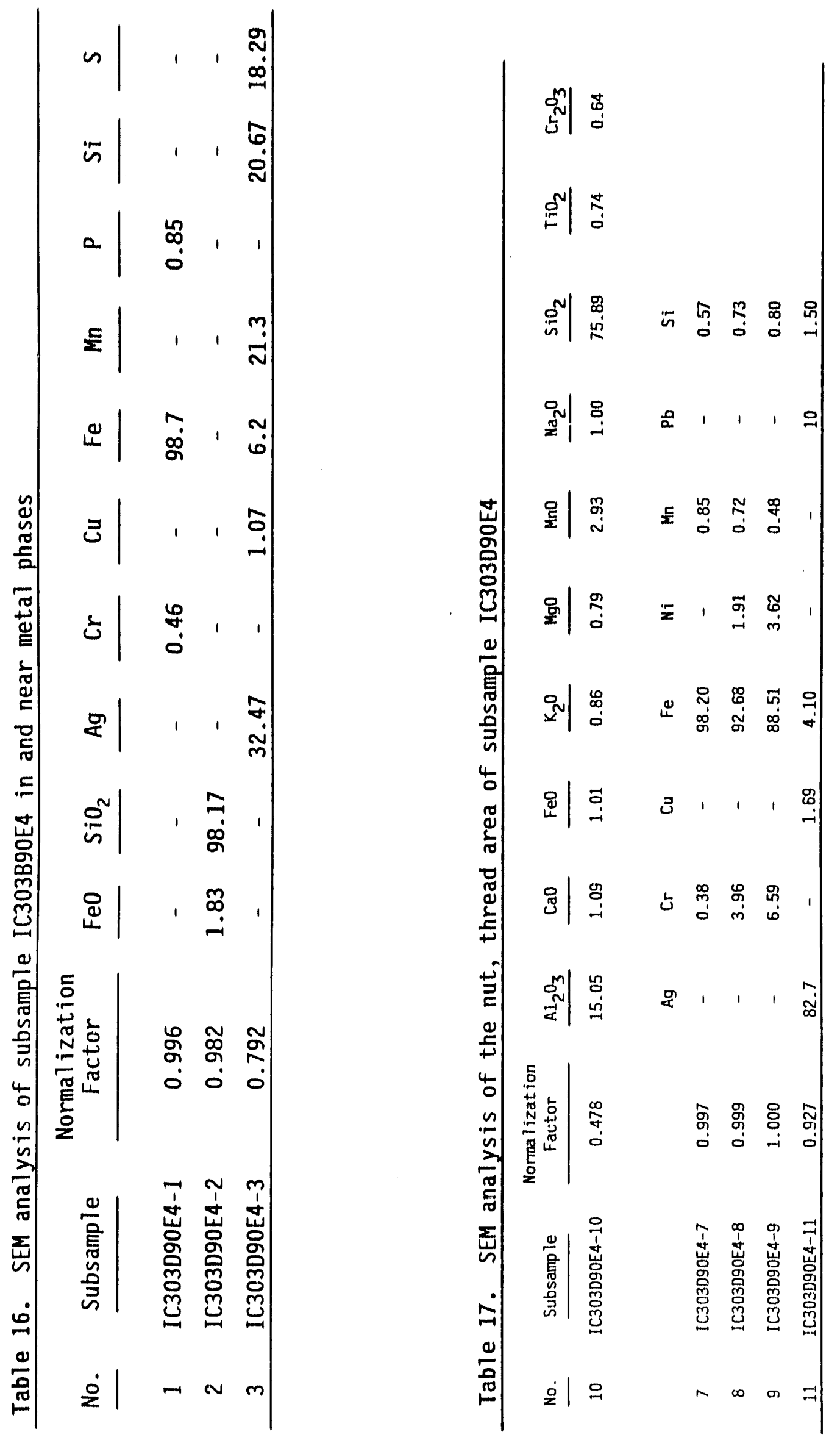


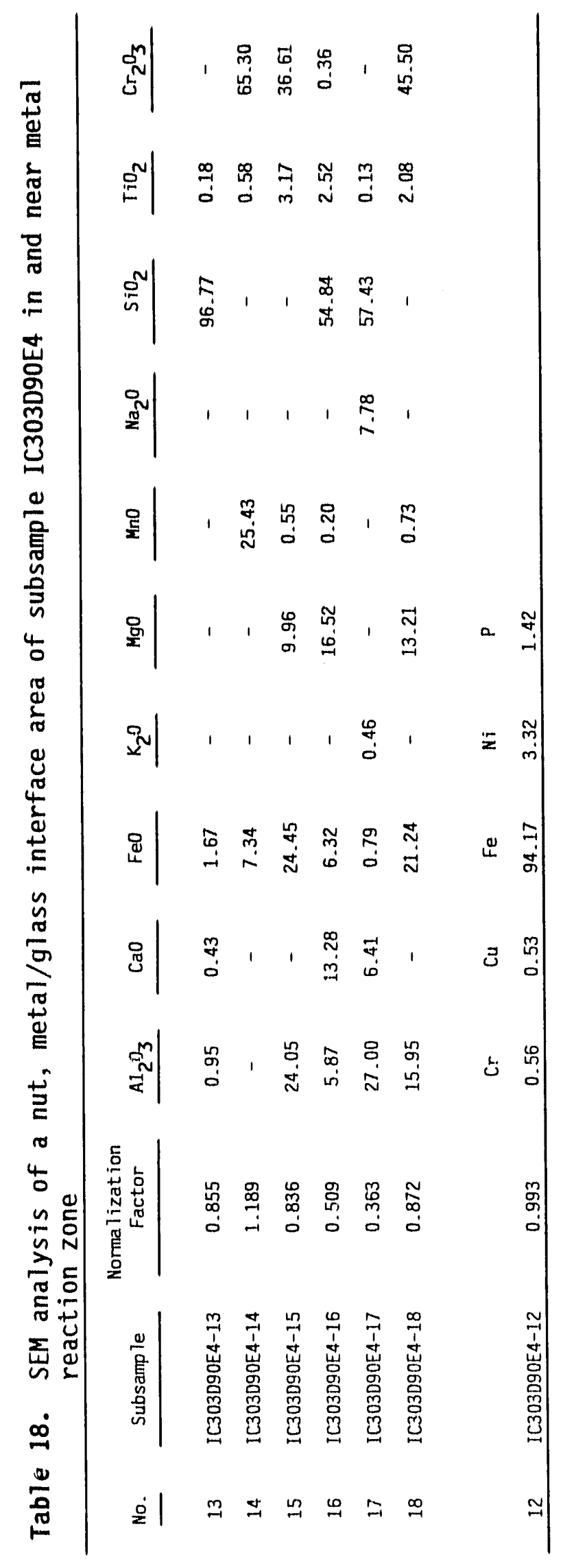




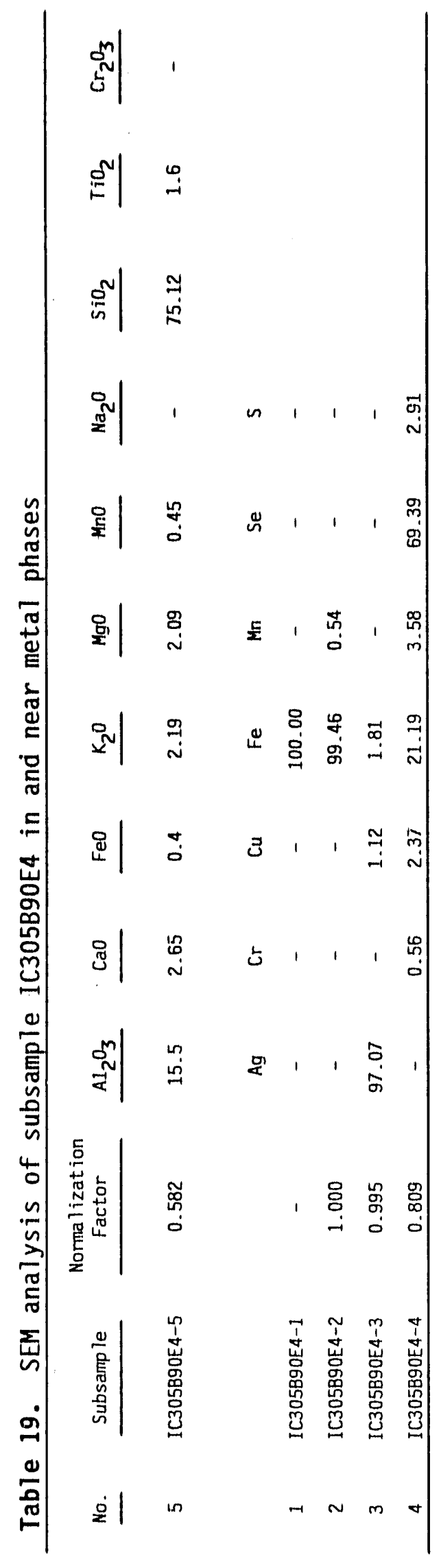


interface with the metal (analysis number 1) contained $\mathrm{Ag}, \mathrm{Mn}, \mathrm{Si}$, and $\mathrm{S}$ (analysis number 3 ). A similar phenomenon appeared in Figure 13 in the areas numbered 10 and 11 . The metal phases labeled 7, 8, and 9 appear to have differences in $\mathrm{Cr}$ and $\mathrm{Ni}$ content. Figure 14, in addition to exhibiting $\mathrm{SiO}_{2}$ (number 13), clinopyroxene (number 16), and plagioclase (number 17), had 2 other phases. One phase was a $\mathrm{Cr}, \mathrm{Mn}$, and Fe bearing oxide (number 14) and the other was a $\mathrm{Cr}, \mathrm{Fe}, \mathrm{Mg}$, and $\mathrm{Al}$ bearing oxide (numbers 15 and 18). These two phases are probably from the spinel group of minerals.

Other interfaces of metal with glass contain TCLP toxic metals (Figure 16). In Figure 16, the phase labeled $14 \mathrm{had} 96.94 \mathrm{wt} \% \mathrm{Ag}$ and $3.06 \mathrm{wt} \% \mathrm{~Pb}$, and the phase labeled $15 \mathrm{had} 4.39 \mathrm{wt} \% \mathrm{Ag}$ and $95.61 \mathrm{wt} \% \mathrm{~Pb}$. The glass was labeled 13 and the metal was labeled 12. Element maps in Figure 17 show the distribution of $\mathrm{Se}$ and $\mathrm{Ag}$ in the metal sample shown in Figure 15. The $\mathrm{Cr}$ distribution in metal is heterogeneous and varies from $<1$ wt\% to over 50 wt\% in one instance. " The metallic phases also contain a large amount of $\mathrm{Si}$, over $30 \mathrm{wt} \%$ in some subsamples, significant $\mathrm{Ti}$ up to about 2 wt\%, and $\mathrm{Mn}$ (with $\mathrm{Cr}$ ) up to $3.6 \mathrm{wt} \%$. The occurrences of $\mathrm{Cr}$ and $\mathrm{Ti}$ along the edges of metal pieces is not uncommon; Figures 18 and 19 illustrate these occurrences. Analyses of the inclusion shown in Figure 19 for subsample IC300D90E4 found $2.11 \mathrm{wt} \% \mathrm{Ti}, 2.64 \mathrm{wt} \% \mathrm{Cr}, 32.81 \mathrm{wt} \% \mathrm{Si}$, and $0.78 \mathrm{wt} \% \mathrm{Mn}$, along with abundant $\mathrm{Fe} ; 2.58 \mathrm{wt} \% \mathrm{Ti}, 3.02 \mathrm{wt} \% \mathrm{Cr}$, and $24.4 \mathrm{wt} \% \mathrm{Si}$ were found on the edge of the inclusion. The occurrence of $\mathrm{Cr}$ and $\mathrm{Ti}$ as rims on metal inclusions indicates that these elements are being reduced from the oxide in the melt to metallic phases, and that the reducing conditions are greater than that required to produce metallic Fe.

\section{Chemical Durability}

TCLP. The INEL samples that were submitted for TCLP metals analysis leached detectable amounts of $\mathrm{Pb}, \mathrm{Ba}, \mathrm{Cr}, \mathrm{Cd}$, and $\mathrm{Hg}$ in concentrations below the regulatory limits. None of the INEL samples were entirely metal. The PNL samples leached detectable amounts of $\mathrm{Ag}, \mathrm{Ba}, \mathrm{Cd}, \mathrm{Cr}, \mathrm{Hg}, \mathrm{Pb}$, and $\mathrm{Se}$ from metal samples, detectable amounts of $\mathrm{Ba}, \mathrm{Cd}, \mathrm{Cr}$, and $\mathrm{Pb}$ from glass samples,

a. Approximately $64 \mathrm{wt} \% \mathrm{Cr}$ was found in subsample IC303C90E4 in an inclusion in a metal edge zone. Other metallic $\mathrm{Cr}$ concentrations range up to $12.7 \mathrm{wt} \%$. 


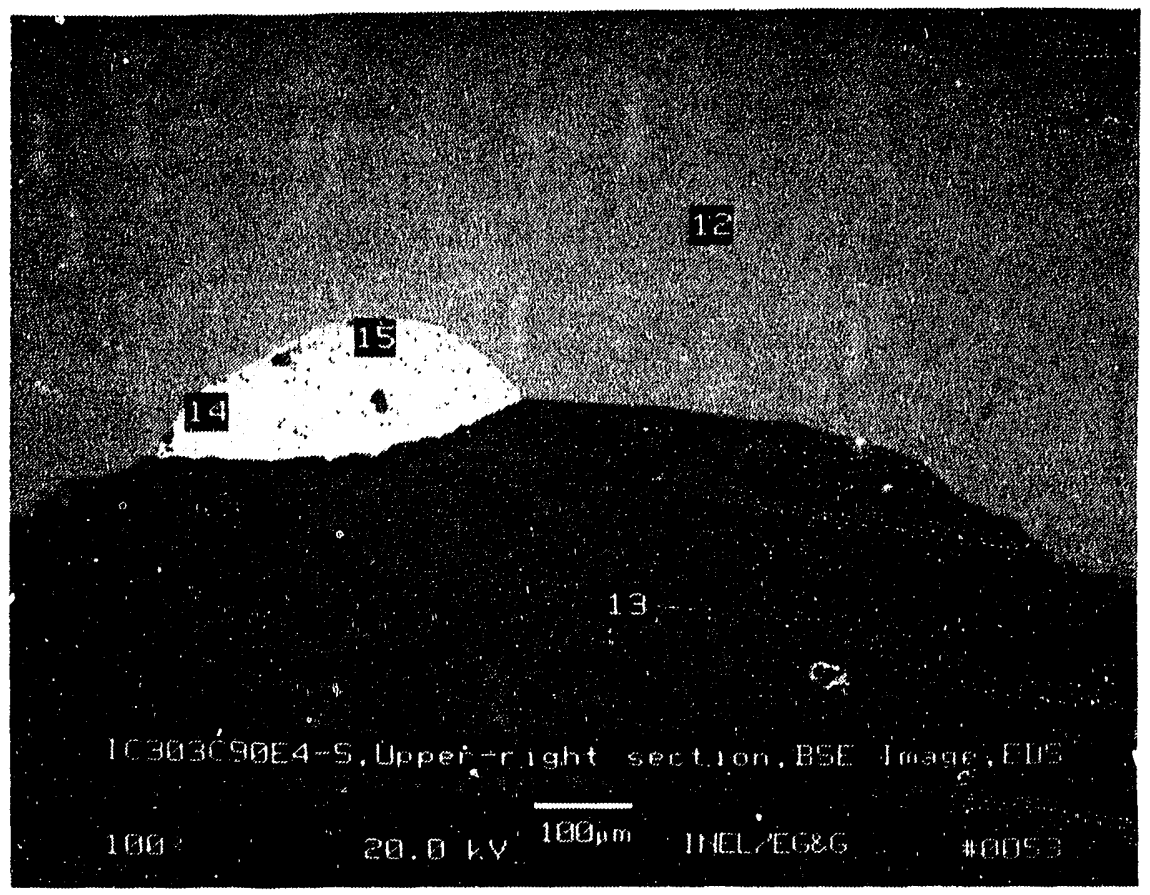

Figure 16. SEM photomicrograph of subsample IC303C90E4 showing a glass (1abeled 13) - metal (1abeled 12) interface with two phases present. The phase labeled 14 has $96.94 \mathrm{wt} \% \mathrm{Ag}$ and $3.06 \mathrm{wt} \% \mathrm{~Pb}$, and the phase labeled 15 has $4.39 \mathrm{wt} \% \mathrm{Ag}$ and 95.61 wt\% $\mathrm{Pb}$ (photomicrograph by $\mathrm{D}$. V. Miley). 

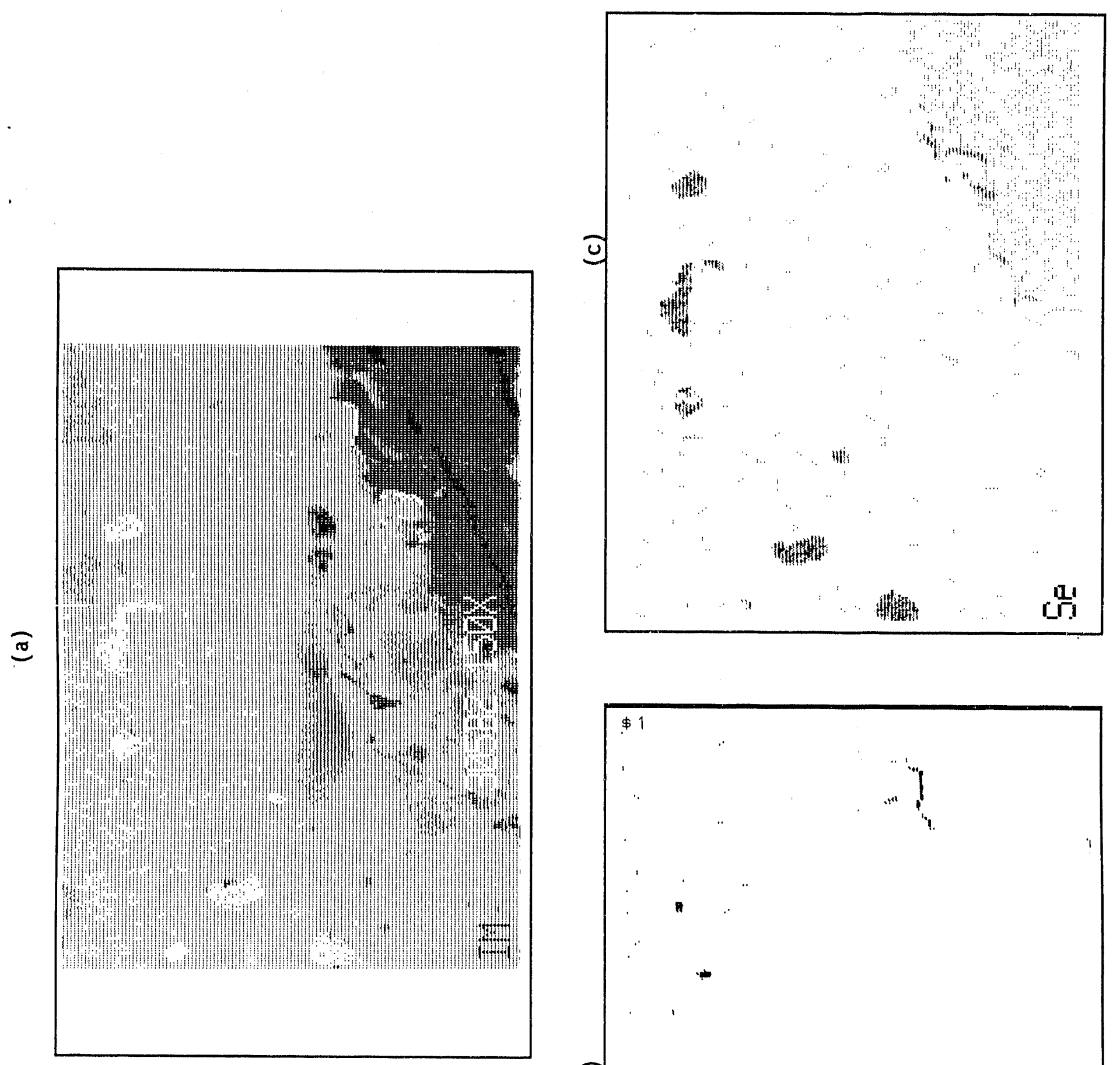

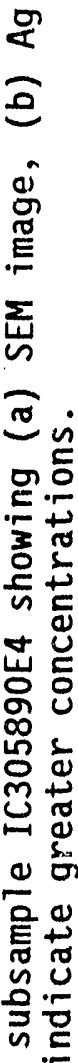

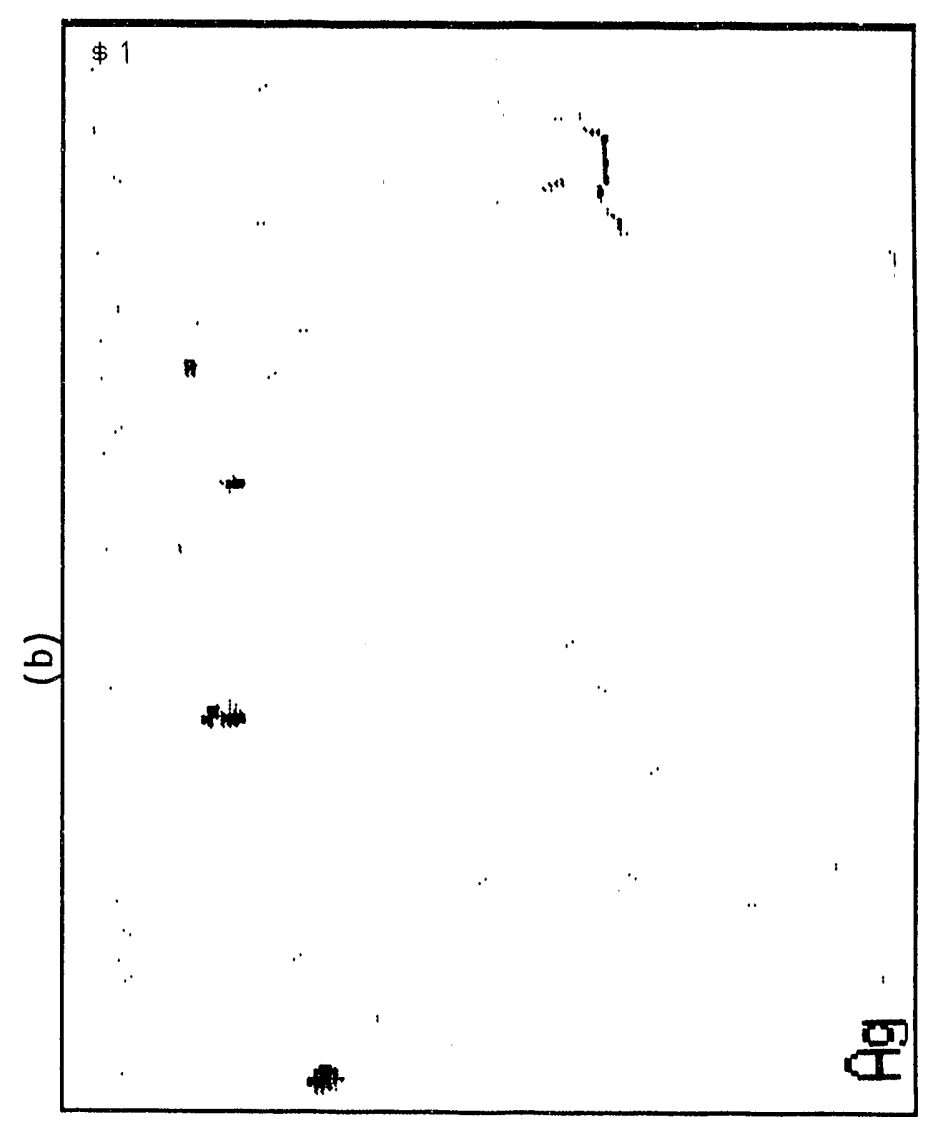

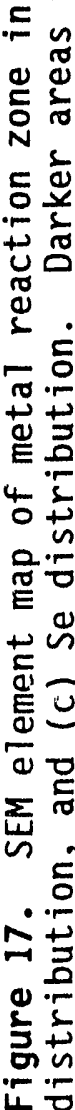


(a)

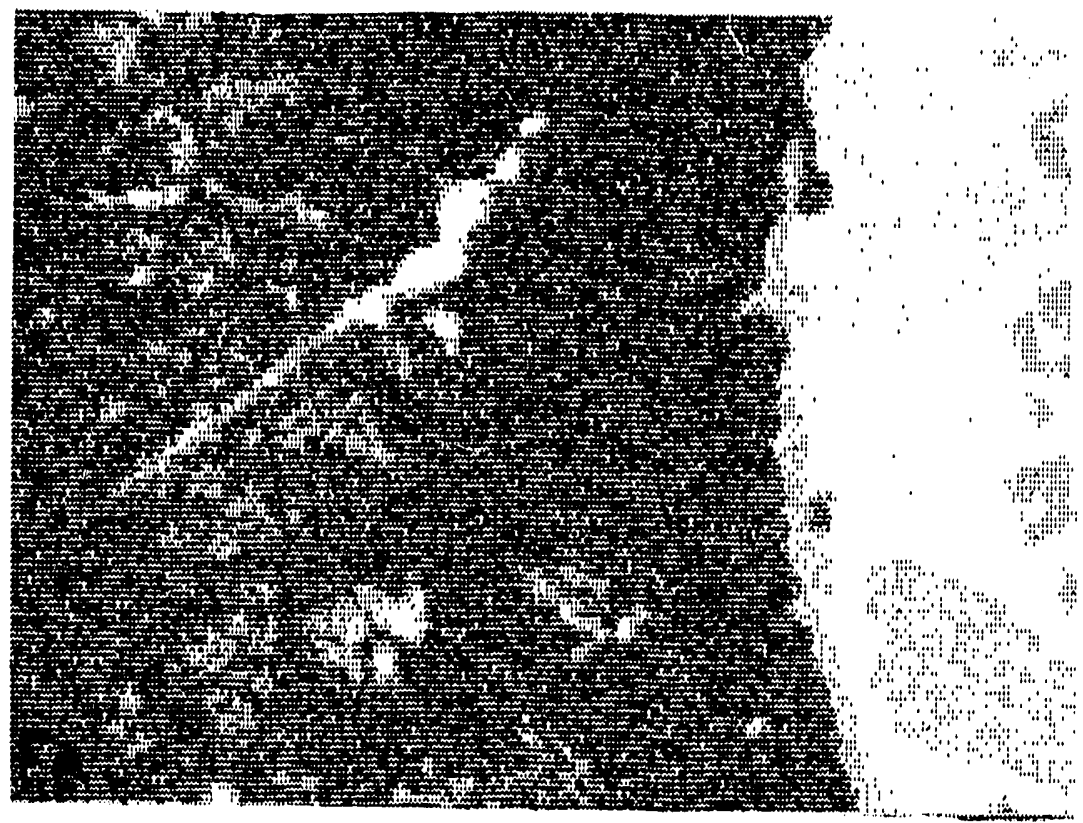

(b)

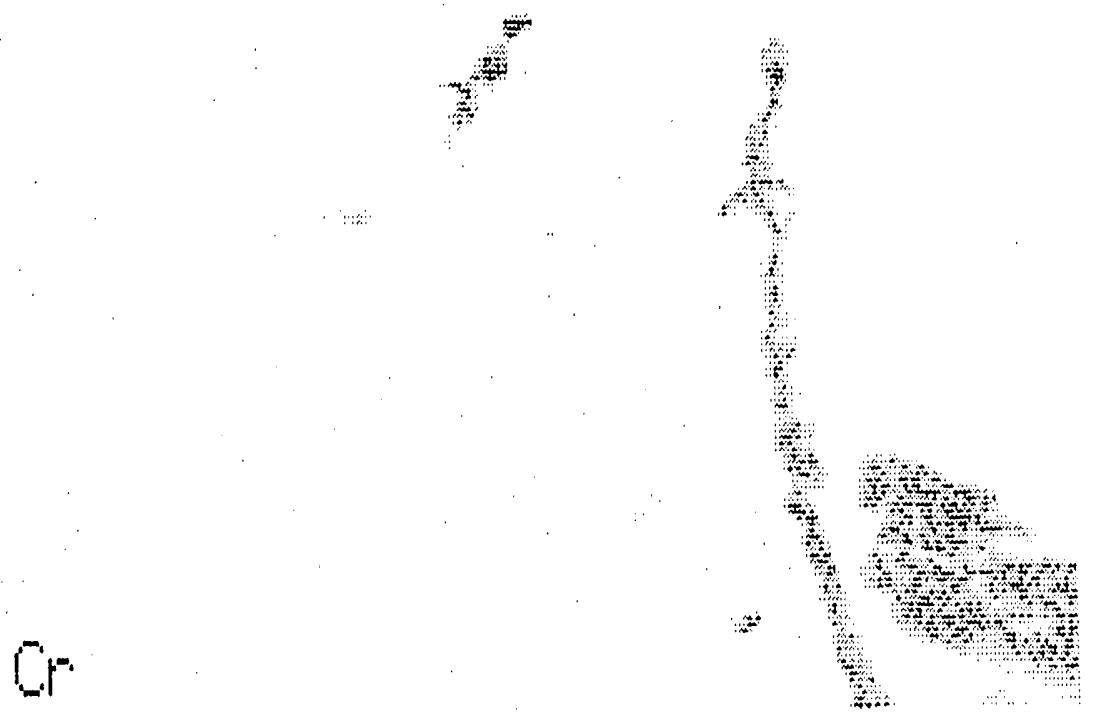

Figure 18. SEM element map of metal reaction zone in subsample IC303D90E4 showing distribution of (a) $\mathrm{Fe}$ and (b) $\mathrm{Cr}$. Darker areas indicate greater concentrations. 
(a)

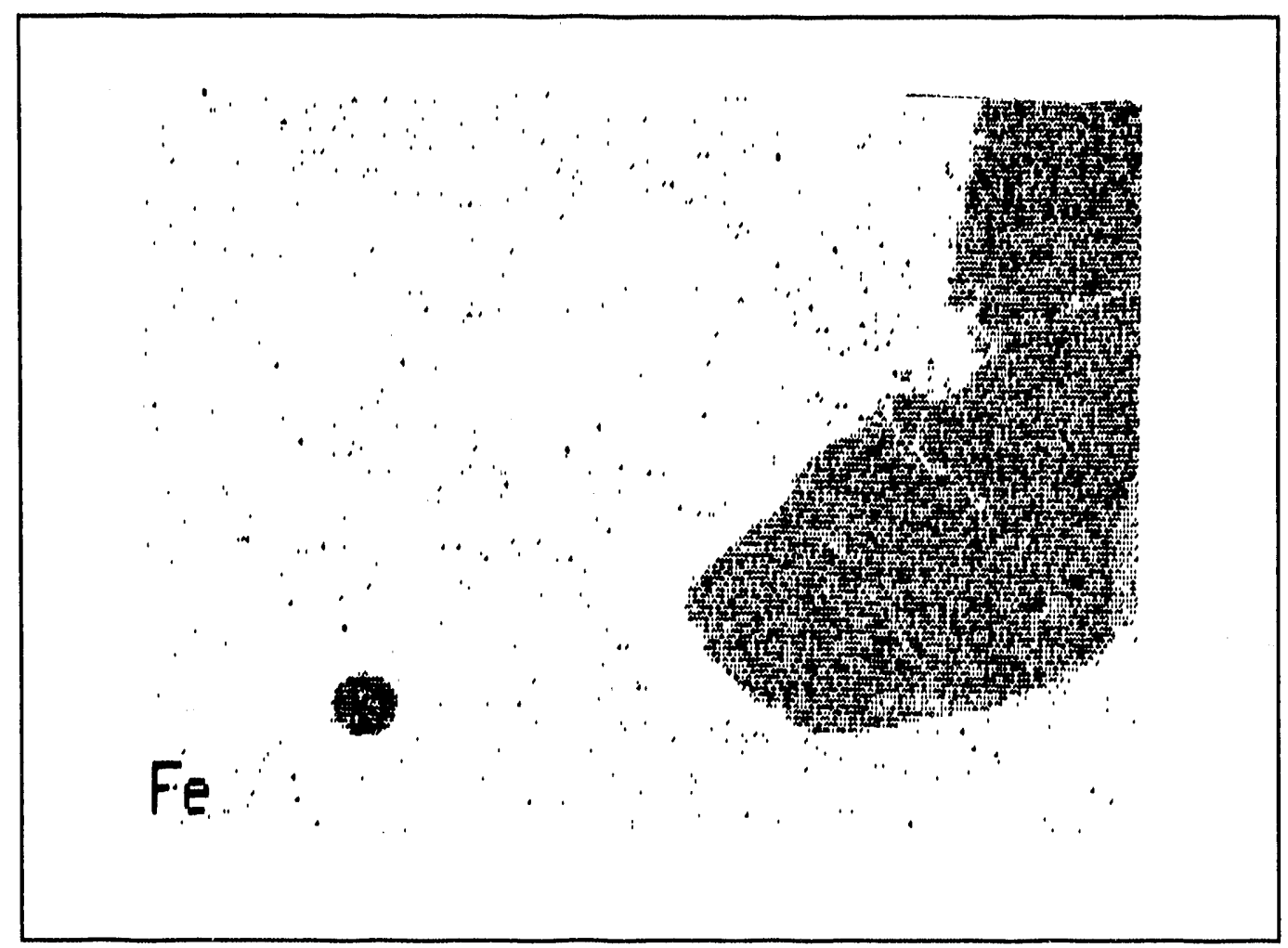

(b)

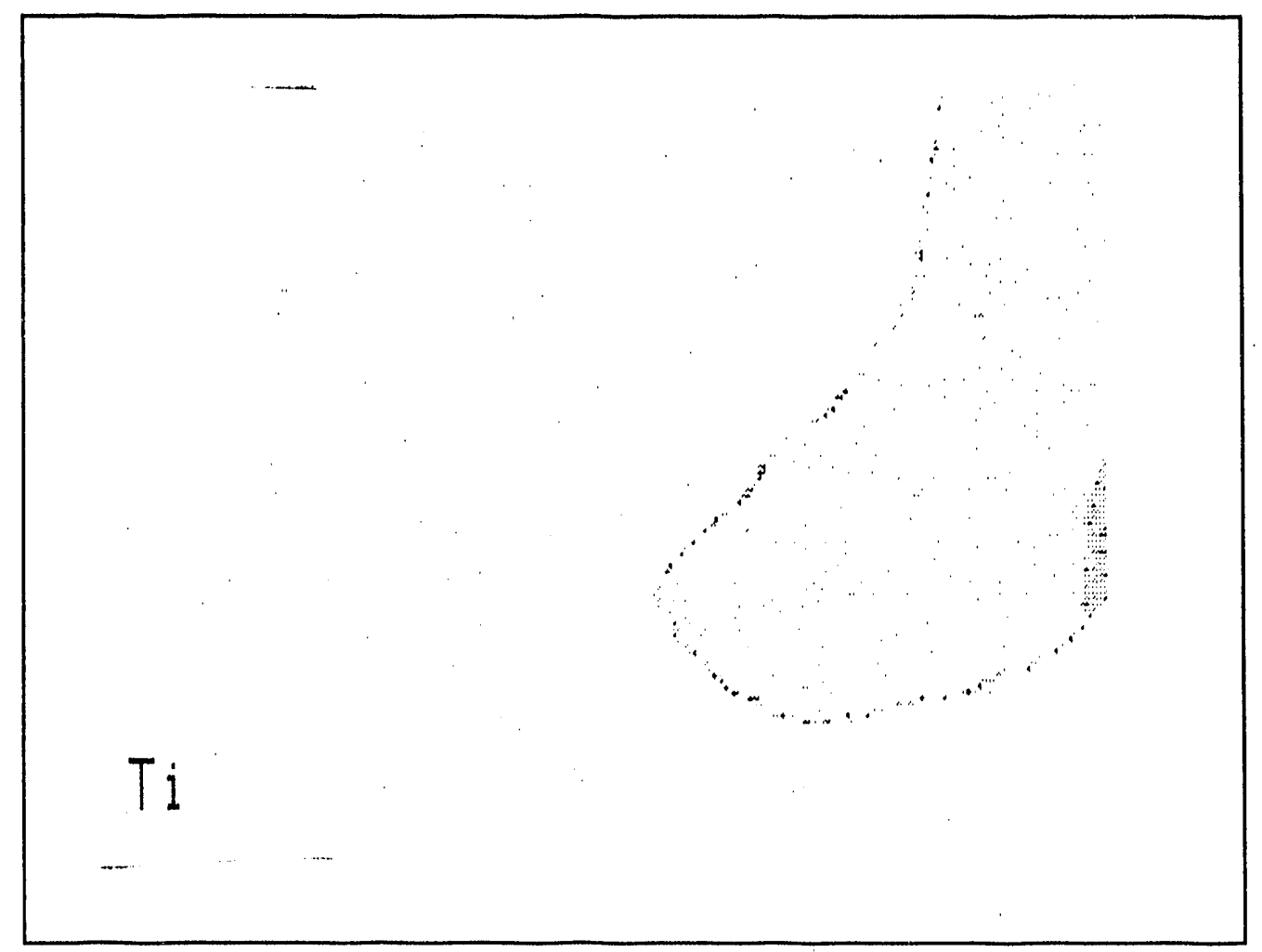

Figure 19. SEM element map of subsample IC300D90E4 showing distribution of (a) $\mathrm{Fe}$ and (b) $\mathrm{Ti}$ in metallic inclusions in glass. Darker areas indicate greater concentrations. 
detectable amounts of $\mathrm{Ba}, \mathrm{Cd}, \mathrm{Hg}$, and Se from pretest basalt, and detectable amounts of $\mathrm{Ba}, \mathrm{Cd}, \mathrm{Cr}$, and $\mathrm{Pb}$ from posttest basalt. The PNL metal TCLP results exceeded the TCLP thresholds for $\mathrm{Pb}$ in several samples and for $\mathrm{Cr}$ in one sample. ${ }^{a}$ This result is especially important in view of the fact that the sample was not crushed or broken prior to leaching and analysis. As expected, Reference 1 found that the method used on the metal samples yielded lower leached amounts in a comparison of glass TCLP results.

\section{MCC-1, PCT, and Determination of Intrinsic Rate of Dissolution}

\section{Static Tests}

Assessing the long-term durability of ISV (and high-level nuclear) waste forms is difficult because it requires extrapolation of data from short-term laboratory tests (a few hours to a few years) to geologic time frames. Much work has been completed and is continuing on evaluating the long-term ( $\geq 100$ year) behavior of the high-level waste glasses, including computer modeling to predict dissolution reaction progress. These models may use geochemical codes to predict dissolution behavior in the long term. These codes can be based on theoretical or empirical data and can be validated in the short-term against laboratory data.

One way to assess the long-term durability performance is to compare the ISV product with natural analogs. A number of natural analogs are similar in composition and morphology to the ISV waste forms. These include obsidian, basalts, tektites, and andesites (all of which can be millions of years old). The relative durabilities of many natural and ancient manmade glasses have been shown to bracket the durability of waste glasses (see References 5, 6, 7, and 8 ). Thus, relating the behavior of the ISV waste forms determined from short-term leach test and modelling results with the observed behavior of natural analogs provides an excellent means of validating the long-term stability of the ISV product.

a. Private communication with Richard K. Farnsworth, EG\&G Idaho, Inc., Idaho Fal1s, Idaho, August 27, 1991. 
Table 20. Bulk chemical and $\mathrm{Fe}^{+2} / \Sigma \mathrm{Fe}$ analysis of sample ES4-1

Oxide

$\mathrm{Ag}_{2} \mathrm{O}$

$\mathrm{Al}_{2} \mathrm{O}_{3}$

$\mathrm{BaO}$

$\mathrm{CaO}$

$\mathrm{Cr}_{2} \mathrm{O}_{3}$

$\mathrm{FeO}$

$\mathrm{Fe}_{2} \mathrm{O}_{3}$

$\mathrm{K}_{2} \mathrm{O}$

MgO

Mno

$\mathrm{Na}_{2} \mathrm{O}$

$\mathrm{SeO}_{2}$

$\mathrm{SiO}_{2}$

Sro

$\mathrm{TiO}_{2}$

TOTAL

$\mathrm{Fe}^{2+} / \mathrm{Fe}$
ES4-1

0.08

12.77

0.11

4.63

0.00

4.44

0.03

4.88

2.17

0.18

1.50

0.04

59.40

0.00

0.90

91.05

0.923 
To allow comparison of leach tests results from waste forms with different compositions, results are given in terms of normalized elemental mass release for the MCC-1 and normalized concentration for the modified MCC-3 test. Normalized elemental mass releases were calcuilated using the following equation:

$N R_{i}=m_{i} /\left(F_{i} \times S a\right)$

where

$$
\begin{aligned}
N R_{i} & =\text { normalized mass release of element } i\left(g / \mathrm{m}^{2}\right) \\
m_{i} & =\text { mass of element } i \text { in leachate }(\mathrm{g}) \\
F_{\mathfrak{i}} & =\text { fraction of element } i \text { in glass (dimensionless) } \\
S A & =\text { surface area of monolith }\left(\mathrm{m}^{2}\right) .
\end{aligned}
$$

The results from both MCC-1 and modified PCT static tests with ES4-1 glass are illustrated in Figure 20. Bulk elemental analysis and $\mathrm{Fe}^{+2} / \Sigma \mathrm{Fe}$ shown in Table 20 were used to normalize releases. The $\mathrm{Fe}^{+2} / \Sigma \mathrm{Fe}$ for the ES-4 glass sample indicates that the melt was very reducing. A summary of the average normalized releases for both MCC-1 and PCT testing is presented in Table 21 and concentration release data for each set of replicates is presented in Appendix A. While limited PCT data exist for comparison because PCT was just established as a standard test, a large amount of MCC-1 data exist for high-level borosilicate nuclear waste glasses and natural analogs. A comparison of the ES-4 glass sample with other typical waste forms, natural analogs, and samples from the ISV Intermediate Field Test 2 (IFT-2) (see References 6 and 10) is presented in Figure 21. The ES-4 product sample is approximately 10 times more durable than a typical high-level waste glass and comparable to natural analogs such as obsidian and granite.

\section{Intrinsic Rate Testing}

Soxhlet testing provide intrinsic rate data at $100^{\circ} \mathrm{C}$. Figure 22 shows results from the Soxhlet tests for the ES4-1 glass sample. Because of the scatter in the results for several elements and the lack of clear trends for 

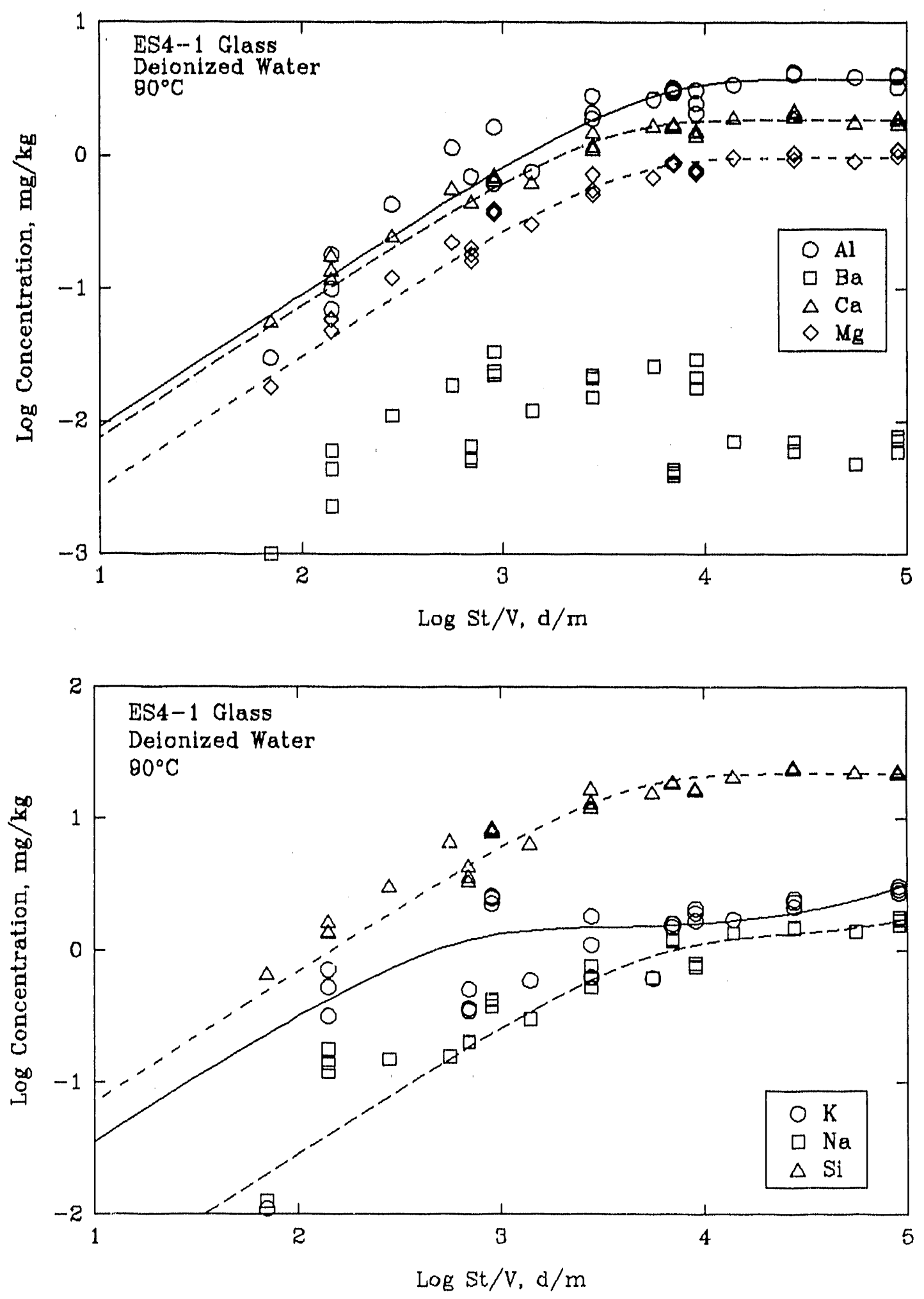

Figure 20. MCC-1 and PCT release versus reaction progress (surface area time/volume) of selected elements from ES-4 sample ES4-1. 


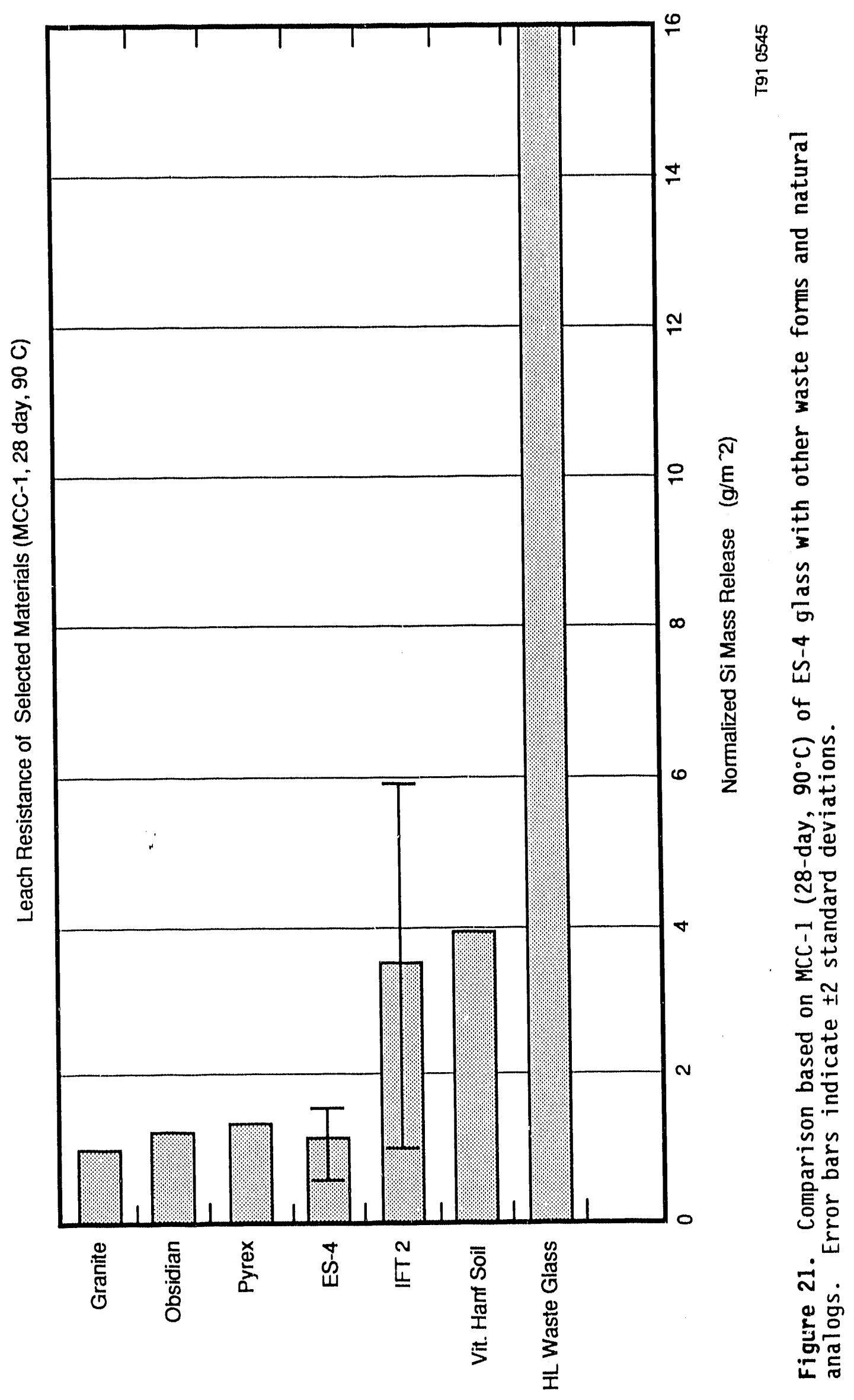




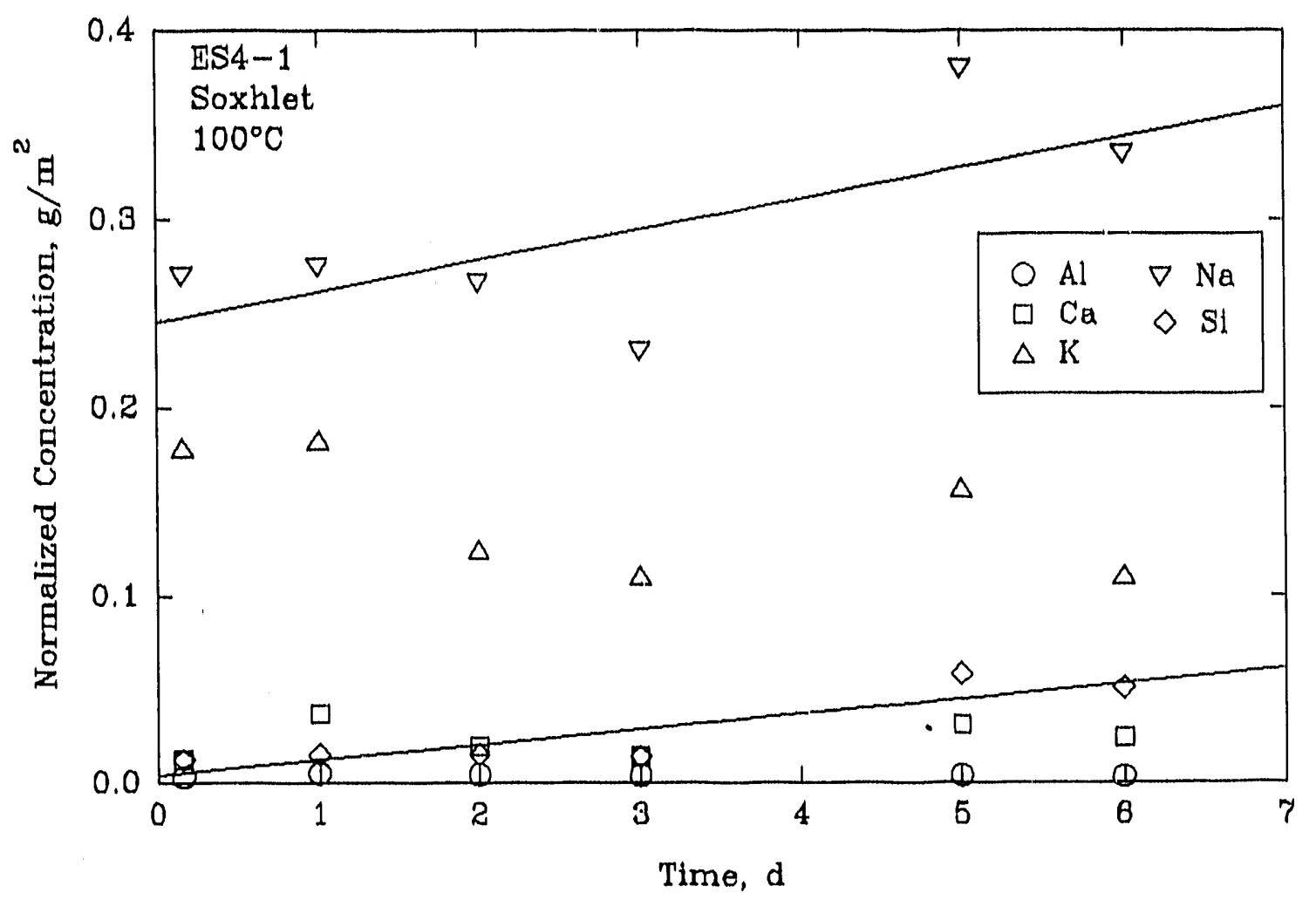

Figure 22. Time-dependent concentrations for selected elements during soxhlet extraction of sample ES4-1 at $100^{\circ} \mathrm{C}$. 
Tab'le 21. Summary of average norma 1 lzed release data for MCC-1 and PCT tests

\begin{tabular}{|c|c|c|c|c|c|}
\hline & & \multicolumn{3}{|c|}{ NORMALI ZED RELEASE $\left(\mathrm{g} / \mathrm{m}^{\wedge} 2\right)$} & \multirow[b]{2}{*}{ PCI, $88 \mathrm{~m}-1$} \\
\hline DLEMENT & PCT, $88 \mathrm{~m}-1$ & PCT, $88 m-1$ & $\mathrm{PCT}, 88 \mathrm{~m}-1$ & PCT, $88 m-1$ & \\
\hline (Detection Limlt) & 7 Dayg & 14 Daya & 28 Dayg & 56 Day日 & 91 Dayg \\
\hline Al $(0.03)$ & 0.054 & 0.170 & 0.376 & 0.498 & 0.471 \\
\hline $\mathrm{Ba}(0.005)$ & 0.070 & 0.138 & 0.235 & 0.261 & 0.382 \\
\hline $\mathrm{Ca}(0.01)$ & 0.149 & 0.235 & 0.420 & 0.542 & 0.574 \\
\hline $\mathrm{Fe}(0.01)$ & & & 0.020 & 0.031 & 0.042 \\
\hline $\mathrm{K}(0.3)$ & 0.116 & 0.164 & 0.292 & 0.407 & 0.291 \\
\hline $\mathrm{Mg}(0.06)$ & 0.169 & 0.292 & 0.191 & 0.603 & 0.689 \\
\hline $\mathrm{Mn}(0.005)$ & 0.123 & 0.177 & 0.291 & 0.284 & 0.445 \\
\hline $\mathrm{Na}(0.02)$ & 0.239 & 0.383 & 0.570 & 0.701 & 0.793 \\
\hline$s 1(0.02)$ & 0.168 & 0.311 & 0.555 & 0.685 & 0.751 \\
\hline$T 1(0.002)$ & & & 0.023 & 0.051 & 0.054 \\
\hline \multirow[t]{4}{*}{ Number of Teats } & 6 & 2 & 6 & 2 & 6 \\
\hline & & & & & \\
\hline & PCT, $880 \mathrm{~m}-1$ & PCT, $880 m-1$ & $\mathrm{PC}^{\prime 1}, 880 \mathrm{~m}-1$ & PCT, $880 m-1$ & PCT, $880 \mathrm{~m}-1$ \\
\hline & 7 Dayg & 14 Days & 28 Days & 56 Days & 91 Dayg \\
\hline A1 $(0.03)$ & 0.053 & 0.058 & 0.071 & 0.068 & 0.054 \\
\hline $\mathrm{Ba}(0.005)$ & & 0.008 & 0.007 & 0.007 & 0.006 \\
\hline $\mathrm{Ca}(0.01)$ & 0.059 & 0.065 & 0.073 & 0.060 & 0.065 \\
\hline $\mathrm{Fe}(0.01)$ & & 0.001 & 0.002 & 0.003 & 0.001 \\
\hline $\mathrm{K}(0.3)$ & 0.043 & 0.049 & 0.066 & 0.092 & 0.037 \\
\hline $\mathrm{Mg}(0.06)$ & 0.077 & 0.084 & 0.088 & 0.087 & 0.090 \\
\hline $\mathrm{Mn}(0.005)$ & 0.009 & 0.007 & 0.008 & 0.009 & 0.013 \\
\hline $\mathrm{Na}(0.02)$ & 0.126 & 0.143 & 0.148 & 0.162 & 0.174 \\
\hline$S 1(0.02)$ & 0.078 & 0.086 & 0.100 & 0.093 & 0.093 \\
\hline $\mathrm{T} 1(0.002)$ & & 0.001 & 0.001 & 0.003 & 0.001 \\
\hline \multirow[t]{4}{*}{ Number of Testa } & 3 & 1 & 3 & 1 & 3 \\
\hline & & & & & \\
\hline & $M C C-1,10 m-1$ & $M C C-1,10 m-1$ & $10 \mathrm{CC}-1,10 \mathrm{~m}-1$ & $M C C-1,10 m-1$ & $M C C-1,10 m-1$ \\
\hline & 7 Days & 14 nays & 28 Days & 56 Days & 91 Daya \\
\hline Al $(0.03)$ & & 0.173 & 0.636 & 1.760 & 1.160 \\
\hline $\mathrm{Ba}(0.005)$ & & & 1.116 & 1.898 & 2.487 \\
\hline $\mathrm{Ca}(0.01)$ & 0.241 & 0.443 & 0.756 & 1.691 & 1.928 \\
\hline \multicolumn{6}{|l|}{ Fe $(0.01)$} \\
\hline$K(0.3)$ & & & 1.284 & 0.821 & 1.962 \\
\hline $\mathrm{Mg}(0.06)$ & & & 0.917 & 1.729 & 2.335 \\
\hline $\mathrm{Mn}(0.005)$ & & 0.566 & 0.967 & 1.530 & 2.450 \\
\hline $\mathrm{Na}(0.02)$ & 0.341 & 1.048 & 0.809 & 1.592 & 3.015 \\
\hline $51(0.02)$ & 0.252 & 0.543 & 1.124 & 2.456 & 2.979 \\
\hline \multicolumn{6}{|l|}{ T1 $(0.002)$} \\
\hline Number of Tests & 1 & 3 & 1 & 1 & 3 \\
\hline
\end{tabular}


other elements (such as $K$ ), dissolution rates for the samples were calculated from least squares fits to $\mathrm{Na}$ and $\mathrm{St}$ only. The results from these fits are given in Table 22. To test the pH stat/ISE apparatus and provide a reference standard for compartson with INEL ISV products, a series of tests with P0798 glass (a reference glass for the waste stream from reprocessing of 1 ight water reactor fuel in Japan) and HW39-2 (a reference glass from the Hanford Waste Vitrification Program (see Reference 8) were performed along with the ES-4 sample. Figures 23,24 , and 25 , and Table 23 summarize the $\mathrm{pH} / \mathrm{stat}$ ISE intrinsic rate results.

The dissolution rates were approximately 5 to 7 times smaller for the ES-4 product compared with the reference waste glasses at $80^{\circ} \mathrm{C}$. Because of the small dissolution rate and low $\mathrm{Na}$ content of the ES-4 product, absolute concentrations of $\mathrm{Na}$ were nearly two orders of magnitude smaller than for the waste glasses and near the detection limit for the ISE. Accuracy and reproductblitty are also poor because at Nat concentrations near $10^{-3} \mathrm{M}$, the response of the ISE is poor and non-linear with respect to $\mathrm{Na}^{+}$concentration. Although several attempts were made to adjust $S / V$ ratios and reduce interferences from competing cations (such as $\mathrm{NH}_{4}^{+}$leakage from the $\mathrm{pH}$ and ion-selective electrodes), the ES-4 product was effectively at the detection limit for this technique because the sample had a very low dissolution rate.

Table 22. Dissolution rates measured for ES-4 glass samples by soxhlet extraction at $100^{\circ} \mathrm{C}$

Sample I'] Dissolution rate $\left[\mathrm{g} /\left(\mathrm{m}^{2} \cdot \mathrm{d}\right)\right]$

$\mathrm{Na}$

Si

ES4 - 1

ES4 - T2

$0.017 \pm 0.009$

$0.026 \pm 0.004$

$0.008 \pm 0.002$

$0.027 \pm 0.002$ 


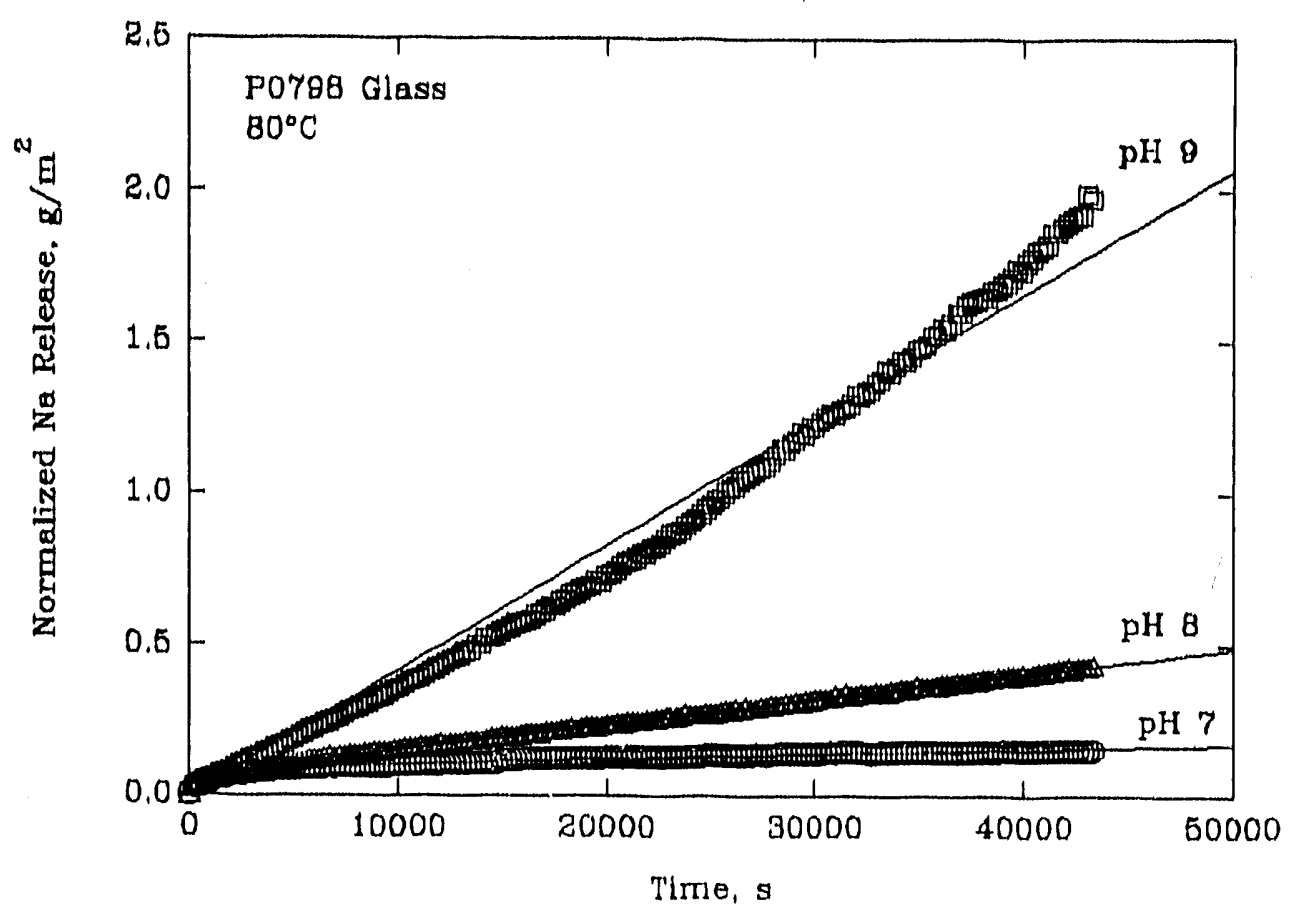

Figure 23. Dissolution behavior of P0798 glass with variation of in situ solution $\mathrm{pH}$ at $80^{\circ} \mathrm{C}$.

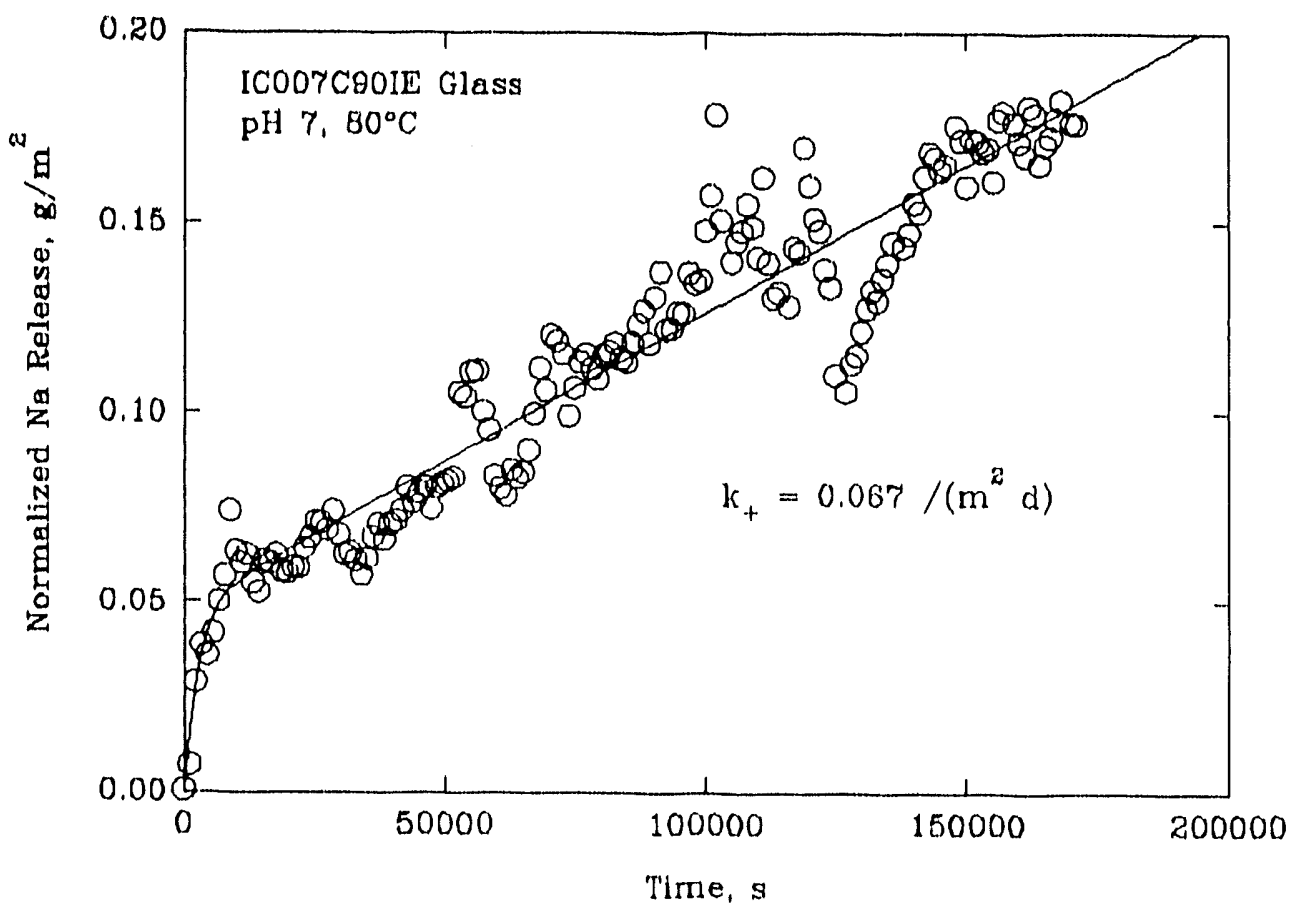

Figure 24. Dissolution behavior of IFT sample IC007C901E at in situ solution $\mathrm{pH} 7$ and $80^{\circ} \mathrm{C}$. 


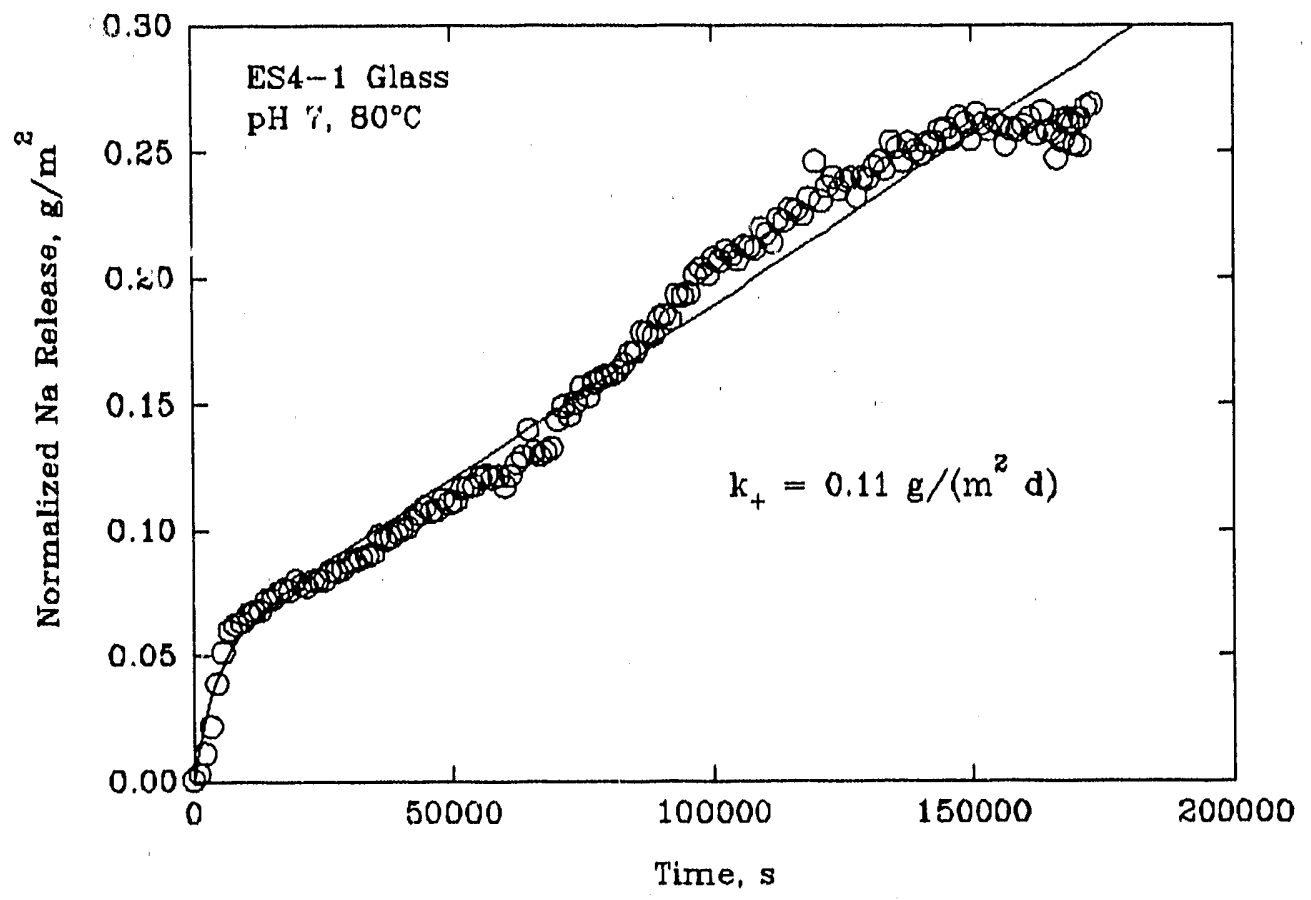

Figure 25. Dissolution behavior of sample ES4-1 at in situ solution $\mathrm{pH} 7$ and $80^{\circ} \mathrm{C}$. 
Table 23. Comparison of intrinsic rates of dissolution $\left(80^{\circ} \mathrm{C}, \mathrm{pH} 8\right)$

Waste Form

ES-4

HWVP39-2, HL Waste Glass

P0798, HL Waste G1ass
Intrinşic Rate,

$\mathrm{g} /\left(\mathrm{m}^{2} \cdot\right.$ days $) \quad \pm 2 \sigma$

0.11

0.551

0.726

0.008

0.002 


\section{CONCLUSIONS}

\section{Chemical and Physical Property Characterization}

Megascopicly, the ES-4 product glass is dark-green with less than 1 vol\% vesicles and commonly exhibits round to nodular magnetic inclusions less than $2 \mathrm{~mm}$ in diameter. White crystalline inclusions, which make up less than 1 vol\%, are also present in the glass. Metal occurs as round to nodular masses up to about $3 \mathrm{~cm}$ in diameter and also as unmelted or partially melted articles from the original scrap such as bolts, nuts, rods, and plates. Because most of the metal is adjacent to the basalt that was placed in the bottom of the test container, the metal is believed to have settled to the bottom of the melt. The evidence also indicates that two silicate liquids were generated in the test, one from the basalt and another from the soil, and the liquids did not mix appreciably.

Analysis on the product materials confirmed that vitreous, crystalline, and metallic phases coexist in the ES-4 product. The manner in which the phases coexist is complex and has only been addressed in a preliminary fashion here. However, some general statements concerning the nature of the ES-4 product can be made. First, the mineralogic properties observed, bulk chemical majcr element concentrations, and density measurements support the hypothesis that two silicate liquids were generated in the test. Second, microscopic work found that metallic phases occur in glass at the center of the meit as well as at the bottom, where metal articles have accumulated with melted metal. The metal articles exhibit microstructural and chemical features that indicate they underwent partial melting. There is evidence that melt condtions were very reducing. Third, some TCLP toxic metals are retained in the ES-4 product in association with iron metallic phases.

The crystalline phase found in glassy-appearing samples is identified as a clinopyroxene; the minerals plagioclase and quartz occur in samples from the melt edge. Gray-crystalline material originating from basalt contains plagioclase and what are believed to be spinel and ilmenite. The phase identification is based on data from index of refraction, density, XRD, bulk chemical, and SEM analyses. 
Metal phases are present in virtually all glass specimens, irrespective of location in the product block. The metal occurs principally as round inclusions several micrometers in size that have apparently formed from melted metal and distributed throughout the glass. Metal articles placed in the test remained intact; the original shapes are obvious in hand specimen, but visual and SEM analysis show that the metal has undergone chemical and physical changes in surficial zones. The metal reaction zones contain crystalline material and TCLP toxic metals in various morphologies, and, in places, are compositionally zoned. TCLP toxic metals are observed to occur in metallic phases near or within other (iron based) metallic phases; the TCLP toxic metals are observed in both bottom and center samples.

\section{Chemical Durability}

The ES-4 product TCLP analysis results are varied; the leachate of many samples did not exceed the TCLP limits, but several did exceed the limits for $\mathrm{Pb}$ and $\mathrm{Cr}$. Because of this fact and the fact that all samples that were entirely metal were not subjected to the correct test, but a test that would be expected to leach a lesser amount, the TCLP results for the ES-4 product as a whole are inconclusive. While the data indicate that glass samples did not appear likely to exceed the TCLP thresholds, insufficient data are available to make a similar statement concerning the metal phases for ES-4. However, a recent ISV test performed at pilot-scale indicated that the metal phase formed from vitrification of a tank that contained sludge with some TCLP metals, did pass TCLP. ${ }^{* 14}$

The implications of the TCLP results on long term performance of the waste form depends on its mechanical, rather than chemical, durability. The degree to which the metal phases are subjected to chemical dissolution depends on the overall mechanical durability of the product because the glass product fused to the basalt. Mechanical durability is a measure of the potential for fracturing and general breakdown of the product; it depends on susceptibility to weathering processes such as freeze-thaw action, burial stress, and other factors. Mechanical durability, while not included in this study, must be

a. Mercury analyses were not avaiable when TCLP results were reported. 
addressed so that adequate engineered controls or barriers are available for use in applying ISV for site remediation.

Based on MCC-1 leach testing ( 28 days, $90^{\circ}$ (c) on one ES-4 sample, the durability of glass phases of the ES-4 product appears to be comparable to obsidian and granite, and 10 times more durable than typical high-level nuclear waste glasses. The measured intrinsic dissolution rates of the ES-4 sample tested was $0.11 \mathrm{~g} /\left(\mathrm{m}^{2} \cdot \mathrm{d}\right)$ at $80^{\circ} \mathrm{C}$ and $\mathrm{pH} 7$. These values are 5 to 7 times smaller than measured for typical borosilicate nuclear waste glasses. These values can be used as initial glass dissolution rate values for health-based risk assessment models.

The megascopic description and chemical and physical property characterization of the ES-4 product demonstrate that the product is heterogeneous in composition. Further work is needed to determine the overall durability of ISV products in buried waste applications. Chemical durability testing of metallic and crystalline phases of ISV products and mechanical durability studies are needed. Also, the relationship between product characteristics observed in different scaled experiments needs to be examined so that test findings can be accurately extrapolated for site remediation prediction. 


\section{REFERENCES}

1. J. W. Shade, R. K. Farnsworth, J. S. Tixier, and B. L. Charboneau, Engineering-Scale Test 4: In Situ Vitrification of Toxic Metals and Volatile Organics Buried in INEL Soils, PNL-7611, June 1991.

2. B. P. McGrail and 0 Bates, An Evaluation of In-Situ Vitrification for Remediation of a Burige Waste Site, VII International Conference on the Physics of Non-Crystap Tine Solids, Churchill College, Cambridge, England, Aug. 4-9, 1991.

3. S. 0. Bates, In Situ Vitrification Waste Form Product Evaluation Strategy, EGG-WTD-9148, August 1990.

4. J. R. Weidner and P. R. Stoots, In Situ Vitrification Engineering-Scale Test ES-INEL-4, ES-INEL-5, ES-INEL-6, and ES-INEL-7 Test Plan, EGG-WM-9090, Rev. 1, October 1990.

5. Materials Characterization Center, Rev. 7, "MCC-1P Static Le ch Test Method." In Nuclear Waste Materials Handbook. Test Methods.

DOE/TIC-11400. Technical Information Center, Springfield, Virginia, 1986.

6. Materials Characterization Center, Rev. 7, "MCC-3S Agitated Powder Leach Test Method," Nuclear Waste Materials Handbook. Test Methods. DOE/TIC-11400. Technical Information Center, Springfield, Virginia, 1986.

7. C. M. Jantzen and N. E. Bibler, Product Consistency Test (PCT) for DWPF Glass: Part I. Test Development and Protocol, DPST-87-575, Savannah River Laboratory, Aiken, South Carolina, 1987.

8. F. Delage and J. L. Dussossoy, "R7T7 Glass Initial Dissolution Rate Measurements Using a High-Temperature Soxhlet Device," Scientific Basis for Nuclear Waste Management XIV. Materials Research Society, Pittsburgh, Pennsylvania, 1991.

9. B. P. McGrail, "Waste Package Component Interactions with Savannah River Defense Waste Glass in a Low-Magnesium Salt Brine," Nuc. Tech. . 75, 2, 1986, pp. 168-186.

10. R. A. Callow, L. E. Thompson, J. R. Weidner, C. A. Loehr, B. P. McGrail, and S. 0. Bates, In Situ Vitrification Application to Buried Waste: Final Report of Intermediate Field Tests at Idaho National Engineering Laboratory, EGG-WTD-9807, August 1991.

11. K. Ishiguro, F. Kamei, N. Sasaki, and H. Nagaki, Long-Term Soxhlet Leach Tests of Simulated Waste Glasses (I). PNCT N831-83-01, Power Reactor and Nuclear Fuels Corporation, Japan, 1983. 
12. B. C. Bunker, G. W. Arnold, E. K. Beauchamp, and D. E. Day, "Mechanisms for Alkali Leaching In Mixed Na-K Silicate Glasses," J. Non.-Cryst. Solids 58:295-322, 1983.

13. C. S. Hurlbut, Jr., Davis Manual of Minerology, New York: John Wiley and Sons, Inc., 1971.

14. L. E. Thompson, "Underground Storage Tank Remediation by use of In Situ Vitrification", Proceedings of the Symposium on Waste Management, Tucson, Arizona, February 24-28, 1991, Vo1.2, pp 627-634. 


\section{APPENDIX A \\ MCC-1 AND PCT CONCENTRATION RELEASE DATA}

This appendix contains the results from the each of the MCC-1 and MCC-3 leach tests (including replicates). For all concentration results, analysis was conducted by inductively coupled plasma atomic emission spectroscopy (ICP) and the results are given in $\mathrm{ppm}$. 


$$
\text { A-2 }
$$




\begin{tabular}{|c|c|c|c|c|c|}
\hline Sample No. & ES4-101 & ES4-1.02 & ES4-103 & ES4-104 & ES4-105 \\
\hline Days of Test & 7 & 7 & 7 & 14 & 28 \\
\hline Test & PC'I & PCT & PCT & PCT & PCT \\
\hline Specimen Wgt., $\mathrm{g}$ & 0.1598 & 0.1603 & 0.161 & 0.1593 & 0.1601 \\
\hline Leachant volume, $\mathrm{mL}$ & 39.98 & 40.06 & 40.25 & 39.86 & 40.05 \\
\hline Nominal s/V & 88 & 88 & 88 & 88 & 88 \\
\hline specimen size, mesh & $-100+200$ & $-100+200$ & $-100+200$ & $-100+200$ & $-100+200$ \\
\hline Initlal $\mathrm{pH}$ & 6.49 & & 6.49 & 6.49 & 6.49 \\
\hline Flnal pH & 7.12 & 7.01 & 7.67 & 7.69 & 8.56 \\
\hline Initial wgt, $g$ & 149.21 & 151.39 & 141.61 & 149.46 & 155.31 \\
\hline Flnal Wgt, $g$ & 148.79 & 150.99 & 141.36 & 149.38 & 155.09 \\
\hline Date of Analyois & $19-0 C T-90$ & $19-0 \mathrm{CT}-90$ & $19-O C T-90$ & $19-$ OCT -90 & 09-JAN-91 \\
\hline \multicolumn{6}{|l|}{ Element } \\
\hline (detection $11 \mathrm{~m} 1 \mathrm{t})$ & & All v & values given & in ppm & \\
\hline A1 $(0.03)$ & 0.120 & 0.070 & 0.430 & 0.755 & 1.900 \\
\hline $\mathrm{As}(0.08)$ & 0.026 & 0.022 & -0.007 & -0.013 & -0.009 \\
\hline B $(0.01)$ & 0.010 & 0.010 & 0.006 & 0.007 & 0.016 \\
\hline $\mathrm{Ba}(0.005)$ & 0.007 & 0.005 & 0.005 & 0.012 & 0.022 \\
\hline $\mathrm{Be}(0.005)$ & 0.000 & 0.000 & 0.000 & 0.000 & 0.000 \\
\hline $\mathrm{Ca}(0.01)$ & 0.376 & 0.356 & 0.452 & 0.631 & 1.200 \\
\hline Cd $(0.005)$ & 0.001 & -0.002 & 0.000 & 0.003 & -0.001 \\
\hline $\mathrm{Ce}(0.04)$ & 0.007 & 0.003 & 0.011 & 0.0 .11 & 0.012 \\
\hline Co $(0.01)$ & 0.002 & 0.001 & -0.001 & 0.003 & -0.001 \\
\hline Cr 10.02 & 0.018 & 0.013 & -0.004 & 0.012 & -0.002 \\
\hline $\mathrm{Cu}(0.005)$ & -0.002 & -0.002 & -0.001 & -0.001 & -0.001 \\
\hline Dy $(0.005)$ & 0.001 & 0.001 & 0.001 & 0.001 & 0.001 \\
\hline Eu $(0.005)$ & 0.000 & 0.000 & 0.000 & 0.000 & -0.008 \\
\hline Fe $(0.01)$ & -0.048 & -0.048 & -0.047 & -0.047 & 0.022 \\
\hline Gd $(0.1)$ & 0.014 & 0.013 & 0.007 & 0.013 & -0.002 \\
\hline $\mathrm{K}(0.3)$ & 0.350 & 0.369 & 0.511 & 0.593 & 1.830 \\
\hline La $(0.01)$ & 0.001 & 0.001 & 0.004 & 0.003 & 0.002 \\
\hline Li $(0.005)$ & 0.003 & 0.002 & 0.003 & 0.003 & 0.011 \\
\hline $\mathrm{Mg}(0.06)$ & 0.181 & 0.163 & 0.201 & 0.304 & 0.550 \\
\hline $\operatorname{Mn}(0.005)$ & 0.015 & 0.011 & 0.009 & 0.021 & 0.035 \\
\hline Mo $(0.02)$ & 0.003 & 0.009 & -0.004 & -0.004 & -0.005 \\
\hline $\mathrm{Na}(0.02)$ & 0.205 & 0.203 & 0.202 & 0.304 & 0.610 \\
\hline Nd $(0.03)$ & 0.003 & 0.002 & 0.004 & 0.002 & 0.003 \\
\hline N1 $(0.03)$ & 0.010 & 0.000 & 0.007 & 0.004 & 0.010 \\
\hline$P(0.1)$ & 0.021 & 0.025 & 0.002 & 0.067 & 0.094 \\
\hline $\mathrm{Pb}(0.06)$ & 0.014 & 0.032 & -0.006 & 0.024 & -0.005 \\
\hline $\mathrm{Ru}(0.05)$ & 0.017 & 0.009 & 0.007 & 0.014 & -0.003 \\
\hline $\mathrm{Sb}(10.05)$ & 0.030 & -0.001 & -0.004 & 0.009 & -0.008 \\
\hline$s i(0.02)$ & 3.730 & 3.426 & 4.428 & 6.563 & 13.300 \\
\hline $\operatorname{sr}(0.003)$ & 0.004 & 0.003 & 0.004 & 0.005 & 0.010 \\
\hline Te $(0.06)$ & 0.019 & 0.040 & -0.019 & 0.014 & -0.025 \\
\hline Th $(0.15)$ & 0.010 & 0.008 & 0.016 & 0.026 & 0.006 \\
\hline Ti $(0.002)$ & 0.001 & 0.001 & 0.001 & 0.001 & 0.001 \\
\hline$v(0.01)$ & 0.001 & 0.002 & 0.003 & 0.004 & 0.004 \\
\hline$Y(0.01)$ & 0.000 & 0.000 & 0.000 & 0.000 & 0.001 \\
\hline $\ln (0.02)$ & -0.001 & -0.004 & -0.007 & -0.005 & -0.011 \\
\hline $\operatorname{lr}(0.01)$ & 0.001 & 0.000 & 0.001 & 0.001 & -0.008 \\
\hline
\end{tabular}




\begin{tabular}{|c|c|c|c|c|c|}
\hline Sample No. & ES4-106 & ES4-107 & ES4-108 & ES4-109 & ES4-110 \\
\hline Dayg of Test & 28 & 28 & 56 & 91 & 91 \\
\hline Test & $\mathrm{PCT}$ & PCT & PCT & $\mathrm{PCT}$ & PCT \\
\hline Specimen Wgt., $g$ & 0.1625 & 0.1625 & 0.1595 & 0.1585 & 0.162 \\
\hline Leachant volume, $\mathrm{mL}$ & 40.65 & 40.65 & 39.9 & 39.63 & 40.52 \\
\hline Nominal s/V & 88 & 88 & 88 & 88 & 88 \\
\hline Speclmen Slze, mesh & $-100+200$ & $-100+200$ & $-100+200$ & $-100+200$ & $-100+200$ \\
\hline Initial $\mathrm{pH}$ & 6.49 & 6.49 & 6.49 & 6.49 & 6.49 \\
\hline Flnal $\mathrm{pH}$ & 8 & 8.03 & 8.14 & 8.07 & 8.11 \\
\hline & & & & & \\
\hline Indtlal wgt, $g$ & 152.58 & 150.76 & 150.9 & 156.15 & 149.93 \\
\hline Final Wgt, $g$ & 152.33 & 150.28 & 150.02 & 155.36 & 148.83 \\
\hline Date of Analyols & $09-J A N-91$ & 09-JAN-91 & 10-DEC-90 & 21-FEB-91 & $21-\mathrm{FEB}-91$ \\
\hline \multicolumn{6}{|l|}{ Element } \\
\hline (detection limit) & & A11 & values given & in $\mathrm{ppm}$ & \\
\hline Al $(0.03)$ & 2.820 & 2.080 & 2.681 & 2.104 & 3.138 \\
\hline $\mathrm{Ag}(0.08)$ & 0.020 & 0.004 & -0.016 & 0.030 & 0.008 \\
\hline $\mathrm{B}(0.01)$ & 0.012 & 0.003 & 0.014 & 0.022 & 0.013 \\
\hline $\mathrm{Ba}(0.005)$ & 0.015 & 0.021 & 0.026 & 0.018 & 0.022 \\
\hline $\mathrm{Be}(0.005)$ & 0.000 & 0.000 & 0.000 & 0.001 & 0.001 \\
\hline $\mathrm{Ca}(0.01)$ & 1.510 & 1.130 & 1.700 & 1.442 & 1.542 \\
\hline $\operatorname{cd}(0.005)$ & 0.002 & 0.000 & 0.000 & 0.001 & 0.001 \\
\hline $\mathrm{Ce}(0.04)$ & 0.006 & -0.004 & -0.004 & 0.030 & 0.020 \\
\hline Co $(0.01)$ & -0.002 & -0.001 & -0.003 & 0.005 & 0.004 \\
\hline Cr 10.02 & 0.000 & 0.000 & -0.001 & 0.008 & 0.011 \\
\hline $\mathrm{Cu}(0.005)$ & 0.000 & 0.002 & -0.002 & 0.005 & 0.004 \\
\hline Dy $(0.005)$ & 0.000 & 0.000 & -0.003 & 0.006 & 0.005 \\
\hline Eu $(0.005)$ & -0.009 & -0.009 & -0.012 & 0.002 & 0.001 \\
\hline $\mathrm{Fe}(0.01)$ & 0.201 & 0.034 & 0.076 & 0.045 & 0.170 \\
\hline Gd $(0.1)$ & -0.001 & 0.004 & -0.010 & 0.034 & 0.026 \\
\hline$K(0.3)$ & 1.110 & 0.630 & 0.619 & 2.107 & 1.695 \\
\hline La $(0.01)$ & 0.000 & -0.001 & -0.002 & 0.008 & 0.006 \\
\hline $\mathrm{Li}(0.005)$ & 0.010 & 0.006 & 0.007 & 0.015 & 0.013 \\
\hline $\mathrm{Mg}(0.06)$ & 0.720 & 0.510 & 0.684 & 0.737 & 0.770 \\
\hline $\mathrm{Mn}(0.005)$ & 0.023 & 0.031 & 0.036 & 0.023 & 0.028 \\
\hline Mo $(0.02)$ & -0.003 & -0.002 & -0.007 & 0.008 & 0.008 \\
\hline $\mathrm{Na}(0.02)$ & 0.770 & 0.530 & 0.622 & 0.806 & 0.749 \\
\hline Nd (0.03) & 0.006 & 0.006 & -0.003 & 0.001 & 0.000 \\
\hline $\mathrm{N} 1 \quad(0.03)$ & -0.003 & -0.007 & -0.004 & 0.032 & 0.025 \\
\hline$P(0.1)$ & 0.209 & 0.078 & 0.003 & 0.220 & 0.150 \\
\hline $\mathrm{Pb}(0.06)$ & 0.014 & 0.008 & -0.026 & 0.033 & 0.039 \\
\hline Ru (0.05) & -0.003 & -0.003 & -0.006 & 0.015 & 0.016 \\
\hline$S b \quad((0.05)$ & -0.019 & -0.019 & -0.020 & 0.030 & 0.029 \\
\hline$S 1(0.02)$ & 17.000 & 12.200 & 15.820 & 16.980 & 17.190 \\
\hline $\operatorname{sr}(0.003)$ & 0.011 & 0.009 & 0.012 & 0.013 & 0.013 \\
\hline $\mathrm{Te}(0.06)$ & 0.003 & 0.008 & -0.044 & 0.037 & 0.031 \\
\hline Th $(0.15)$ & 0.011 & 0.004 & 0.001 & 0.033 & 0.027 \\
\hline $\mathrm{Ti}(0.002)$ & 0.022 & 0.003 & 0.017 & 0.008 & 0.039 \\
\hline$V(0.01)$ & 0.005 & 0.002 & 0.002 & 0.011 & 0.009 \\
\hline$Y(0.01)$ & 0.000 & 0.000 & -0.001 & 0.002 & 0.002 \\
\hline $\mathrm{Zn}(0.02)$ & -0.016 & -0.011 & -0.014 & -0.011 & 0.016 \\
\hline $\mathrm{zr}(0.0 .1)$ & -0.009 & -0.010 & -0.006 & 0.000 & 0.002 \\
\hline
\end{tabular}




\begin{tabular}{|c|c|c|c|c|c|}
\hline Sample No. & ES4-111 & ES4-112 & ES4-113 & ES4-114 & ES4-115 \\
\hline Days of Test & 91 & 7 & 14 & 28 & 56 \\
\hline Teat & PCT & Blank & Blank & Blank & Blank \\
\hline specimen wgt., g & 0.175 & $N / A$ & $N / A$ & $\# N / A$ & $\# N / A$ \\
\hline Leachant volume, $\mathrm{mL}$ & 43.01 & 39.55 & 38 & 41.05 & 37.88 \\
\hline Nominal s/V & 88 & $\# N / A$ & $\# N / A$ & $\# \mathrm{~N} / \mathrm{A}$ & $\# N / A$ \\
\hline speolmen sizg, mesh & $-100+200$ & $\# N / A$ & $\# N / A$ & $\# N / A$ & $\# N / A$ \\
\hline Inttial $\mathrm{pH}$ & 6.49 & 6.49 & 6.49 & 6.49 & 6.49 \\
\hline Flnal $\mathrm{pH}$ & 8.01 & 5.09 & 5.91 & 4.61 & 8.28 \\
\hline & & & & & \\
\hline Initlal Wgt, $g$ & 151.83 & 144.95 & 143.27 & 153.26 & 145.07 \\
\hline Flnal Wgt, $g$ & 150.81 & 144.93 & 143.2 & 152.95 & 144.41 \\
\hline Date of Analyola & $21-F E B-91$ & $19-0 \mathrm{CT}-90$ & $19-0 \mathrm{CT}-90$ & O9-JAN-91 & 20-DEC-90 \\
\hline \multicolumn{6}{|l|}{ Element } \\
\hline (detection limit) & & A11 v & values glven & in $\mathrm{ppm}$ & \\
\hline A1 $(0.03)$ & 2.500 & 0.005 & -0.007 & 0.000 & -0.025 \\
\hline $\mathrm{Ag}(0.08)$ & 0.012 & 0.005 & -0.011 & -0.011 & 0.000 \\
\hline B $(0.01)$ & 0.014 & 0.004 & 0.003 & 0.001 & 0.005 \\
\hline $\mathrm{Ba}(0.005)$ & 0.029 & -0.001 & 0.001 & 0.000 & 0.000 \\
\hline Be $(0.005)$ & 0.001 & 0.000 & 0.000 & 0.000 & 0.000 \\
\hline $\mathrm{Ca}(0.01)$ & 1.570 & -0.026 & 0.022 & 0.000 & 0.017 \\
\hline $\operatorname{cd}(0.005)$ & 0.000 & 0.002 & 0.000 & -0.001 & -0.001 \\
\hline $\mathrm{Ce}(0.04)$ & 0.030 & -0.006 & 0.007 & -0.001 & -0.019 \\
\hline Co $(0.01)$ & 0.005 & 0.000 & 0.001 & -0.003 & -0.002 \\
\hline Cr $\quad 0.02$ & 0.006 & 0.002 & 0.007 & -0.006 & -0.001 \\
\hline $\mathrm{Cu}(0.005)$ & 0.004 & -0.002 & -0.001 & 0.000 & -0.002 \\
\hline Dy $(0.005)$ & 0.006 & 0.000 & 0.001 & 0.001 & -0.003 \\
\hline$E u(0.005)$ & 0.002 & 0.000 & -0.010 & -0.010 & -0.014 \\
\hline $\mathrm{Fe}(0.01)$ & 0.055 & -0.048 & -0.047 & -0.004 & 0.000 \\
\hline $\mathrm{Gd}(0.1)$ & 0.029 & -0.020 & 0.005 & 0.012 & -0.019 \\
\hline $\mathrm{K}(0.3)$ & 1.949 & -0.079 & 0.101 & 0.430 & -1.016 \\
\hline La $(0.01)$ & 0.008 & -0.003 & 0.001 & 0.001 & -0.003 \\
\hline L1 $(0.005)$ & 0.011 & 0.000 & 0.000 & 0.000 & -0.002 \\
\hline $\mathrm{Mg}(0.06)$ & 0.792 & -0.011 & 0.010 & 0.000 & -0.003 \\
\hline $\mathrm{Mn}(0.005)$ & 0.041 & -0.001 & 0.000 & 0.000 & 0.000 \\
\hline Mo $(0.02)$ & 0.008 & 0.002 & 0.000 & -0.004 & -0.002 \\
\hline $\mathrm{Na}(0.02)$ & 0.760 & -0.042 & -0.021 & 0.040 & -0.045 \\
\hline Nd $(0.03)$ & 0.001 & 0.004 & 0.001 & 0.004 & 0.001 \\
\hline $\mathrm{N} 1(0.03)$ & 0.030 & 0.001 & -0.004 & 0.004 & -0.010 \\
\hline$P(0.1)$ & 0.121 & -0.050 & 0.024 & 0.017 & -0.019 \\
\hline $\mathrm{Pb}(0.06)$ & 0.038 & 0.005 & -0.005 & -0.002 & -0.174 \\
\hline$R u(0.05)$ & 0.016 & -0.006 & 0.008 & -0.001 & -0.005 \\
\hline $\mathrm{sb}(10.05)$ & 0.031 & 0.006 & -0.011 & -0.020 & -0.010 \\
\hline $51(0.02)$ & 16.720 & -0.017 & -0.014 & 0.000 & -0.015 \\
\hline $\operatorname{sr}(0.003)$ & 0.014 & 0.000 & 0.001 & 0.000 & 0.000 \\
\hline Te $(0.06)$ & 0.044 & -0.002 & 0.001 & -0.010 & -0.006 \\
\hline Th $(0.15)$ & 0.028 & 0.007 & 0.009 & 0.001 & 0.000 \\
\hline $\mathrm{T} 1(0.002)$ & 0.012 & -0.001 & 0.001 & 0.000 & -0.001 \\
\hline $\mathrm{V}(0.01)$ & 0.010 & -0.003 & 0.000 & 0.000 & -0.003 \\
\hline$Y(0.01)$ & 0.001 & 0.000 & 0.000 & 0.001 & -0.001 \\
\hline $\ln (0.02)$ & -0.015 & -0.001 & 0.000 & 0.003 & 0.005 \\
\hline $\mathrm{zr}(0.01)$ & 0.001 & -0.001 & 0.001 & -0.008 & -0.006 \\
\hline
\end{tabular}




\begin{tabular}{|c|c|c|c|c|c|}
\hline Sample No. & ESA-116 & ES4-117 & ES4-118 & ISS4-119 & $E S 4-120$ \\
\hline Dayg of Teat & 91 & -7 & 7 & 7 & 14 \\
\hline Test & Blank & PCT & POT & PCT & PCT \\
\hline Speolmen Wgt., g & $\$ N / A$ & 0.1355 & 0.1443 & 0.1442 & 0.1302 \\
\hline Leachant volume, $\mathrm{mL}$ & 37.95 & 33.87 & 36.07 & 36.05 & 32.05 \\
\hline Nominal $s / v$ & $\# N / A$ & 88 & 88 & 88 & 88 \\
\hline specimen size, mesh & $\# N / A$ & $-100+200$ & $-100+200$ & $-100+200$ & $-100+200$ \\
\hline & & & & & \\
\hline Inttlal $\mathrm{pH}$ & 6.49 & 6.14 & 6.14 & 6.14 & 6.14 \\
\hline FInal pH & 7.33 & 7.82 & 7.69 & 7.6 & \\
\hline & & & & & \\
\hline Indtial wgt, $g$ & 146.67 & 139.14 & 143.88 & 142.13 & 133.92 \\
\hline Flnal Wgt, $g$ & 145.88 & 138.83 & 143.67 & 141.86 & 133.75 \\
\hline Date of Analyolo & $21-F E B-91$ & $19-\mathrm{DEC}-90$ & $19-0 C T-90$ & $19-0 C T-90$ & $19-0 C T-90$ \\
\hline Element & & & & & \\
\hline (detection $1 \mathrm{im}(\mathrm{t})$ & & A11 & valueg given & in ppm & \\
\hline Al $(0.03)$ & 0.058 & 0.627 & 0.320 & 0.385 & 1.254 \\
\hline As $(0.08)$ & 0.011 & 0.031 & 0.034 & 0.012 & -0.014 \\
\hline$B(0.01)$ & 0.006 & 0.006 & 0.005 & 0.004 & 0.006 \\
\hline $\mathrm{Ba}(0.005)$ & 0.001 & 0.007 & 0.006 & 0.007 & 0.013 \\
\hline $\mathrm{Be}(0.005)$ & 0.001 & 0.000 & 0.000 & 0.000 & 0.000 \\
\hline $\mathrm{Ca}(0.01)$ & 0.040 & 0.476 & 0.358 & 0.442 & 0.807 \\
\hline Cd $(0.005)$ & 0.001 & -0.001 & 0.002 & 0.004 & 0.002 \\
\hline Ce (0.04) & 0.029 & -0.001 & 0.008 & 0.005 & 0.001 \\
\hline Co $(0.01)$ & 0.004 & 0.002 & 0.004 & 0.002 & 0.001 \\
\hline Cr 10.02 & 0.003 & 0.006 & 0.004 & 0.006 & 0.006 \\
\hline $\mathrm{Cu}(0.005)$ & 0.004 & -0.001 & -0.001 & -0.001 & -0.002 \\
\hline Dy $(0.005)$ & 0.006 & 0.000 & 0.001 & 0.001 & 0.000 \\
\hline Eu $(0.005)$ & 0.001 & 0.000 & 0.000 & 0.001 & 0.000 \\
\hline Fe $(0.01)$ & 0.003 & -0.048 & -0.049 & -0.044 & -0.039 \\
\hline Gd $(0.1)$ & 0.061 & -0.007 & 0.003 & 0.001 & 0.008 \\
\hline$k \quad(0.3)$ & 0.713 & 0.347 & 0.364 & 0.394 & 0.675 \\
\hline La $(0.01)$ & 0.007 & -0.001 & 0.001 & 0.003 & -0.001 \\
\hline L1 $(0.005)$ & 0.004 & 0.003 & 0.002 & 0.002 & 0.005 \\
\hline $\mathrm{Mg}(0.06)$ & 0.045 & 0.221 & 0.170 & 0.189 & 0.386 \\
\hline $\mathrm{Mn}(0.005)$ & 0.001 & 0.012 & 0.012 & 0.011 & 0.014 \\
\hline Mo $(0.02)$ & 0.007 & 0.005 & 0.008 & 0.002 & 0.003 \\
\hline $\mathrm{Na}(0.02)$ & 0.070 & 0.243 & 0.170 & 0.192 & 0.401 \\
\hline Nd $(0.03)$ & 0.000 & -0.001 & 0.003 & 0.002 & 0.000 \\
\hline $\mathrm{N1}(0.03)$ & 0.029 & 0.010 & 0.005 & -0.002 & 0.009 \\
\hline$P(0.1)$ & 0.072 & 0.134 & 0.038 & 0.029 & -0.001 \\
\hline $\mathrm{Pb}(0.06)$ & 0.037 & 0.031 & 0.034 & 0.024 & 0.007 \\
\hline Ru $(0.05)$ & 0.015 & 0.005 & 0.012 & 0.012 & 0.001 \\
\hline $\mathrm{sb} \quad(0.05)$ & 0.037 & -0.004 & -0.006 & -0.003 & 0.001 \\
\hline $51(0.02)$ & 0.000 & 4.809 & 3.778 & 4.329 & 8.585 \\
\hline sr $(0.003)$ & 0.001 & 0.004 & 0.003 & 0.004 & 0.006 \\
\hline $\mathrm{Te}(0.06)$ & 0.028 & 0.054 & 0.040 & 0.013 & 0.004 \\
\hline Th $(0.15)$ & 0.035 & 0.014 & 0.019 & 0.021 & 0.003 \\
\hline $\mathrm{I} 1(0.002)$ & 0.002 & 0.001 & 0.001 & 0.001 & 0.003 \\
\hline$v(0.01)$ & 0.005 & 0.000 & 0.001 & 0.002 & 0.001 \\
\hline$Y(0.01)$ & 0.002 & 0.000 & 0.000 & 0.001 & 0.000 \\
\hline $\mathrm{Zn}(0.02)$ & 0.001 & -0.001 & -0.004 & 0.000 & -0.002 \\
\hline $\mathrm{Zr} \quad(0.01)$ & -0.001 & -0.001 & 0.001 & 0.001 & 0.000 \\
\hline
\end{tabular}




\begin{tabular}{|c|c|c|c|c|c|}
\hline Sample No. & ES4-121 & ES4-122 & E84-123 & ES4-124 & ES4-125 \\
\hline Dayg of Teat & 28 & 28 & 28 & 56 & 91 \\
\hline Test & PCT & PCT & PCT & PCT & PCT \\
\hline Speclmen Wgt., $\mathrm{g}$ & 0.144 & 0.146 & 0.132 & 0.138 & 0.1439 \\
\hline Leachant volume, mL & 35.99 & 36.5 & 33.02 & 34.49 & 36 \\
\hline Nomlnal s/V & 88 & 88 & 88 & 88 & 88 \\
\hline Speclmen s1ze, megh & $-100+200$ & $-100+200$ & $-100+200$ & $-100+200$ & $-100+200$ \\
\hline Inttial pH & 6.14 & 6.14 & 6.14 & 6.14 & 6.14 \\
\hline Flnal pH & 8.64 & 8.32 & 8.06 & 8.01 & 5.44 \\
\hline & & & & & \\
\hline Indtlal Wgt, $g$ & 144.28 & 143.63 & 143.49 & 141.54 & 152.97 \\
\hline Flnal wgt, $g$ & 143.9 & 142.98 & 143.21 & 140.3 & 152 \\
\hline Date of Analyole & $09-J A N-91$ & $09-J A N-91$ & $09-J A N-91$ & 20-DEC-90 & $21-F E B-91$ \\
\hline & & & & & \\
\hline \multicolumn{6}{|l|}{ Element } \\
\hline (detection limit) & & Allv & glues given & In $\mathrm{ppm}$ & \\
\hline$A 1(0.03)$ & 2.790 & 2.190 & $\begin{array}{r}1.650 \\
\end{array}$ & 3.186 & 2.552 \\
\hline $\mathrm{Ag}(0.08)$ & 0.003 & 0.008 & -0.005 & -0.006 & 0.049 \\
\hline B $(0.01)$ & 0.010 & 0.010 & 0.009 & 0.012 & 0.023 \\
\hline $\mathrm{Ba}(0.005)$ & 0.022 & 0.022 & 0.020 & 0.020 & 0.090 \\
\hline $\mathrm{Be}(0.005)$ & 0.000 & 0.000 & 0.000 & 0.000 & 0.001 \\
\hline $\mathrm{Ca}(0.01)$ & 1.300 & 1.150 & 1.050 & 1.566 & 2.508 \\
\hline Cd $(0.005)$ & 0.000 & 0.001 & 0.000 & -0.001 & 0.007 \\
\hline $\mathrm{Ce}(0.04)$ & 0.003 & 0.017 & 0.006 & -0.018 & 0.042 \\
\hline Co $(0.01)$ & -0.001 & 0.000 & 0.000 & -0.001 & 0.023 \\
\hline Cr $\quad 10.02$ & 0.005 & -0.002 & -0.003 & 0.004 & 0.008 \\
\hline $\mathrm{Cu}(0.005)$ & -0.001 & 0.000 & 0.000 & 0.005 & 0.025 \\
\hline Dy $(0.005)$ & 0.000 & 0.002 & 0.001 & -0.003 & 0.008 \\
\hline Eu $(0.005)$ & -0.011 & -0.011 & -0.012 & -0.015 & 0.001 \\
\hline $\mathrm{Fe}(0.01)$ & 0.003 & 0.065 & 0.024 & 0.118 & 0.112 \\
\hline Gd $(0.1)$ & -0.008 & 0.004 & 0.010 & -0.032 & 0.046 \\
\hline$k(0.3)$ & 1.250 & 1.760 & 0.960 & 0.342 & 2.852 \\
\hline La $(0.01)$ & 0.001 & 0.002 & 0.001 & -0.004 & 0.013 \\
\hline II $(0.005)$ & 0.009 & 0.010 & 0.007 & 0.007 & 0.015 \\
\hline $\mathrm{Mg}(0.06)$ & 0.590 & 0.540 & 0.480 & 0.704 & 1.183 \\
\hline $\operatorname{Mn}(0.005)$ & 0.028 & 0.028 & 0.030 & 0.021 & 0.127 \\
\hline Mo $(0.02)$ & -0.002 & 0.001 & -0.003 & -0.004 & 0.008 \\
\hline $\mathrm{Na}(0.02)$ & 0.640 & 0.560 & 0.510 & 0.686 & 1.293 \\
\hline Nd $(0.03)$ & 0.000 & 0.009 & 0.004 & -0.002 & 0.046 \\
\hline $\mathrm{N} 1(0.03)$ & -0.004 & 0.015 & -0.001 & -0.016 & 0.038 \\
\hline$P(0.1)$ & 0.041 & 0.094 & 0.078 & 0.018 & 0.148 \\
\hline $\mathrm{Pb}(0.06)$ & 0.012 & 0.017 & -0.003 & -0.021 & 0.058 \\
\hline$R u(0.05)$ & 0.000 & 0.006 & 0.000 & -0.006 & 0.018 \\
\hline $\mathrm{Sb}(10.05)$ & -0.007 & -0.005 & -0.011 & -0.012 & 0.044 \\
\hline$S 1(0.02)$ & 14.900 & 12.500 & 11.400 & 17.620 & 24.350 \\
\hline$s r(0.003)$ & 0.010 & 0.011 & 0.009 & 0.012 & 0.023 \\
\hline $\mathrm{Te}(0.06)$ & 0.005 & 0.014 & -0.020 & -0.032 & 0.040 \\
\hline $\operatorname{Th}(0.15)$ & 0.013 & 0.005 & 0.006 & -0.005 & 0.038 \\
\hline$T 1(0.002)$ & 0.022 & 0.014 & 0.002 & 0.031 & 0.003 \\
\hline$v(0.01)$ & 0.004 & 0.004 & 0.004 & 0.002 & 0.005 \\
\hline$Y(0.01)$ & 0.000 & 0.001 & 0.001 & 0.000 & 0.005 \\
\hline $\mathrm{zn}(0.02)$ & -0.014 & -0.009 & -0.007 & 0.124 & -0.001 \\
\hline $2 \mathrm{~g} \quad(0.01)$ & -0.009 & -0.005 & -0.008 & -0.006 & 0.000 \\
\hline
\end{tabular}




\begin{tabular}{|c|c|c|c|c|c|}
\hline Sample No. & ES4-126 & ES4-127 & ES4-151 & ES4-152 & ES4-153 \\
\hline Days of Test & 91 & 91 & 7 & 7 & 7 \\
\hline Test & PCT & PCT & PCT & PCT & PCT \\
\hline Specimen Wgt., $g$ & 0.1442 & 0.151 & 1.3547 & 1.3257 & 1.323 \\
\hline Leachant volume, $\mathrm{mL}$ & 36.03 & 37.76 & 33.85 & 33.09 & 33.11 \\
\hline Nominal $\mathrm{s} / \mathrm{V}$ & 88 & 88 & 880 & 880 & 880 \\
\hline Specimen size, mesh & $-100+200$ & $-100+200$ & $-100+200$ & $-100+200$ & $-100+200$ \\
\hline Initial pH & 6.14 & 6.14 & 6.14 & 619 & 614 \\
\hline Final $\mathrm{pH}$ & 8.32 & 8.31 & 7.33 & 8.54 & 8.64 \\
\hline & & & & & \\
\hline Initial Wgt, $g$ & 140.59 & 141.27 & 144.88 & 141.77 & 138.83 \\
\hline Final Wgt, $g$ & 139.3 & 139.97 & 144.77 & 141.37 & 138.73 \\
\hline Date of Analysis & 21-FEB-91 & 21-FEB-91 & $19-0 \mathrm{CT}-90$ & $19-$ OCT-90 & $19-$ OCT -90 \\
\hline \multicolumn{6}{|l|}{ Element } \\
\hline (detection limit) & & All & values given & in $\mathrm{ppm}$ & \\
\hline Al $(0.03)$ & 3.519 & 3.402 & 3.157 & 2.999 & 3.248 \\
\hline As $(0.08)$ & 0.012 & 0.006 & -0.005 & 0.009 & -0.005 \\
\hline$B(0.01)$ & 0.020 & 0.014 & 0.017 & 0.018 & 0.017 \\
\hline $\mathrm{Ba}(0.005)$ & 0.025 & 0.024 & 0.004 & 0.004 & 0.004 \\
\hline $\mathrm{Be}(0.005)$ & 0.001 & 0.001 & 0.000 & 0.000 & 0.000 \\
\hline $\mathrm{Ca}(0.01)$ & 1.557 & 1.549 & 1.704 & 1.746 & 1.667 \\
\hline Cd $(0.005)$ & 0.001 & 0.002 & 0.004 & 0.002 & 0.002 \\
\hline $\mathrm{Ce}(0.04)$ & 0.024 & 0.035 & 0.011 & 0.005 & 0.008 \\
\hline Co $(0.01)$ & 0.004 & 0.005 & 0.002 & 0.004 & 0.002 \\
\hline $\operatorname{Cr} \quad 0.02$ & 0.011 & 0.012 & 0.013 & 0.013 & 0.006 \\
\hline $\mathrm{Cu}(0.005)$ & 0.004 & 0.006 & -0.001 & -0.001 & -0.001 \\
\hline Dy $(0.005)$ & 0.005 & 0.008 & 0.001 & 0.000 & 0.000 \\
\hline Eu $(0.005)$ & 0.000 & 0.001 & 0.000 & 0.000 & 0.000 \\
\hline Fe $(0.01)$ & 0.157 & 0.263 & -0.024 & -0.004 & -0.033 \\
\hline $\mathrm{Gd}(0.1)$ & 0.005 & 0.035 & 0.023 & -0.004 & 0.018 \\
\hline $\mathrm{K}(0.3)$ & 1.751 & 2.345 & 1.621 & 1.602 & 1.517 \\
\hline La $(0.01)$ & 0.006 & 0.011 & 0.003 & 0.003 & 0.002 \\
\hline Li $(0.005)$ & 0.013 & 0.015 & 0.020 & 0.018 & 0.018 \\
\hline $\mathrm{Mg}(0.06)$ & 0.786 & 0.820 & 0.883 & 0.899 & 0.862 \\
\hline $\mathrm{Mn}(0.005)$ & 0.024 & 0.030 & 0.008 & 0.007 & 0.010 \\
\hline Mo $(0.02)$ & 0.008 & 0.776 & 0.002 & 0.006 & 0.006 \\
\hline $\mathrm{Na}(0.02)$ & 0.763 & 0.776 & 1.218 & 1.230 & 1.193 \\
\hline Nd $(0.03)$ & 0.002 & 0.002 & 0.004 & 0.001 & 0.001 \\
\hline $\mathrm{Ni}(0.03)$ & 0.022 & 0.040 & 0.002 & 0.009 & 0.013 \\
\hline$P(0.1)$ & 0.155 & 0.208 & 0.094 & 0.111 & 0.072 \\
\hline $\mathrm{Pb}(0.06)$ & 0.042 & 0.042 & 0.035 & 0.040 & 0.042 \\
\hline Ru $(0.05)$ & 0.014 & 0.017 & 0.018 & 0.007 & 0.011 \\
\hline $\mathrm{Sb}(10.05)$ & 0.032 & 0.028 & -0.003 & 0.009 & 0.011 \\
\hline $\mathrm{Si}(0.02)$ & 17.640 & 17.230 & 19.160 & 19.250 & 18.880 \\
\hline Sr $(0.003)$ & 0.014 & 0.014 & 0.009 & 0.010 & 0.009 \\
\hline $\mathrm{Te}(0.06)$ & 0.034 & 0.022 & 0.016 & 0.044 & 0.013 \\
\hline Th $(0.15)$ & 0.030 & 0.039 & 0.010 & 0.015 & 0.010 \\
\hline $\mathrm{Ti}(0.002)$ & 0.044 & 0.061 & 0.003 & 0.003 & 0.002 \\
\hline$v(0.01)$ & 0.010 & 0.012 & 0.008 & 0.006 & 0.005 \\
\hline$Y(0.01)$ & 0.001 & 0.003 & 0.000 & 0.000 & 0.001 \\
\hline $\mathrm{Zn}(0.02)$ & -0.018 & -0.019 & 0.000 & -0.001 & -0.003 \\
\hline $\mathrm{Zr} \quad(0.01)$ & 0.002 & 0.004 & 0.001 & 0.000 & 0.000 \\
\hline
\end{tabular}




\begin{tabular}{|c|c|c|c|c|c|}
\hline Sample No. & ES4-154 & ES4-155 & ES4-156 & ES4-157 & ES4-158 \\
\hline Days of Telst & 14 & 28 & 28 & 28 & 56 \\
\hline Test & PCT & PCT & PCT & PCT & PCT \\
\hline Specimen Wgt., $\mathrm{g}$ & 1.321 & 1.355 & 1.361 & 1.328 & 1.331 \\
\hline Leachant volume, $\mathrm{mL}$ & 33.05 & 33.88 & 34.02 & 33.18 & 33.28 \\
\hline Nominal $\mathrm{s} / \mathrm{V}$ & 880 & 880 & 880 & 880 & 880 \\
\hline Specimen size, mesh & $-100+200$ & $-100+200$ & $-100+200$ & $-100+200$ & $-100+200$ \\
\hline Initial pH & 6.14 & 6.14 & 6.14 & 6.14 & 6.14 \\
\hline Final $\mathrm{pH}$ & 8.621 & 7.74 & 8.05 & 8.06 & 7.87 \\
\hline Initial Wgt, $g$ & 144.44 & 144.15 & 139.78 & 146.37 & 139.24 \\
\hline Final Wgt, $g$ & 144.28 & 143.81 & 139.47 & 145.97 & 138.64 \\
\hline Date of Analysis & $19-$ OCT-90 & $09-J A N-91$ & 09-JAN-91 & $09-J A N-91$ & $20-D E C-90$ \\
\hline \multicolumn{6}{|l|}{ Element } \\
\hline (detection limit) & & Al1 & valueg given & in $\mathrm{ppm}$ & \\
\hline Al $(0.03)$ & 3.445 & 4.280 & 4.280 & 4.140 & 3.920 \\
\hline $\mathrm{AB}(0.08)$ & -0.002 & 0.003 & 0.005 & 0.004 & -0.013 \\
\hline$B(0.01)$ & 0.018 & 0.020 & 0.010 & 0.010 & 0.020 \\
\hline $\mathrm{Ba}(0.005)$ & 0.007 & 0.006 & 0.007 & 0.006 & 0.005 \\
\hline $\mathrm{Be}(0.005)$ & 0.000 & 0.000 & 0.000 & 0.000 & 0.000 \\
\hline $\mathrm{Ca}(0.01)$ & 1.954 & 1.990 & 2.160 & 2.210 & 1.803 \\
\hline $\operatorname{cd}(0.005)$ & 0.001 & 0.000 & 0.000 & 0.001 & -0.002 \\
\hline $\operatorname{Ce}(0.04)$ & 0.007 & 0.013 & 0.004 & 0.017 & -0.009 \\
\hline Co $(0.01)$ & 0.003 & -0.002 & -0.002 & -0.001 & -0.002 \\
\hline $\operatorname{Cr} \quad 10.02$ & 0.010 & -0.001 & 0.004 & 0.000 & 0.001 \\
\hline $\mathrm{Cu}(0.005)$ & -0.001 & 0.002 & -0.001 & 0.000 & -0.002 \\
\hline Dy $(0.005)$ & 0.001 & 0.002 & 0.001 & 0.002 & -0.002 \\
\hline Eu $(0.005)$ & 0.000 & -0.012 & -0.011 & -0.011 & -0.011 \\
\hline$F \in(0.01)$ & -0.027 & 0.086 & 0.027 & 0.023 & 0.028 \\
\hline Gd $(0.1)$ & -0.010 & -0.012 & -0.003 & 0.004 & -0.016 \\
\hline$k(0.3)$ & 1.744 & 2.490 & 2.160 & 2.360 & 1.043 \\
\hline $\operatorname{La}(0.01)$ & 0.002 & 0.003 & 0.000 & 0.001 & -0.004 \\
\hline $\operatorname{Li}(0.005)$ & 0.022 & 0.027 & 0.029 & 0.029 & 0.026 \\
\hline $\mathrm{Mg}(0.06)$ & 0.969 & 0.940 & 1.050 & 1.040 & 0.911 \\
\hline $\mathrm{Mn}(0.005)$ & 0.007 & 0.007 & 0.005 & 0.011 & 0.005 \\
\hline Mo $(0.02)$ & 0.001 & -0.003 & -0.002 & 0.000 & -0.003 \\
\hline $\mathrm{Na}(0.02)$ & 1.374 & 1.520 & 1.490 & 1.500 & 1.411 \\
\hline Nd $(0.03)$ & 0.001 & 0.004 & 0.000 & 0.004 & 0.006 \\
\hline $\mathrm{Ni}(0.03)$ & 0.002 & 0.007 & 0.002 & 0.011 & -0.013 \\
\hline$P(0.1)$ & 0.049 & 0.112 & 0.083 & 0.108 & 0.065 \\
\hline $\mathrm{Pb}(0.06)$ & 0.049 & 0.001 & 0.009 & 0.014 & -0.172 \\
\hline Ru $(0.05)$ & 0.018 & 0.000 & 0.000 & 0.003 & -0.004 \\
\hline $\mathrm{sb} \quad(0.05)$ & 0.005 & -0.006 & -0.008 & -0.002 & -0.017 \\
\hline si $(0.02)$ & 21.000 & 24.600 & 24.900 & 23.900 & 22.820 \\
\hline $\operatorname{sr}(0.003)$ & 0.011 & 0.012 & 0.012 & 0.012 & 0.011 \\
\hline $\operatorname{Te}(0.06)$ & 0.018 & -0.010 & -0.015 & -0.003 & -0.028 \\
\hline Th $(0.15)$ & 0.010 & 0.003 & 0.004 & 0.004 & -0.003 \\
\hline $\mathrm{Ti}(0.002)$ & 0.003 & 0.010 & 0.002 & 0.002 & 0.002 \\
\hline $\mathrm{V}(0.01)$ & 0.006 & 0.008 & 0.007 & 0.007 & 0.005 \\
\hline$Y(0.01)$ & 0.000 & 0.001 & 0.001 & 0.001 & 0.001 \\
\hline $\ln (0.02)$ & -0.001 & -0.023 & -0.025 & -0.022 & -0.019 \\
\hline $\operatorname{Zr}(0.01)$ & 0.001 & -0.008 & -0.010 & -0.009 & -0.007 \\
\hline
\end{tabular}




\begin{tabular}{|c|c|c|c|c|c|}
\hline Sample No. & ES4-159 & ES4-160 & ES4-161 & ES4-162 & ES4-163 \\
\hline Days of Test & 91 & 91 & 91 & 7 & 14 \\
\hline Test & PCT & PCT & PCT & Blank & Blank \\
\hline specimen Wgt., $g$ & 1.336 & 1.3265 & 1.344 & $\# N / A$ & $\# \mathrm{~N} / \mathrm{A}$ \\
\hline Leachant volume, $\mathrm{mL}$ & 33.39 & 33.15 & 33.56 & 33.31 & 34.67 \\
\hline Nominal s/V & 880 & 880 & 880 & $\# N / A$ & $\# \mathrm{~N} / \mathrm{A}$ \\
\hline specimen size, mesh & $-100+200$ & $-100+200$ & $-100+200$ & $\# N / A$ & \#N/A \\
\hline Initial $\mathrm{pH}$ & 6.14 & 6.14 & 6.14 & 6.14 & 6.14 \\
\hline Final $\mathrm{pH}$ & 8.23 & 8.25 & 7.92 & 4.83 & 5.68 \\
\hline & & & & & \\
\hline Initial Wgt, $g$ & 148.37 & 141.6 & 147.09 & 145.81 & 138.89 \\
\hline Final Wgt, $g$ & 1.47 .43 & 140.29 & 145.95 & 145.72 & 138.68 \\
\hline Date of Analysis & 21-FEB-91 & 21-FEB-91 & 21-FEB-91 & $19-0 C T-90$ & $19-$ OCT -90 \\
\hline \multicolumn{6}{|l|}{ Element } \\
\hline (detection limit) & & All v & ralues given & in $\mathrm{ppm}$ & \\
\hline Al $(0.03)$ & 3.964 & 4.084 & 3.285 & -0.001 & -0.006 \\
\hline $\mathrm{As}(0.08)$ & 0.021 & 0.016 & 0.018 & -0.005 & 0.002 \\
\hline B $(0.01)$ & 0.025 & 0.021 & 0.022 & 0.000 & 0.004 \\
\hline $\mathrm{Ba}(0.005)$ & 0.006 & 0.008 & 0.007 & 0.001 & 0.000 \\
\hline $\mathrm{Be}(0.005)$ & 0.001 & 0.001 & 0.001 & 0.000 & 0.000 \\
\hline $\mathrm{Ca}(0.01)$ & 1.946 & 1.756 & 1.898 & -0.020 & 0.050 \\
\hline $\operatorname{cd}(0.005)$ & 0.000 & 0.001 & 0.001 & 0.000 & 0.002 \\
\hline $\mathrm{Ce}(0.04)$ & 0.038 & 0.043 & 0.032 & 0.004 & -0.003 \\
\hline Co $(0.01)$ & 0.005 & 0.007 & 0.005 & 0.002 & -0.001 \\
\hline $\operatorname{cr}(0.02$ & 0.007 & 0.006 & 0.007 & 0.013 & 0.008 \\
\hline Cu $(0.005)$ & 0.007 & 0.007 & 0.004 & 0.003 & -0.002 \\
\hline Dy $(0.005)$ & 0.007 & 0.008 & 0.006 & 0.000 & 0.000 \\
\hline Eu $(0.005)$ & 0.002 & 0.002 & 0.001 & 0.000 & -0.001 \\
\hline Fe $(0.01)$ & 0.081 & 0.132 & 0.033 & 0.046 & -0.048 \\
\hline Gd $(0.1)$ & 0.040 & 0.044 & 0.042 & 0.008 & 0.000 \\
\hline $\mathrm{K}(0.3)$ & 2.939 & 3.113 & 2.749 & 0.030 & -0.003 \\
\hline $\mathrm{La}(0.01)$ & 0.011 & 0.010 & 0.008 & -0.002 & -0.003 \\
\hline $\mathrm{Li}(0.005)$ & 0.035 & 0.032 & 0.031 & 0.000 & 0.000 \\
\hline $\mathrm{Mg}(0.06)$ & 1.105 & 0.998 & 1.094 & -0.003 & 0.007 \\
\hline $\operatorname{Mn}(0.005)$ & 0.009 & 0.012 & 0.014 & 0.000 & 0.000 \\
\hline MO $(0.02)$ & 0.010 & 0.009 & 0.010 & 0.008 & -0.001 \\
\hline $\mathrm{Na}(0.02)$ & 1.712 & 1.566 & 1.793 & -0.021 & -0.025 \\
\hline Nd $(0.03)$ & 0.002 & 0.002 & -0.004 & -0.001 & -0.005 \\
\hline $\mathrm{Ni}(0.03)$ & 0.040 & 0.043 & 0.036 & 0.006 & -0.007 \\
\hline$P(0.1)$ & 0.195 & 0.186 & 0.286 & 0.036 & -0.029 \\
\hline $\mathrm{Pb}(0.06)$ & 0.044 & 0.060 & 0.039 & 0.012 & -0.010 \\
\hline Ru $(0.05)$ & 0.020 & 0.020 & 0.018 & 0.004 & 0.003 \\
\hline $\mathrm{sb}(10.05)$ & 0.033 & 0.039 & 0.038 & 0.003 & 0.008 \\
\hline $\mathrm{si}(0.02)$ & 23.170 & 22.220 & 22.730 & -0.016 & -0.022 \\
\hline $\operatorname{sr}(0.003)$ & 0.012 & 0.011 & 0.012 & 0.001 & 0.001 \\
\hline Te $(0.06)$ & 0.019 & 0.041 & 0.029 & 0.017 & -0.015 \\
\hline Th $(0.15)$ & 0.042 & 0.049 & 0.035 & 0.014 & 0.002 \\
\hline $\mathrm{Ti}(0.002)$ & 0.008 & 0.032 & 0.006 & 0.001 & 0.000 \\
\hline $\mathrm{v}(0.01)$ & 0.015 & 0.014 & 0.013 & -0.002 & -0.003 \\
\hline$Y(0.01)$ & 0.002 & 0.003 & 0.002 & 0.000 & 0.000 \\
\hline $\mathrm{zn}(0.02)$ & -0.021 & 0.024 & -0.019 & 0.000 & -0.005 \\
\hline $\operatorname{lr}(0.01)$ & 0.000 & 0.001 & -0.001 & 0.000 & -0.001 \\
\hline
\end{tabular}




\begin{tabular}{|c|c|c|c|c|c|}
\hline Sample No. & ES4-164 & ES4-165 & ES4-166 & ES4-201 & ES4-202 \\
\hline Days of Test & 28 & 56 & 91 & 7 & 14 \\
\hline Test & Blank & Blank & Blank & MCC-1 & MCC-1 \\
\hline Specimen Wgt., g & $\# N / A$ & $\# N / A$ & $\neq N / A$ & 1.0275 & 1.447 \\
\hline Leachant volume, $\mathrm{mL}$ & 33.78 & 31.79 & 36.03 & 45.52 & 47.51 \\
\hline Nominal s/V & $\# N / A$ & $\# \mathrm{~N} / \mathrm{A}$ & $\# N / A$ & 10 & 10 \\
\hline specimen size, mesh & $\# \mathrm{~N} / \mathrm{A}$ & $\# N / A$ & $\# \mathrm{~N} / \mathrm{A}$ & Monolith & Monolith \\
\hline Initial pH & 6.14 & 6.14 & 6.14 & 6.35 & 6.35 \\
\hline Final $\mathrm{pH}$ & 7.38 & 7.41 & 7.26 & 6.23 & 8.49 \\
\hline & & & & & \\
\hline Initial Wgt, $g$ & 138.15 & 135.49 & 139.81 & 131.62 & 132.18 \\
\hline Final Wgt, $g$ & 137.83 & 134.93 & 138.86 & 131.48 & 132 \\
\hline Date of Analysis & $09-\mathrm{JAN}-91$ & $20-D E C-90$ & $21-\mathrm{FEB}-91$ & $19-$ OCT-90 & O9-JAN-91 \\
\hline \multicolumn{6}{|l|}{ Element } \\
\hline (detection limit) & & Al1 & values given & in $\mathrm{ppm}$ & \\
\hline Al $(0.03)$ & 0.000 & -0.032 & 0.081 & 0.010 & 0.100 \\
\hline As $(0.08)$ & 0.005 & -0.013 & 0.026 & 0.014 & -0.007 \\
\hline$B(0.01)$ & 0.000 & 0.003 & 0.010 & 0.001 & -0.002 \\
\hline $\mathrm{Ba}(0.005)$ & 0.000 & 0.000 & 0.002 & 0.001 & 0.004 \\
\hline $\operatorname{Be}(0.005)$ & 0.000 & 0.000 & 0.001 & 0.000 & 0.000 \\
\hline $\mathrm{Ca}(0.01)$ & 0.000 & 0.089 & 0.005 & 0.057 & 0.120 \\
\hline $\operatorname{cd}(0.005)$ & 0.000 & -0.002 & 0.002 & 0.000 & 0.000 \\
\hline $\operatorname{Ce}(0.04)$ & 0.006 & -0.009 & 0.037 & 0.047 & 0.010 \\
\hline Co $(0.01)$ & -0.001 & -0.004 & 0.007 & 0.008 & -0.001 \\
\hline Cr $\quad 0.02$ & -0.004 & -0.004 & 0.007 & 0.009 & 0.005 \\
\hline $\mathrm{Cu}(0.005)$ & 0.000 & 0.001 & 0.006 & 0.007 & 0.000 \\
\hline Dy $(0.005)$ & 0.001 & -0.003 & 0.008 & 0.010 & 0.002 \\
\hline Eu $(0.005)$ & -0.011 & -0.015 & 0.003 & -0.001 & -0.011 \\
\hline $\mathrm{Fe}(0.01)$ & -0.003 & 0.003 & 0.005 & -0.048 & -0.005 \\
\hline $\mathrm{Gd}(0.1)$ & -0.007 & -0.015 & 0.044 & 0.009 & 0.005 \\
\hline$K(0.3)$ & 0.000 & -0.923 & 1.442 & 0.011 & 0.720 \\
\hline $\operatorname{La}(0.01)$ & 0.001 & -0.004 & 0.009 & -0.001 & 0.003 \\
\hline Li $(0.005)$ & 0.002 & 0.001 & 0.007 & 0.001 & 0.001 \\
\hline $\operatorname{Mg}(0.06)$ & 0.000 & 0.003 & 0.063 & 0.018 & 0.059 \\
\hline $\mathrm{Mn}(0.005)$ & 0.000 & 0.000 & 0.001 & 0.000 & 0.007 \\
\hline Mo $(0.02)$ & 0.001 & -0.007 & 0.013 & 0.004 & -0.002 \\
\hline $\mathrm{Na}(0.02)$ & 0.050 & -0.019 & 0.092 & 0.013 & 0.140 \\
\hline Nd $(0.03)$ & 0.003 & 0.004 & 0.002 & -0.002 & 0.004 \\
\hline $\mathrm{Ni}(0.03)$ & 0.004 & -0.010 & 0.037 & 0.005 & 0.010 \\
\hline$p(0.1)$ & -0.002 & -0.063 & 0.089 & -0.002 & 0.013 \\
\hline $\mathrm{Pb}(0.06)$ & 0.002 & -0.040 & 0.060 & 0.009 & 0.002 \\
\hline $\mathrm{Ru}(0.05)$ & -0.002 & -0.006 & 0.024 & 0.001 & -0.004 \\
\hline $\mathrm{sb}((0.05)$ & -0.009 & -0.031 & 0.047 & 0.000 & -0.011 \\
\hline si $(0.02)$ & 0.000 & -0.013 & 0.004 & 0.675 & 1.410 \\
\hline $\operatorname{sr}(0.003)$ & 0.001 & 0.001 & 0.001 & 0.001 & 0.001 \\
\hline Te $(0.06)$ & 0.001 & -0.056 & 0.070 & 0.014 & -0.007 \\
\hline Th $(0.15)$ & 0.003 & -0.003 & 0.043 & 0.007 & -0.003 \\
\hline $\mathrm{Ti}(0.002)$ & 0.000 & 0.000 & 0.003 & 0.000 & -0.001 \\
\hline$v(0.01)$ & 0.000 & -0.003 & 0.006 & -0.002 & 0.000 \\
\hline$Y(0.01)$ & 0.001 & -0.001 & 0.002 & -0.001 & 0.001 \\
\hline $\mathrm{Zn}(0.02)$ & 0.003 & 0.006 & 0.000 & -0.008 & 0.000 \\
\hline $\begin{array}{ll}x & (0.01) \\
\end{array}$ & -0.008 & -0.005 & 0.000 & -0.001 & -0.009 \\
\hline
\end{tabular}




\begin{tabular}{|c|c|c|c|c|c|}
\hline Sample No. & ES4-203 & ES4-204 & ES4-205 & ES4-206 & ES4-207 \\
\hline Dayg of Test & 14 & 14 & 28 & 56 & 91 \\
\hline Test & $\mathrm{MCC}-1$ & $\mathrm{MCC}-1$ & $\mathrm{MCC}-1$ & $\mathrm{MCC}-1$ & $\mathrm{MCC}-1$ \\
\hline specimen Wgt., $g$ & 1.0595 & 1.0584 & 0.9804 & 0.9765 & 1.0031 \\
\hline Leachant volume, $\mathrm{mL}$ & 45.95 & 46.63 & 45.41 & $4,6.05$ & 45 \\
\hline Nominal $\mathrm{s} / \mathrm{V}$ & 10 & 10 & 10 & 10 & 10 \\
\hline Specimen Size, mesh & Monolith & Monolith & Monolith & Monolith & Monolith \\
\hline Initial $\mathrm{pH}$ & 6.35 & 6.35 & 6.35 & 6.35 & 6.35 \\
\hline Final $\mathrm{pH}$ & 7.72 & 7.12 & 8.71 & 8.69 & 8.32 \\
\hline Initial wgt, $g$ & 131.68 & 132.99 & 129.21 & 132.76 & 129.22 \\
\hline Final Wgt, $\mathrm{g}$ & 131.38 & 132.62 & 128.4 & 131.84 & 127.12 \\
\hline Date of Analysis & 09-JAN-91 & 09-JAN-91 & $09-\mathrm{JAN}-91$ & 20-DEC-90 & 21-FEB-91 \\
\hline \multicolumn{6}{|l|}{ Element } \\
\hline (detection limit) & & A.11V & values given & in ppm & \\
\hline Al $(0.03)$ & 0.070 & 0.180 & 0.430 & 1.147 & 1.632 \\
\hline $\mathrm{As}(0.08)$ & -0.001 & -0.013 & 0.002 & -0.077 & 0.015 \\
\hline $\mathrm{B}(0.01)$ & -0.003 & -0.006 & 0.003 & 0.004 & 0.011 \\
\hline $\mathrm{Ba}(0.005)$ & 0.002 & 0.006 & 0.011 & 0.019 & 0.022 \\
\hline $\mathrm{Be}(0.005)$ & 0.000 & 0.000 & 0.000 & 0.000 & 0.001 \\
\hline $\mathrm{Ca}(0.01)$ & 0.140 & 0.180 & 0.250 & 0.570 & 0.661 \\
\hline $\mathrm{Cd}(0.005)$ & -0.001 & -0.002 & 0.000 & -0.003 & 0.000 \\
\hline $\mathrm{Ce}(0.04)$ & 0.007 & 0.003 & 0.009 & -0.009 & 0.047 \\
\hline Co $(0.01)$ & -0.001 & -0.002 & 0.000 & -0.002 & 0.008 \\
\hline $\operatorname{Cr} \quad 0.02$ & -0.003 & -0.003 & -0.003 & 0.001 & 0.009 \\
\hline $\mathrm{Cu}(0.005)$ & 0.001 & 0.000 & 0.003 & -0.001 & 0.007 \\
\hline Dy $(0.005)$ & 0.001 & 0.000 & 0.003 & -0.002 & 0.010 \\
\hline Eu $(0.005)$ & -0.011 & -0.012 & -0.011 & -0.014 & 0.003 \\
\hline Fe $(0.01)$ & 0.000 & -0.005 & -0.004 & 0.000 & 0.010 \\
\hline $\mathrm{Gd}(0.1)$ & 0.017 & 0.009 & 0.001 & -0.024 & 0.060 \\
\hline $\mathrm{K}(0.3)$ & 0.530 & 0.320 & 1.310 & -0.332 & 2.511 \\
\hline $\operatorname{La}(0.01)$ & 0.001 & 0.003 & 0.002 & -0.004 & 0.013 \\
\hline $\mathrm{Li}(0.005)$ & 0.002 & 0.001 & 0.003 & 0.002 & 0.012 \\
\hline $\mathrm{Mg}(0.06)$ & 0.048 & 0.059 & 0.120 & 0.222 & 0.363 \\
\hline $\mathrm{Mn}(0.005)$ & 0.006 & 0.006 & 0.011 & 0.017 & 0.021 \\
\hline Mo $(0.02)$ & 0.002 & 0.001 & 0.000 & -0.007 & 0.009 \\
\hline $\mathrm{Na}(0.02)$ & 0.180 & 0.120 & 0.150 & 0.158 & 0.427 \\
\hline Nd $(0.03)$ & 0.009 & 0.002 & 0.004 & -0.002 & -0.001 \\
\hline $\mathrm{Ni}(0.03)$ & 0.003 & 0.000 & 0.012 & -0.008 & 0.054 \\
\hline$P(0.1)$ & 0.028 & 0.043 & 0.061 & -0.029 & 0.144 \\
\hline $\mathrm{Pb}(0.06)$ & 0.002 & 0.006 & 0.012 & -0.034 & 0.054 \\
\hline Ru $(0.05)$ & 0.000 & 0.00 & 0.003 & -0.004 & 0.028 \\
\hline $\mathrm{sb}((0.05)$ & -0.004 & -0.003 & -0.003 & -0.018 & 0.041 \\
\hline $\mathrm{si}(0.02)$ & 1.420 & 1.690 & 3.120 & 6.799 & 8.562 \\
\hline $\operatorname{sr}(0.003)$ & 0.001 & 0.002 & 0.002 & 0.005 & 0.007 \\
\hline $\mathrm{Te}(0.06)$ & -0.005 & 0.006 & -6.005 & -0.043 & 0.053 \\
\hline Th $(0.15)$ & 0.007 & 0.007 & 0.007 & 0.003 & 0.049 \\
\hline $\mathrm{Ti}(0.002)$ & -0.001 & -0.002 & -0.004 & -0.001 & 0.005 \\
\hline$v(0.01)$ & 0.000 & 0.000 & 0.002 & -0.001 & 0.010 \\
\hline$Y(0.01)$ & 0.000 & 0.000 & 0.001 & -0.001 & 0.003 \\
\hline $\mathrm{Zn}(0.02)$ & 0.001 & 0.000 & -0.001 & -0.005 & 0.005 \\
\hline $\mathrm{Zr}(0.01)$ & -0.010 & -0.011 & -0.010 & -0.008 & 0.001 \\
\hline
\end{tabular}




\begin{tabular}{|c|c|c|c|c|c|}
\hline Sample No. & ES4-208 & ES4-209 & ES4-210 & ES4-211 & ES4-212 \\
\hline Days of Test & 91 & 91 & 7 & 14 & 28 \\
\hline Test & $M C C-1$ & $\mathrm{MCC}-1$ & Blank & Blank & Blank \\
\hline Specimen Wgt., $g$ & 1.0585 & 1.0301 & $\# \mathbb{N} / \mathrm{A}$ & $\# N / A$ & $\# \mathrm{~N} / \mathrm{A}$ \\
\hline Leachant volume, $\mathrm{mL}$ & 45.99 & 45.05 & 46.11 & 46.67 & 42.31 \\
\hline Nominal s/V & 10 & 10 & N/A & $\# \mathrm{~N} / \mathrm{A}$ & $\# \mathrm{~N} / \mathrm{A}$ \\
\hline specimen size, mesh & Monolith & Monolith & $\# N / A$ & $\# \mathrm{~N} / \mathrm{A}$ & $\# N / A$ \\
\hline Initial pH & 6.35 & 6.35 & 6.35 & 6.35 & 6.35 \\
\hline Final $\mathrm{pH}$ & 5.1 & 7.34 & 5.72 & 5.52 & 8.21 \\
\hline & & & & & \\
\hline Initial wgt, $g$ & 162.35 & 156.92 & 123.18 & 126.53 & 121.66 \\
\hline Final wgt, $g$ & 161.52 & 156.02 & 122.59 & 125,99 & 121.11 \\
\hline Date of Analysis & $21-F E B-91$ & 21-FEB-91 & $19-$ OCT-90 & 09-JAN-91 & 09-JAN-91 \\
\hline \multicolumn{6}{|l|}{ Element } \\
\hline (detection limit) & & Ald & glues given & in $\mathrm{ppm}$ & \\
\hline $\mathrm{Al}(0.03)$ & 0.358 & 0.620 & -0.005 & 0.000 & 0.000 \\
\hline As $(0.08)$ & 0.013 & 0.002 & 0.010 & -0.021 & -0.003 \\
\hline$B(0.01)$ & 0.012 & 0.015 & 0.000 & 0.000 & 0.000 \\
\hline $\mathrm{Ba}(0.005)$ & 0.033 & 0.024 & -0.001 & 0.000 & 0.000 \\
\hline $\operatorname{Be}(0.005)$ & 0.001 & 0.001 & 0.000 & 0.000 & 0.000 \\
\hline $\mathrm{Ca}(0.01)$ & 0.715 & 0.694 & -0.023 & 0.000 & 0.000 \\
\hline $\operatorname{cd}(0.005)$ & 0.002 & 0.001 & -0.001 & 0.001 & -0.001 \\
\hline $\mathrm{Ce}(0.04)$ & 0.049 & 0.045 & 0.000 & -0.012 & 0.009 \\
\hline Co $(0.01)$ & 0.008 & 0.006 & -0.001 & -0.003 & -0.001 \\
\hline $\mathrm{Cr} \quad(0.02$ & 0.006 & 0.005 & 0.003 & -0.001 & -0.002 \\
\hline $\mathrm{Cu}(0.005)$ & 0.009 & 0.007 & -0.002 & 0.000 & -0.001 \\
\hline Dy $(0.005)$ & 0.009 & 0.008 & -0.001 & 0.001 & 0.002 \\
\hline Eu $(0.005)$ & 0.003 & 0.003 & 0.000 & -0.012 & -0.011 \\
\hline Fe $(0.01)$ & 0.013 & 0.007 & -0.051 & 0.004 & 0.005 \\
\hline $\mathrm{Gd}(0.1)$ & 0.059 & 0.068 & -0.019 & 0.013 & 0.007 \\
\hline $\mathrm{K}(0.3)$ & 2.297 & 2.614 & -0.044 & 0.660 & 0.790 \\
\hline $\mathrm{La}(0.01)$ & 0.012 & 0.014 & 0.002 & 0.000 & 0.003 \\
\hline $\mathrm{Li}(0.005)$ & 0.011 & 0.011 & 0.000 & 0.002 & 0.001 \\
\hline $\mathrm{Mg}(0.06)$ & 0.375 & 0.391 & -0.006 & 0.000 & 0.000 \\
\hline $\mathrm{Mn}(0.005)$ & 0.041 & 0.028 & -0.001 & 0.000 & 0.000 \\
\hline Mo $(0.02)$ & 0.007 & 0.008 & -0.001 & -0.002 & -0.002 \\
\hline $\mathrm{Na}(0.02)$ & 0.379 & 0.419 & -0.025 & 0.030 & 0.060 \\
\hline Nd $(0.03)$ & -0.001 & -0.001 & -0.004 & -0.001 & 0.005 \\
\hline $\mathrm{Ni}(0.03)$ & 0.054 & 0.054 & 0.001 & 0.003 & 0.009 \\
\hline$P(0.1)$ & 0.135 & 0.118 & -0.030 & -0.004 & 0.002 \\
\hline $\mathrm{Pb}(0.06)$ & 0.039 & 0.043 & -0.007 & -0.020 & 0.002 \\
\hline Ru $(0.05)$ & 0.024 & 0.027 & 0.005 & -0.004 & $c .002$ \\
\hline $\mathrm{Sb}((0.05)$ & 0.039 & 0.036 & -0.013 & -0.019 & -0.003 \\
\hline$S i(0.02)$ & 8.055 & 8.234 & -0.026 & 0.000 & 0.000 \\
\hline $\operatorname{sr}(0.003)$ & 0.008 & 0.007 & 0.000 & 0.001 & 0.001 \\
\hline Te $(0.06)$ & 0.038 & 0.029 & -0.004 & -0.035 & -0.007 \\
\hline Th $(0.15)$ & 0.043 & 0.052 & 0.006 & -0.003 & 0.010 \\
\hline $91(0.002)$ & 0.003 & 0.003 & 0.000 & -0.001 & -0.001 \\
\hline$V(0.01)$ & 0.007 & 0.010 & 0.003 & 0.000 & 0.000 \\
\hline$Y(0.01)$ & 0.003 & 0.003 & 0.000 & 0.001 & 0.001 \\
\hline $\mathrm{Zn}(0.02)$ & 0.000 & -0.005 & -0.001 & 0.001 & 0.000 \\
\hline $\operatorname{Zr}(0.01)$ & 0.001 & 0.001 & -0.001 & -0.009 & -0.010 \\
\hline
\end{tabular}




\begin{tabular}{|c|c|c|c|}
\hline Sample No. & ES4-213 & ES4-214 & \\
\hline Days of Test & 56 & 91 & \\
\hline Test & Blank & Blank & \\
\hline Specimen Wgt., $\mathrm{g}$ & $\# N / A$ & $\# \mathrm{~N} / \mathrm{A}$ & \\
\hline Leachant volume, $\mathrm{mL}$ & 43.35 & 42.53 & \\
\hline Nominal $\mathrm{s} / \mathrm{V}$ & $\# N / A$ & $\# N / A$ & \\
\hline Specimen size, mesh & $\# N / A$ & $\# \mathrm{~N} / \mathrm{A}$ & \\
\hline Initial $\mathrm{pH}$ & 6.35 & 6.35 & \\
\hline Final $\mathrm{pH}$ & 8.33 & 6.28 & \\
\hline & & & \\
\hline Initial wgt, $g$ & 124.75 & 122.43 & \\
\hline Final Wgt, $g$ & 123.52 & 120.91 & \\
\hline Date of Analysis & 20-DEC-90 & 21-FEB-91 & \\
\hline \multicolumn{4}{|l|}{ Element } \\
\hline (detection limit) & A11 & values given & in $\mathrm{ppm}$ \\
\hline AI $(0.03)$ & -0.043 & 0.086 & \\
\hline $\mathrm{As}(0.08)$ & -0.022 & 0.005 & \\
\hline$B(0.01)$ & -0.003 & 0.005 & \\
\hline $\mathrm{Ba}(0.005)$ & 0.000 & 0.002 & \\
\hline $\operatorname{Be}(0.005)$ & 0.000 & 0.001 & \\
\hline $\mathrm{Ca}(0.01)$ & 0.010 & 0.052 & \\
\hline $\mathrm{Cd}(0.005)$ & -0.002 & 0.001 & \\
\hline $\mathrm{Ce}(0.04)$ & 0.014 & 0.045 & \\
\hline Co $(0.01)$ & -0.004 & 0.006 & \\
\hline $\operatorname{Cr} \quad(0.02$ & -0.006 & 0.005 & \\
\hline $\mathrm{Cu}(0.005)$ & -0.002 & 0.007 & \\
\hline Dy $(0.005)$ & -0.004 & 0.008 & \\
\hline Eu $(0.005)$ & -0.014 & 0.003 & \\
\hline $\mathrm{Fe}(0.01)$ & -0.003 & 0.008 & \\
\hline $\mathrm{Gd}(0.1)$ & -0.013 & 0.043 & \\
\hline$k(0.3)$ & -0.665 & 1.679 & \\
\hline La $(0.01)$ & -0.004 & 0.011 & \\
\hline $\mathrm{Li}(0.005)$ & -0.002 & 0.007 & \\
\hline $\mathrm{Mg}(0.06)$ & -0.005 & 0.071 & \\
\hline $\min (0.005)$ & -0.001 & 0.002 & \\
\hline Mo $(0.02)$ & -0.005 & 0.009 & \\
\hline $\mathrm{Na}(0.02)$ & -0.019 & 0.073 & \\
\hline $\mathrm{Nd}(0.03)$ & -0.003 & -0.002 & \\
\hline $\mathrm{Ni}(0.03)$ & -0.011 & 0.045 & \\
\hline$P(0.1)$ & -0.069 & 0.103 & \\
\hline $\mathrm{Pb}(0.06)$ & -0.043 & 0.039 & \\
\hline $\mathrm{Ru}(0.05)$ & -0.008 & 0.025 & \\
\hline $\mathrm{Sb} \quad(0.05)$ & -0.022 & 0.042 & \\
\hline Si $(0.02)$ & -0.022 & 0.011 & \\
\hline $\operatorname{sr}(0.003)$ & 0.000 & 0.001 & \\
\hline $\operatorname{Te}(0.06)$ & -0.051 & 0.028 & \\
\hline$T h(0.15)$ & -0.003 & 0.041 & \\
\hline Ti $(0.002)$ & -0.002 & 0.003 & \\
\hline $\mathrm{V}(0.01)$ & -0.004 & 0.007 & \\
\hline$Y(0.01)$ & 0.000 & 0.003 & \\
\hline $\ln (0.02)$ & 0.013 & 0.000 & \\
\hline$Z_{E}(0.01)$ & -0.008 & 0.001 & \\
\hline
\end{tabular}



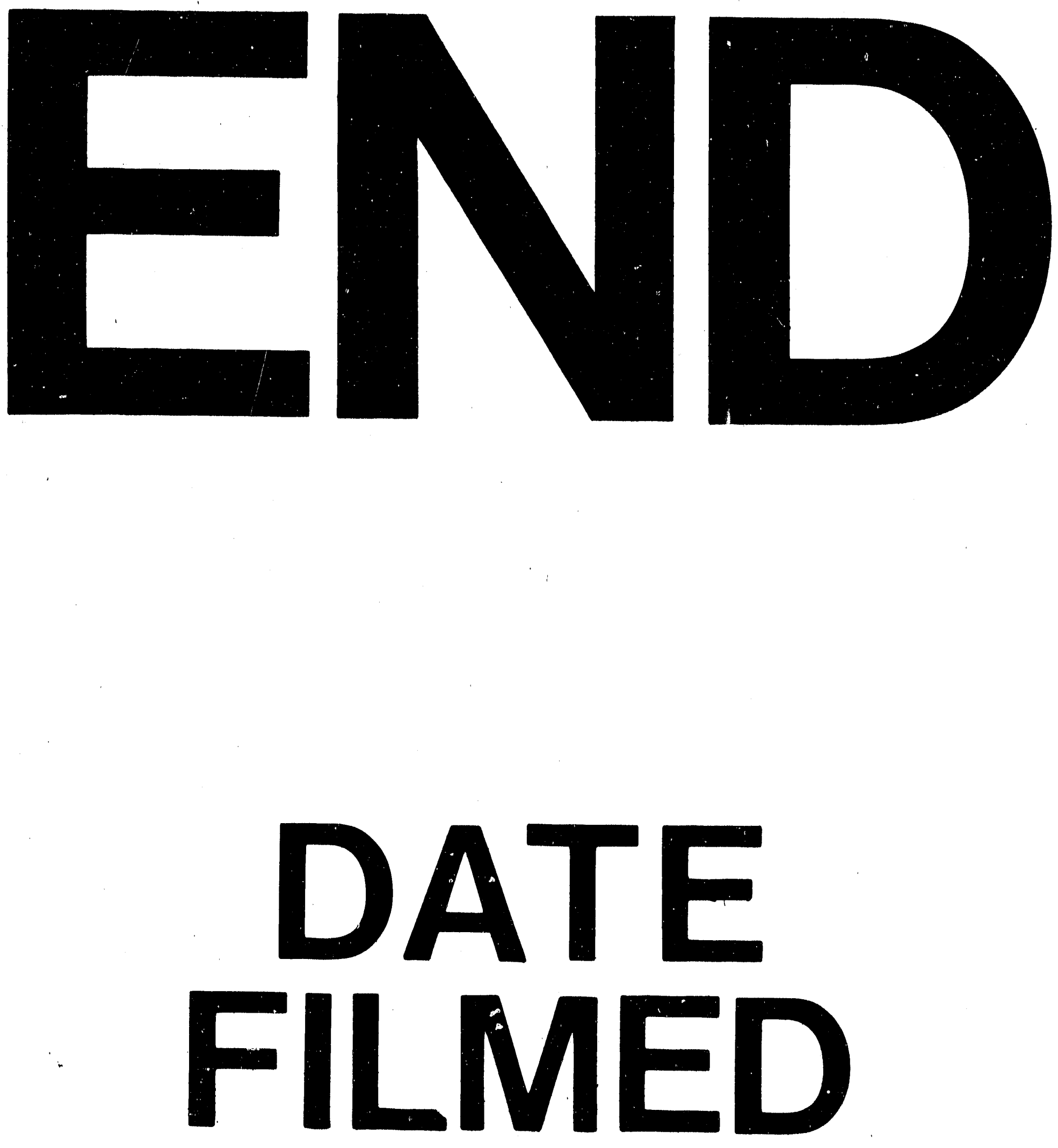

1

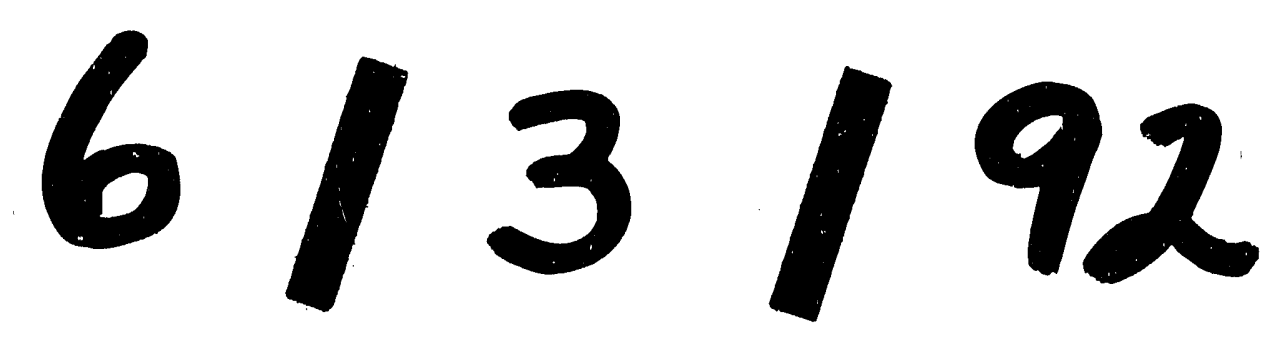


